\title{
Antipsychotic-induced hyperprolactinemia in children and adolescents with mainly autism spectrum disorders : prevalence, symptoms, clinical consequences and genetic risk factors
}

Citation for published version (APA):

Roke, Y. (2013). Antipsychotic-induced hyperprolactinemia in children and adolescents with mainly autism spectrum disorders : prevalence, symptoms, clinical consequences and genetic risk factors. [Doctoral Thesis, Maastricht University]. Datawyse / Universitaire Pers Maastricht. https://doi.org/10.26481/dis.20130904yr

Document status and date:

Published: 01/01/2013

DOI:

10.26481/dis.20130904yr

Document Version:

Publisher's PDF, also known as Version of record

Please check the document version of this publication:

- A submitted manuscript is the version of the article upon submission and before peer-review. There can be important differences between the submitted version and the official published version of record. People interested in the research are advised to contact the author for the final version of the publication, or visit the DOI to the publisher's website.

- The final author version and the galley proof are versions of the publication after peer review.

- The final published version features the final layout of the paper including the volume, issue and page numbers.

Link to publication

\footnotetext{
General rights rights.

- You may freely distribute the URL identifying the publication in the public portal. please follow below link for the End User Agreement:

www.umlib.nl/taverne-license

Take down policy

If you believe that this document breaches copyright please contact us at:

repository@maastrichtuniversity.nl

providing details and we will investigate your claim.
}

Copyright and moral rights for the publications made accessible in the public portal are retained by the authors and/or other copyright owners and it is a condition of accessing publications that users recognise and abide by the legal requirements associated with these

- Users may download and print one copy of any publication from the public portal for the purpose of private study or research.

- You may not further distribute the material or use it for any profit-making activity or commercial gain

If the publication is distributed under the terms of Article $25 \mathrm{fa}$ of the Dutch Copyright Act, indicated by the "Taverne" license above, 


\section{Antipsychotic-induced hyperprolactinemia in boys with autism spectrum disorders and disruptive behavior disorders}

Prevalence, risk factors and clinical consequences 
The printing of this thesis was financially supported by Foundation "De Open Ankh", Soesterberg, The Netherlands, Foundation "to support VCVGZ", Arnhem, The Netherlands and Fund for Scientific Research of Sexuality", Amsterdam, The Netherlands.

(C) Copyright Y Roke, Maastricht 2013

ISBN 9789461592446

Production: Datawyse | Universitaire Pers Maastricht 


\title{
Antipsychotic-induced hyperprolactinemia in boys with autism spectrum disorders and disruptive behavior disorders
}

\author{
Prevalence, risk factors and clinical consequences
}

\author{
PROEFSCHRIFT \\ ter verkrijging van de graad van doctor aan de Universiteit Maastricht, \\ op gezag van de Rector Magnificus, prof. dr. L.L.G. Soete, \\ volgens het besluit van het College van Decanen, \\ in het openbaar te verdedigen op \\ woensdag 4 september 2013 om 16.00 uur
}

door

Y. Roke

geboren op 17 maart 1976

te De Bilt, Nederland

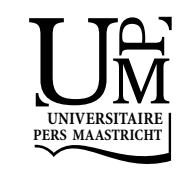




\section{Promotores}

Prof. dr. P.N. van Harten

Prof. dr. J.K. Buitelaar, Universitair Medisch Centrum St. Radboud Nijmegen

\section{Copromotor}

Dr. A.M. Boot, Universitair Medisch Centrum Groningen

\section{Beoordelingscommissie}

Prof. dr. I.Y.R. Myin-Germeys (voorzitter)

Prof. dr. T.A.M.J. van Amelsvoort

Prof. dr. S.L.S. Drop, Universitair Medisch Centrum Rotterdam

Prof. dr. J. P.C.J. Selten

Dr. W. Staal, Universitair Medisch Centrum St. Radboud Nijmegen 
Aan Ralph, Youri, Robin en Stijn 



\section{Contents}

CHAPTER 1

Introduction

PART 1 - Review

CHAPTER 2

Antipsychotic medication in children and adolescents: a descriptive review of the effects on prolactin level and associated side effects.

Published in J Child Adolesc Psychopharmacol. 2009 Aug;19(4):403-14.

PART 2a - Antipsychotic-induced hyperprolactinemia in children and adolescents

CHAPTER 3

Risk of hyperprolactinaemia and sexual side effects in adolescents with psychiatric disorders and long-term use of antipsychotics. A case control study.

Published in J Child Adolesc Psychopharmacol. 2012 Dec;22(6):432-9.

CHAPTER 4

Antipsychotic-induced hyperprolactinemia and testosterone levels in boys. Published in Horm Res Paediatr. 2012 Apr;77(4):235-40.

CHAPTER 5

Bone mineral density in male adolescents with autism spectrum disorders and disruptive behavior disorder with or without antipsychotic treatment Published in Eur J Endocrinol. 2012 Dec;167(6):855-63.

PART 2 b - Genetic risk factors

CHAPTER 6

The effect of the Taq1A variant in the dopamine $\mathrm{D}_{2}$ receptor gene and common CYP2D6 alleles on prolactin levels in risperidone treated boys. Accepted for publication in Pharmogenomics and Genomics

\section{CHAPTER 7}

Discussion/conclusion

Samenvatting

Dankwoord

Curriculum vitae 



\section{CHAPTER I}

\section{Introduction}

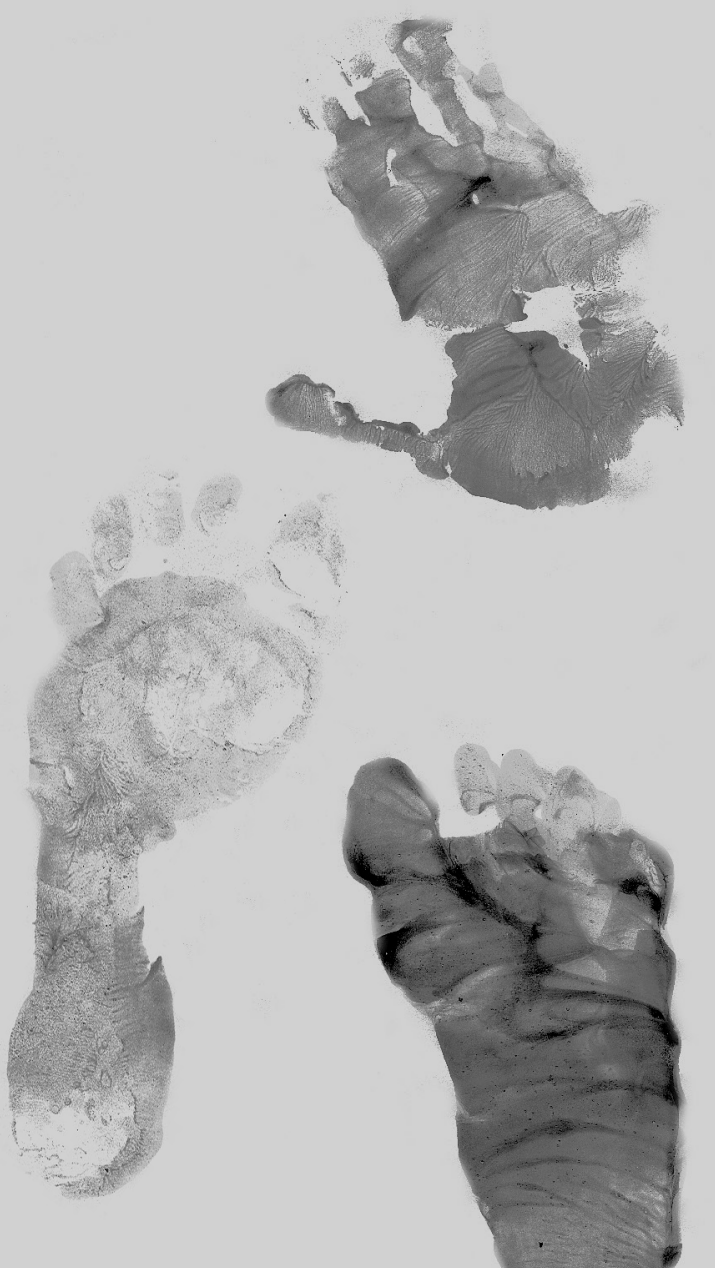


CHAPTER I 


\section{Introduction}

Children and adolescents diagnosed with autism spectrum disorders (ASD) and disruptive behavior disorders (DBD) are often treated with antipsychotics. These antipsychotics can correct behavioral disorders, but a large fraction of the prescribed medication influences the hormonal balance of the patient. In particular, prolactin levels can be severely affected.

This thesis focuses on antipsychotic (AP)-induced hyperprolactinemia (the presence of abnormally high, above the 97.5th percentile for age and gender, levels of the hormone prolactin in the blood) in children and adolescents with ASD and DBD. We pay special attention to the prevalence, associated signs and symptoms, clinical consequences, and pharmacogenetics of hyperprolactinemia. In the current chapter we introduce ASD and DBD, as well as the main functions and pathophysiology of the hormone prolactin, which are the main topics of this thesis. This is followed by a description of the state of the art concerning AP-induced hyperprolactinemia in children and adolescents. We focus our attention on the prevalence, the possible short- and long-term consequences and the genetic risk factors of hyperprolactinemia. This chapter ends with an outline of the thesis.

\section{Autism Spectrum Disorder (ASD)}

ASD is a neurodevelopmental disorder characterized by impaired social interaction and communication, and by restricted and repetitive behavior (Wing 1997). Psychiatric disorders are defined and classified by the Diagnostic and Statistical Manual (DSM). The fourth edition (DSM-IV) identifies a set of Pervasive Developmental Disorders that are considered "autism spectrum disorders" (ASDs). These disorders include Autistic Disorder, Asperger's Disorder, and Pervasive Developmental Disorder Not Otherwise Specified (PDD-NOS). The DSM-IV has been under revision for several years and a new edition, the DSM-5, will be released this year. Significant changes to the criteria and categories of ASDs are planned for the new edition. One of the most significant changes is that the separate diagnostic labels of Autistic Disorder, Asperger's Disorder, and PDD-NOS will be collectively replaced by the term "Autism Spectrum Disorder." Distinctions will now be made according to the level of severity of the disorder. The diagnostic criteria require that symptoms become apparent before the age of three years. Autism has a strong genetic basis, although the genetics of autism are complex and it is unclear to what extent ASD can be explained by rare genetic variants with potentially major effect size, such as mutations and copy number variations, or by the combined effect of several common genetic variants. The prevalence of ASD is about 1-2 individuals per 100 people worldwide (Baio 2008). Since the 1980s the number of children and adolescents diagnosed with ASD has increased dramatically. This increase can be explained in 
part by changes in diagnostic practice, a broadening of diagnostic criteria, and greater parental age. Whether actual prevalence has increased as a consequence of external factors, such as e.g. increased environmental risk factors, is unresolved. Recently the relationship between mental health diagnosis and treatment with second-generation APs was investigated. The study showed that children and adolescents with an ASD diagnosis were more likely to receive AP treatment to reduce maladaptive behaviors, such as irritability, self-injury, stereotypes, and hyperactivity (Aman 2009, Matone 2012).

\section{Disruptive Behavior Disorders (DBD)}

The main DBDs are Oppositional Defiant Disorder (ODD) and Conduct Disorder (CD). The essential features of ODD are a recurrent pattern of negativistic, defiant, disobedient, and hostile behavior toward persons with authority (a defiant headstrong symptom cluster) and temper tantrums and irritability (a more affective symptom cluster). The essential features of CD are a repetitive and persistent pattern of behavioral routines that violate the basic rights of others and major ageappropriate societal norms or rules. In many cases, CD is preceded by ODD. The main four symptom categories of the disorder are: (1) physical aggression or threats of harm to people or animals, (2) destruction of property, (3) acts of deceitfulness or theft, and (4) serious violations of age-appropriate rules. CD usually occurs in older children and adolescents. The prevalence of DBD is relatively high: $2 \%$ for CD and 3.2\% for ODD (Lahey 1999). Boys seem to be more affected than girls. However, the existing classification systems might be intrinsically biased towards identifying aggressive and antisocial behavior in boys than in girls (Lahey 1999). DBDs result in displayed aggression and severe behavioral problems. These difficulties often result in presentation to psychiatric services. A treatment with medication such as atypical antipsychotics often occurs. A significant rise in the use of atypical antipsychotics to treat DBD-related aggression in child and adolescent populations is evident (Loy 2012). Furthermore, there is some limited evidence that (primarily) risperidone reduces aggression and conduct problems on the short- and the long- term in children aged 5- to- 18 years with DBDs (Chroonenberghs 2005, Loy 2012).

\section{Prolactin}

The anterior pituitary lactotroph cells secrete prolactin, a 198-amino acid polypeptide, in a pulsatile manner with 13-14 peaks per day. Prolactin secretion is under inhibitory control by the hypothalamus through dopamine. There is a marked circadian variation with a maximum secretion four hours from sleep onset and a 
minimum secretion six hours after waking (Frantz 1978, Freeman 2000). There can be as much as a fourfold variation in prolactin levels depending on the time of day or night that sampling is done; there are also transient mild increases related to meals, stress, and sexual activity (Bevan 1991). Prolactin levels are higher during menstrual midcycle and the second half of the menstrual cycle. During pregnancy, levels rise 10-20-fold in the blood, reaching $200 \mu \mathrm{g} / \mathrm{L}$ at term and $300 \mu \mathrm{g} / \mathrm{L}$ during nursing (Lenton 1979). The normal upper limit range for adults is $15-25 \mu \mathrm{g} / \mathrm{L}$ (Bevan 1991]. Prolactin is known for its ability to induce and maintain lactation and cause amenorrhea during lactation. However, prolactin has over 300 separate biological activities including effects on water and salt balance, growth and development, endocrinology and metabolism, brain function and behavior, reproduction, and immune system regulation and protection (Bole-Feysot 1998). Indeed, not only does prolactin play multiple roles in reproduction in addition to lactation, but it also plays multiple homeostatic roles (e.g. immune regulation, angiogenesis, and electrolyte transportation) in the body. This diversity in biological activities is important to bear in mind when prescribing APs with prolactin elevating qualities to children and adolescents; an increase in prolactin levels may potentially influence multiple homeostatic systems.

\section{Antipsychotic-induced hyperprolactinemia}

Antipsychotics (e.g. haloperidol, pimozide, risperidone) cause dopamine 2 (D2) blockade in the brain. There are four main dopamine pathways:

1. The nigrostriatal pathway that extends from the substantia nigra to the basal ganglia. This pathway is involved in movement and movement disorders.

2. The mesolimbic pathway that extends from the ventral tegmental area to the nucleus accumbens. This pathway is involved in the positive symptoms of schizophrenia and plays a role in feelings/ mechanisms of pleasure and reward.

3. The mesocortical pathway that extends from the ventral tegmental area to the cortex. This pathway regulates motivation and emotional response (and is thought to cause the negative symptoms of schizophrenia).

4. The tuberoinfundibular pathway that extends from the hypothalamus to the anterior pituitary. Blocking this pathway may cause hyperprolactinemia (Halbreich 2003). In this thesis we will focus on this pathway (see table 1 for agents with dopamine D2 blocking qualities). 
Table 1. Agents with dopamine D2 blocking qualities

\begin{tabular}{|c|c|c|}
\hline Drug class & Drug & Prolactin Elevation \\
\hline Antipsychotics & $\begin{array}{l}\text { All typical Antipsychotics } \\
\text { Amisulpiride } \\
\text { Risperidone } \\
\text { Olanzapine } \\
\text { Clozapine } \\
\text { Quetiapine } \\
\text { Aripiprazol }\end{array}$ & $\begin{array}{c}+++ \\
+++ \\
+++ \\
+ \\
0 \\
0 \\
-\end{array}$ \\
\hline Antidepressants & $\begin{array}{l}\text { Amitriptyline } \\
\text { Clomipramine } \\
\text { Citalopram } \\
\text { Fluoxetine } \\
\text { Paroxetine } \\
\text { Sertraline } \\
\text { Mirtazapine } \\
\text { Venlafaxine }\end{array}$ & $\begin{array}{c}+ \\
+++ \\
+/- \\
+/- \\
+/- \\
+/- \\
0 \\
0\end{array}$ \\
\hline Anti-emetics & $\begin{array}{l}\text { Domperidone } \\
\text { Metoclopramide }\end{array}$ & $\begin{array}{l}+ \\
+\end{array}$ \\
\hline Estrogens & All contraceptives & + \\
\hline Opiates & All & + \\
\hline Calcium channel blockers & Verapamil & + \\
\hline $\mathrm{H} 2$-antagonists & Cimetidine & + \\
\hline Proton pump inhibitors & Omeprazole & + \\
\hline
\end{tabular}

Hyperprolactinemia is a common side effect of long-term AP treatment in children and adolescents (Calarge 2010, Roke 20121,2). APs are increasingly prescribed to children and adolescents with psychiatric disorders and have been used successfully to reduce maladaptive behaviors, such as irritability, self-injury, stereotypies and hyperactivity in children and adolescents with ASD and irritability and aggressive behavior in children and adolescents with DBD (Aman 2009, Matone 2012). While risperidone and aripiprazole have been approved by the United States Food and Drug Administration (FDA) for the treatment of children and adolescents with irritability associated with ASD (RUPP 2002, Stigler 2006, Wink 2010), these drugs have not yet been approved for this indication in Europe. APs are also frequently used off-label, to treat severe aggression in children and adolescents with DBD. Despite their efficacy (Wink 2010), there are concerns about the widespread use of these drugs given their side effect profile, including weight gain, metabolic adverse effects (dyslipidemia, hyperglycemia, and diabetes), cardiac side effects (QTc prolongation), extrapyramidal side effects, and increased prolactin levels (Molitch 2005, Correll 20081,2, Vitiello 2009). The side effects of APs are well described in adults (Hasan 2012, Singh 2012) but less well studied in children and adolescents. One of these side effects is hyperprolactinemia. Hyperprolactinemia may decrease gonadotropin levels and thereby decrease estrogen and testosterone levels in the blood (Halbreich 2003, Haddad 2004). Estrogen and testosterone levels play im- 
portant roles in puberty, sexual functioning, and bone mineralization (Saranac 2010); decreased levels may result in delayed puberty and disorders in sexual functioning (Cutler 2003, Knegtering 2003), and may diminish bone mineral density. It is not known at what threshold of elevated prolactin level these adverse effects develop. In fact, little is known about the consequences of persistently elevated prolactin levels in children and adolescents, and in particular about the effects of elevated but still subclinical levels of prolactin. This thesis will provide insight into the possible short- and long-term effects of hyperprolactinemia and will describe monitoring and management strategies.

\section{Prevalence of AP-induced hyperprolactinemia}

The clinical practice guideline published by the Endocrine Society states that "to establish the diagnosis of hyperprolactinemia, we recommend a single measurement of serum prolactin; a level above the upper limit of normal confirms the diagnosis as long as the serum sample was obtained without excessive venipuncture stress." (Melmed 2011). In children and adolescent the upper limit of normal can be defined as a prolactin level above the 97.5th percentile for age and gender (for example the study of Emlinger et al. 2002 describes reference data for children and adolescents of Caucasian ethnicity).

AP-induced hyperprolactinemia is present in about $50 \%$ of children and adolescents who are treated long-term (more than two years of treatment) with AP with D2 blocking qualities (Roke 20121, Calarge 2010). Short-term studies have shown a steep increase in the prolactin level within the first 6 weeks, with levels stabilizing in the first 3 months (Aman 2002, Snyder 2002, Findling 2004, Biederman 2005), followed by a slow decline after 1 year (Turgay 2002, Findling 2004, Croonenberghs 2005, Stevens 2005, Anderson 2007). Average prolactin levels were found to be above the reference value after 2 (Reyes 2006, Staller 2006) and 3 years of continued risperidone treatment (Calarge 2010, Roke 20121,2), although two studies reported that prolactin levels tended to normalize after 12 months (Migliardi 2009) and 22 months (Anderson 2007) of AP use. Most studies defined hyperprolactinemia using adult reference ranges, primarily $0-18 \mathrm{ng} / \mathrm{mL}$ and $0-30$ $\mathrm{ng} / \mathrm{mL}$ for male and female patients, respectively. Prolactin levels change during childhood and adolescence and should be matched for age and gender; otherwise there is a risk of underestimating the prevalence of hyperprolactinemia.

\section{Possible prolactin-related side effects}

\section{Gynecomastia}

Gynecomastia is defined as a swelling of the breast tissue in males that is mostly caused by an imbalance of the hormones estrogen and testosterone with more ef- 
fect of estrogen. If puberty advances and testosterone levels increase the gynecomastia disappears. Estrogens are primarily produced in adipose tissue. Under the influence of the aromatase enzyme adrenal androgens are converted into estrogens in the adipose tissue. Gynecomastia is a normal transient phenomenon caused by a temporary dysregulation between estrogen and testosterone. There is an association between the total percentage body fat and the prevalence of gynecomastia. Newborns, pubertal males, and older men have a higher prevalence of gynecomastia. The lifetime prevalence of gynecomastia in males is about 50\% (Bembo 2004, Hanavadi 2006). Hyperprolactinemia may be an indirect cause of gynecomastia. Hyperprolactinemia may cause a decrease in the secretion of luteinizing hormone which in turn may lead to decreased testosterone levels in boys. In girls the hypogonadotropic hypogonadism may lead to decreased estrogen levels which may delay puberty or cause menstrual disorders. In children and adolescents treated with APs, the reported point prevalence of gynecomastia is about 3-7\% (Roke 2009, Sikich 2004, Reyes 2006, Staller 2006). However, the studies primarily reported on pre-pubertal children. The studies relied on spontaneous self-reports, rather than physical examination and systematic questionnaires, to establish the presence of gynecomastia. This practice has probably led to underestimation of the prevalence of gynecomastia. One study did use physical examination and questionnaires to examine the presence of gynecomastia. This study reported a much higher point prevalence of $40 \%$ for the boys using AP, and a $21 \%$ point prevalence of gynecomastia in the AP-naïve-boys. These percentages of the AP-naïve group are comparable to the prevalence of gynecomastia in healthy pubertal boys.

\section{Galactorrhea}

Galactorrhea is a milky nipple discharge unrelated to the normal milk production of breast-feeding. Although the condition occurs mostly in women, galactorrhea can develop in men and even, although rarely, in infants. Excessive breast stimulation, medication side effects, or disorders of the pituitary gland may all contribute to galactorrhea. Frequently, galactorrhea results from increased levels of prolactin, the hormone that stimulates milk production. In female children and adolescents treated with APs, the prevalence of galactorrhea varied from 3.6-10\%, whereas there were no male children or adolescents with galactorrhea (Roke 2009).

\section{Amenorrhea}

Amenorrhea is the absence of menstruation (one or more missed menstrual periods). Women who have missed at least three sequential menstrual periods have amenorrhea (secondary amenorrhea), as do girls who have not had menarche by the age of 16 years (primary amenorrhea). In females treated with prolactin elevating APs 6-15\% report having amenorrhea (Melkersson 2005). However, most studies investigating the effect of hyperprolactinemia on the menstrual cycle had serious methodological limitations, such as the small number of patients included in most studies and the concomitant use of oral contraceptives, which could have 
influenced the prolactin level and may have confounded the results (Ouwehand 2012). Therefore no firm conclusions can be drawn about the relationship between the increased frequencies of menstrual disorders in women with AP-induced hyperprolactinemia.

\section{Sexual dysfunctioning}

Sexual dysfunctioning is defined as disorders that interfere with a full sexual response cycle (Balon 2007). For men this may be erectile dysfunction, ejaculate dysfunction, lack or loss of sexual desire, and difficulty or inability to have an orgasm. For females sexual dysfunctioning involves inadequate lubrication, pain during intercourse, lack or loss of sexual desire, and the difficulty or inability to have an orgasm.

Prolactin plays a role in the central control of sexual behavior and activity, mainly through modulating the effects of dopaminergic and serotonergic systems on sexual function. Circulating prolactin levels increase after having an orgasm, implying that prolactin plays a role in the acute regulation of sexual arousal following orgasm in both men and women. Prolactin also plays a role in sexual function influencing penile erection in men (Galdiero 2012). In adult studies hyperprolactinemia is primarily associated with libido and orgasm dysfunctions (Knegtering 2008).

\section{Possible long-term consequences of hyperprolactinemia}

\section{Hypogonadotropic hypogonadism}

Gonadotropin-releasing hormone (GnRH), released in a pulsatile manner from the hypothalamus, stimulates release of luteinizing hormone (LH) and follicle stimulating hormone (FSH) from the anterior pituitary. Prolactin inhibits the release of GnRH in the hypothalamus. The positive feedback of low estradiol on LH secretion in women is also blocked. Consequently, estrogen levels in women and testosterone levels in men are suppressed, with marked individual variability in the prolactin level causing gonadal hypofunction (Smith 2002, Kishimoto 2008). Hypogonadotropic hypogonadism may cause delayed puberty and in adults loss of hair, infertility, orgasm and libido problems, loss of bone mass, high plasma levels of cholesterol/ lipids, glucose intolerance, and increased abdominal fat (Wu 2009).

\section{Delayed puberty}

Delayed puberty is defined as a failure to develop secondary sexual characteristics by a certain age, usually set as two standard deviations from the mean. In girls, delayed puberty is defined as lack of breast development by age 13, lack of menarche by age 16 , or more than five years between thelarche and menarche. In boys, puberty is considered delayed if testicular enlargement does not occur by 14 years of age or more than five years are required to complete genital enlargement 
(McKeever 2000, Rosen 2001). Hyperprolactinemia may cause hypogonadotropic hypogonadism, which may lead to a delay in puberty. Just two studies have investigated the possible relationship between hyperprolactinemia and a delay in puberty. One retrospective analysis of 222 children (older than 10 years) treated with risperidone with a follow-up of one year did not show a delay in progressing Tanner stadia of puberty due to prolactin elevation (Dunbar 2004). Another extension study ( $N=33$, children and adolescents 6-15 years of age) also showed no delay in puberty after two years of risperidone treatment and prolactin elevation (Reyes 2006). These studies however have limitations: firstly, an observation period of one year is rather short and not enough to conclude whether there truly is a delay in pubertal development, and secondly, the two year extension study included just 33 patients, a small sample size with limited statistical power to draw any final conclusions about hyperprolactinemia and the influence on pubertal development.

\section{Diminished bone mineral density}

Adolescence is the most important time for attaining peak bone mass (Davies 2005). Peak bone mass can be defined as the amount of bony tissue present at the end of the skeletal maturation. It is an important determinant of future osteoporotic fracture risk. During childhood the increase of lean body mass, mainly muscles, is important for optimal bone mass (Taes 2009). Disturbances in this process during puberty may increase the risk of osteoporosis later in life. APs may influence the attainment of peak bone mass in three ways. Firstly, APs may induce change in energy metabolism and insulin signaling, which could lead to a lower bone mineral density (BMD) (Houseknecht 2009, Schwetz 2012), which in turn could increase the risk of osteoporosis later in life. Secondly, AP-induced hyperprolactinemia might directly affect bone turnover, by stimulating bone resorption relative to bone formation (Seriwatanachai 2008, Motyl 2012), and thirdly, prolonged hyperprolactinemia may cause hypogonadotropic hypogonadism (Graham 2011), resulting from the suppression of gonadotropin-releasing hormone (GnRH) secretion in the hypothalamus and the diminished secretion of LH and FSH by the pituitary gland, resulting in a diminished secretion of sex hormones and ultimately in changes of bone metabolism (Schwetz 2012). Sex hormones increase BMD.

Only one study has investigated the effect of AP-induced hyperprolactinemia on BMD in boys with different diagnoses ( $n=83$; mean age 11.9 years, SD 2.8) (Calarge 2010). BMD was lower in boys with hyperprolactinemia than in boys without hyperprolactinemia, but comparisons with healthy controls were not made. In adolescents with prolactinomas, in which prolactin levels are at least two to four times higher than in AP-induced hyperprolactinemia, BMD was decreased and was not restored after 2 years of treatment with dopamine agonists (Colao 2000). Several studies of adults have shown AP-induced hypogonadism to be associated with a decreased BMD (Abraham 20031,2, Meany 2004, 'O Keane 2005) and two large case-control studies (44,500 patients and 16,341 patients) showed AP medication 
to be associated with a two-fold increased risk of hip or femur fractures (Hugentholz 2005, Howard 2007).

\section{Prolactinomas/ cancer risk}

Treatment with potent D2-receptor antagonists, such as risperidone, may be associated with pituitary tumors. A retrospective pharmacovigilance study performed as part of the United States FDA's Adverse Event Reporting System database reported an association between treatment with risperidone and the prevalence of pituitary tumors (Sfarzman 2006). A Swedish study ( $\mathrm{N}=969$, follow-up 8 years) found a small but significant increase in the overall cancer risk in prolactinomainduced hyperprolactinemic patients after diagnosis compared to ten individuals individually matched to each patient for sex, birth year, and county of residence, selected from the general population. This overall increased risk of cancer in hyperprolactinemia patients was mainly attributed to an increased risk of upper gastro-intestinal (hazard ratio (HR) 3.69) and hematopoietic cancer (HR 3.51) (Berinder 2011). In prolactinomas the prolactin level is two to four times more elevated than in AP-induced hyperprolactinemia. These data are not conclusive and have no clinical consequences at this moment. However, the relationship between APinduced hyperprolactinemia and (long-term) risk of cancer should be a topic for future longitudinal studies.

\section{Hyperprolactinemia and genetic risk factors}

Pharmacogenetic differences in individuals may explain variations in prolactin elevation in response to AP medication leading to clinical consequences. As D2 antagonism plays an important role in the prolactin elevation, the dopamine D2 receptor gene (DRD2) is an attractive candidate gene to investigate variations in AP-induced prolactin elevation response. Post mortem brain studies (Thompson 1997) revealed a lower dopamine D2 receptor density in the striatum and related structures in A1 allele carriers of the DRD2 Taq1A polymorphism (rs1800497) compared to that in non-carriers. Similar results, a lower $-141 \mathrm{C}$ Ins/Del promoter polymorphism in the dopamine D2 receptor gene, were found in a Japanese (Arinami 1997) and a Swedish association (Jönsson 1999) studies of patients with schizophrenia. Other studies show an association between the presence of the A1 allele of Taq1A and a higher prolactin level elevation in relation to AP treatment in female (Mihara 2001), and male patients with schizophrenia (Young 2004). Another study of children and adolescents treated long-term with risperidone showed four times more prolactin-related side effects in Taq1A A1 allele carriers (Calarge 2009). Since prolactin elevation is related to levels of APs in the blood, the gene coding for the cytochrome P450 2D6 enzyme (CYP2D6) is another interesting candidate gene for explaining variations in prolactin level after treatment with AP medication, especially risperidone. The CYP2D6 gene is highly polymorphic resulting in different phenotypic metabolism rates of the encoded enzyme. Normal me- 
tabolizers are homozygous for functional CYP2D6 alleles or heterozygous with one functional CYP2D6 allele; poor metabolizers (7\% of Caucasian, 1\% of Asian, and 3\% of African individuals) have no functional CYP2D6 alleles. Ultra rapid metabolizers have a duplication (rapid) or multiplications (ultrarapid) of the intact CYP2D6 gene (found in $2 \%$ of the Caucasian population and up to $25 \%$ of several Ethiopian subpopulations) (Sachse 1997, Berecz 2004). An earlier study showed the number of functional CYP2D6 alleles to be associated with the prolactin level. The more functional the CYP2D6 alleles, the higher the risperidone and 9-OH risperidone levels and as a consequence the higher prolactin levels (Troost 2007). However, other studies report a higher risk of clinically important side effects among risperidone treated patients with impaired CYP2D6 enzyme activity (Berecz 2004, De Leon 2005). In this thesis we want to investigate whether the A1 allele of the DRD2 Taq1A polymorphism and the CYP2D6 enzyme activity play a role in developing hyperprolactinemia. If these pharmacogenetic differences influence prolactin levels, they may have clinical consequences and provide input to considerations as to whether these risk factors should be assessed before prescribing the APs.

\section{Outline of the thesis}

The overall aim of this thesis was to evaluate the prevalence and (genetic) risk factors of AP-induced hyperprolactinemia and prolactin-related side effects (e.g., gynecomastia, galactorrhea, sexual functioning disorders) in young males with ASD and / or DBD treated long-term (>16 months) with AP. Further, this study investigated whether those young males with AP-induced hyperprolactinemia had hypogonadotropic hypogonadism, delayed puberty, or diminished BMD, when compared to the males with ASD or DBD without hyperprolactinemia with and without AP treatment and to healthy controls. Knowledge about the risk factors and the outcome parameters could answer the question whether it is better to actively monitor prolactin levels before and during treatment in all patients with AP treatment or to monitor only when prolactin-related-side effects occur. We also wanted to investigate if pre-treatment assessment of genetic risk factors may help in deciding whether to prescribe a prolactin elevating antipsychotic or not.

The study was divided in two parts:

\section{Part 1, Chapter 2: Literature Review}

This chapter contains a descriptive review of AP-induced hyperprolactinemia in children and adolescents. Data on prolactin levels available for haloperidol, pimozide, risperidone, olanzapine, clozapine, ziprasidone, and quetiapine are re- 
viewed, based on 29 selected studies. Literature searches were done using the English Medline/ Embase/ Psychinfo/ EBM databases (1965- August 2008).

\section{Part 2a, Chapters 3-5: Prevalence and risk factors}

This part evaluates AP-induced hyperprolactinemia in children/adolescents and the risk factors.

The work is presented in three different chapters (chapter 3-5).

All participants for this cross-sectional study were recruited from the total patient population of the outpatient adolescent clinic of the GGz Central Psychiatric Center, the Netherlands, during the period from October 2006 to November 2009. We included 62 children and adolescents ( 56 boys and 6 girls aged between 10 and 20 years) in the AP treated group (treatment with any AP medication lasted continuously for more than 16 months) and 57 children and adolescents in the medication-naïve group (47 boys, 10 girls). All participants had an IQ above 85 and were excluded if they had a history of thyroid disorders, syndromes or other chronic diseases affecting puberty, endocrine disorders, if they used oral corticosteroids or anticonvulsants, or if they had a known cause of hyperprolactinemia (Verhelst 2003, Melmed 2011).

In detail Chapter 3 aims to investigate the long-term treatment effects of risperidone on prolactin levels and prolactin-related side effects in pubertal boys with ASD and DBD. The prevalence of hyperprolactinemia and prolactin-related symptoms such as sexual functioning disorders are described.

Chapter 4 evaluates the effect of AP-induced-hyperprolactinemia on testosterone, LH, FSH, Inhibin B, and puberty in boys with ASD and DBD.

Chapter 5 presents a study of the long-term effects of AP treatment and AP-induced hyperprolactinemia on BMD and body composition in male adolescents with ASD and DBD.

\section{Part 2b, Chapter 6}

In this study the effect of the Taq1A variant in the Dopamine D2 receptor gene (DRD2) and common functional genetic variants in the cytochrome P450 2D6 gene (CYP2D6) on prolactin levels in boys with ASD and DBD treated with risperidone is investigated. 


\section{Chapter 7: Summary and discussion}

In this chapter the presented data is summarized and discussed, and recommendations are given together with suggestions for future research.

\section{References}

Abraham G, Halbreich U, Friedman R, Josiassen R. Bone mineral density and prolactin associations in patients with chronic schizophrenia. Schizophr Res. 59: 17-8, 20031.

Abraham G, Paing W, Kaminski J, Joseph A, Kohegyi E, Josiassen R. Effects of elevated serum prolactin on bone mineral density and bone metabolism in female patients with schizophrenia: a prospective study. Am J Psychiatry.160: 1618-20, 20032.

Aman MG, De Smedt G, Derivan A, Lyons B, Findling RL. Double-blind, placebo-controlled study of risperidone for the treatment of disruptive behaviors in children with subaverage intelligence. Am J Psychiatry. 159: 1337-46, 2002.

Aman M, McDougle C, Scahill L, Handen B, Arnold L, Johnson C, Stigler K, Bearss K, Butter E, Swiezy N, Sukhodolsky D, Ramadan Y, Pozdol S, Nikolov R, Lecavalier L, Kohn A, Koenig K, Hollway J, Korzekwa P, Gavaletz A, Mulick J, Hall K, Dziura J, Ritz L, Trollinger S, Yu S, Vitiello B, Wagner A. Medication and Parent Training in Children With Pervasive Developmental Disorders and Serious Behavior Problems: Results From a Randomized Clinical Trial. J Am Acad Child Adolesc Psychiatry. 48: 1143$54,2009$.

Anderson GM, Scahill L, McCracken JT, McDougle CJ, Aman MG, Tierney E. Effects of short- and long-term risperidone treatment on prolactin levels in children with autism. Biol Psychiatry. 61: 545-50, 2007.

Arinami T, Gao M, Hamaguchi H, Toru M. A functional polymorphism in the promoter region of the dopamine D2 receptor gene is associated with schizophrenia.Hum Mol Genet. 6: 577-82, 1997.

Baio J. Prevalence of autism spectrum disorders - autism and developmental disabilities monitoring network, 14 sites, United States, 2008. MMWR Surveill Summ 61:1-25, 2012.

Balon R, Segraves T, Clayton A. Issues for DSM-V: Sexual Dysfunction, Disorder, or Variation Along Normal Distribution: Toward Rethinking DSM Criteria of Sexual Dysfunctions. Am J Psychiatry. 164:198200, 2007.

Bembo SA, Carlson HE. Gynecomastia: its features, and when and how to treat it. Cleve Clin J Med. 71: 511-7, 2004.

Berecz R, Dorado P, De La Rubia A, Cáceres MC, Degrell I, LLerena A. The role of cytochrome P450 enzymes in the metabolism of risperidone and its clinical relevance for drug interactions. Curr Drug Targets. 5: 573-9, 2004.

Berinder K, Akre 0, Granath F, Hulting AL. Cancer risk in hyperprolactinemia patients: a populationbased cohort study. Eur J Endocrinol. 165:209-15, 2011.

Bevan JS. Interpreting prolactin levels: Implications for the management of large pituitary lesions. British Journal of Neurosurgery. 5: 3-6, 1991.

Biederman J, Mick E, Wozniak J, Aleardi M, Spencer T, Faraone SV. An open-label trial of risperidone in children and adolescents with bipolar disorder. J Child Adolesc Psychopharmacol. 15:311-317, 2005.

Bole-Feysot C, Goffin V, Edery M, Binart N, Kelly PA. Prolactin (PRL) and its receptor: actions, signal transduction pathways and phenotypes observed in PRL receptor knockout mice. Endocr Rev. 19: 225-268, 1998.

Calarge CA, Ellingrod VL, Acion L, Miller DD, Moline J, Tansey MJ, Schlechte JA.Variants of the dopamine D2 receptor gene and risperidone-induced hyperprolactinemia in children and adolescents. Pharmacogenet Genomics. 19: 373-82, 2009.

Calarge CA, Zimmerman B, Xie D, Kuperman S, Schlechte J. A cross-sectional evaluation of the effect of risperidone and selective serotonine reuptake inhibitors on bone mineral density in boys. J Clin Psychiatry. 1: 338-347, 2010. 
Colao A, Di Somma C, Loche S, Di Sarno A, Klain M, Pivonello R. Prolactinomas in adolescents: persistent bone loss after 2 years of prolactin normalization. Clin Endocrinol. 52 319-27, 2002.

Correll CU. Monitoring and management of antipsychotic-related metabolic and endocrine adverse events in pediatric patients. Int Rev Psychiatry. 20:195-201, 20081.

Correll CU. Assessing and maximizing the safety and tolerability of antipsychotics used in the treatment of children and adolescents. J Clin Psychiatry. 69: 26-36, 20082.

Croonenberghs J, Fegert JM, Findling RL, De Smedt G, Van Dongen S. Risperidone in children with disruptive behavior disorders and subaverage intelligence: a 1-year, open-label study of 504 patients. J Am Acad Child Adolesc Psychiatry. 44:64-72, 2005.

Cutler AJ. Sexual dysfunction and antipsychotic treatment. Psychoneuroendocrinology. 28 :69-82, 2003.

Davies J, Evans B, Gregory J. Bone mass acquisition in healthy children. Arch Dis Child. 90: 373-8, 2005.

De Leon J, Susce MT, Pan RM, Fairchild M, Koch WH, Wedlund PJ. The CYP2D6 poor metabolizer phenotype may be associated with risperidone adverse drug reactions and discontinuation. J Clin Psychiatry. 66:15-27, 2005.

Dunbar F, Kusumakar V, Daneman D, Schulz M. Growth and sexual maturation during long-term treatment with risperidone. Am J Psychiatry. 161: 918-20, 2004.

Emlinger MW, Kühnel W, Ranke MB. Reference ranges for serum concentrations of Lutotropin (LH), Follitropin (FSH), Estradiol (E2), Prolactin, Progesterone, Sex Hormone Binding Globuline (SHBG), Dehydroepiandrosterone sulfate (DHEAS), Cortisol and Ferritin in neonates, children and young adults. Clin Chem Lab Med. 40: 1151-1160, 2002.

Findling RL, McNamara NK. Atypical antipsychotics in the treatment of children and adolescents: clinical applications. J Clin Psychiatry. 65: 30-44, 2004.

Frantz AG. Prolactin. The New England Journal of Medicine. 198:201-207, 1978.

Freeman ME, Kanyicska B, Lerant A, Nagy G. Prolactin: structure, function, and regulation of secretion. Physiol Rev. 80:1523-631, 2000.

Galdiero M, Pivonello R, Grasso LF, Cozzolino A, Colao A. Growth hormone, prolactin, and sexuality. J Endocrinol Invest. 35: 782-94, 2012.

Graham S, Howgate D, Anderson W, Howes C, Heliotis M, Mantalaris A, Tsiridis E, Tsapakis E. Risk of osteoporosis and fracture incidence in patients on antipsychotic medication. Expert Opin Drug Saf. 10: 575-602, 2011.

Haddad PM, Wieck A: Antipsychotic-induced hyperprolactinaemia: mechanisms, clinical features and management. Drugs. 64: 2291-314, 2004.

Halbreich U, Kinon BJ, Gilmore JA, Kahn LS. Elevated prolactin levels in patients with schizophrenia: mechanisms and related adverse effects. Psychoneuroendocrinology. 28: 53-67, 2003.

Hanavadi S, Banerjee D, Monypenny IJ, Mansel RE. The role of tamoxifen in the management of gynaecomastia. Breast 15: 276-80, 2006.

Hasan A, Falkai P, Wobrock T, Lieberman J, Glenthoj B, Gattaz WF, Thibaut F, Möller HJ; World Federation of Societies of Biological Psychiatry (WFSBP) Task Force on Treatment Guidelines for Schizophrenia. World Federation of Societies of Biological Psychiatry (WFSBP) Guidelines for Biological Treatment of Schizophrenia, part 1: update 2012 on the acute treatment of schizophrenia and the management of treatment resistance. World J Biol Psychiatry. 13: 318-78, 2012.

Howard L, Kirkwood G, Leese M. Risk of hip fracture in patients with a history of schizophrenia. Br J Psychiatry. 190:129-34, 2007.

Houseknecht K, Robertson A, Zavadoski W, Gibbs E, Johnson D, Rollema H. Acute effects of atypical antipsychotics on whole-body insulin resistance in rats: implications for adverse metabolic effects. Neuropsychopharmacolog. 32: 289-97, 2007.

Hugenholtz G. Antipsychotic in daily clinical practice: patterns, choices and consequences. Universiteit Utrecht. Utrecht, Utrecht 2005.

Jönsson EG, Nöthen MM, Neidt H, Forslund K, Rylander G, Mattila-Evenden M, Asberg M, Propping P, Sedvall GC. Association between a promoter polymorphism in the dopamine D2 receptor gene and schizophrenia. Schizophr Res. 40:31-6,1999. 
Knegtering H, van der Moolen AE, Castelein S, Kluiter H, van den Bosch RJ. What are the effects of antipsychotics on sexual dysfunctions and endocrine functioning? Psychoneuroendocrinology. 28: 109$23,2003$.

Knegtering H, van den Bosch R, Castelein S, Bruggeman R, Sytema S, van Os J. Are sexual side effects of prolactin-raising antipsychotics reducible to serum prolactin? Psychoneuroendocrinology. 33:7117, 2008.

Kishimoto T, Watanabe K, Shimada N, Makita K, Yagi G, Kashima H. Antipsychotic-induced hyperprolactinemia inhibits the hypothalamo-pituitary-gonadal axis and reduces bone mineral density in male patients with schizophrenia. J Clin Psychiatry. 69: 385-91, 2008.

Lahey BB, Goodman SH, Waldman ID, Bird H, Canino G., Jensen P, Regier D, Leaf PJ, Gordon R, Applegate B. Relation of age of onset to the type and severity of child and adolescent conduct problems. J. Abnorm. Child. Psychol. 27: 247-260, 1999.

Lenton EA, Brook LM, Sobowale 0, Cooke ID. Prolactin concentrations in normal menstrual cycles and conception cycles. Clinical Endocrinology. 10: 383-391, 1979.

Loy JH, Merry SN, Hetrick SE, Stasiak K. Atypical antipsychotics for disruptive behaviour disorders in children and youths. Cochrane Database Syst Rev. 12: 9, 2012.

Matone M, Localio R, Huang YS, dosReis S, Feudtner C, Rubin D. The relationship between mental health diagnosis and treatment with second-generation antipsychotics over time: a national study of U.S. Medicaid-enrolled children. Health Serv Res. 47: 1836-60, 2012.

McKeever M. Delayed Puberty. Pediatrics in Review. 21: 250-251, 2000.

Meaney A, Smith S, Howes O, O'Brien M, Murray R, O'Keane V. Effects of long-term prolactin-raising antipsychotic medication on bone mineral density in patients with schizophrenia. Br J Psychiatry.184: 503-8, 2004.

Melkersson K. Differences in prolactin elevation and related symptoms of atypical antipsychotics in schizophrenic patients. J Clin Psychiatry. 66: 761-7, 2005.

Melmed S, Casanueva FF, Hoffman AR, Kleinberg DL, Montori VM, Schlechte JA, Wass JA. Diagnosis and treatment of hyperprolactinemia: an Endocrine Society clinical practice guideline. J Clin Endocrinol Metab. 96: 273-88, 2011.

Migliardi G, Spina E, D'Arrigo C, Gagliano A, Germanò E, Siracusano R, Diaz FJ, de Leon J. Short- and longterm effects on prolactin of risperidone and olanzapine treatments in children and adolescents. Prog Neuropsychopharmacol Biol Psychiatry. 33: 1496-501, 2009.

Mihara K, Suzuki A, Kondo T, Yasui-Furukori N, Ono S, Otani K, Kaneko S, Inoue Y. Relationship between Taq1 A dopamine D2 receptor (DRD2) polymorphism and prolactin response to bromperidol. Am J Med Genet. 105:271-4, 2001.

Molitch ME. Medication-induced hyperprolactinemia. Mayo Clin Proc. 80: 1050-7, 2005.

Motyl K, Dick-de-Paula I, Maloney A, Lotinun S, Bornstein S, de Paula F, Baron R, Houseknecht K, Rosen C. Trabecular bone loss after administration of the second-generation antipsychotic risperidone is independent of weight gain. Bone. 50: 490-8, 2012.

O'Keane V, Meaney A. Antipsychotic drugs: a new risk factor for osteoporosis in young women with schizophrenia? J Clin Psychopharmacol. 25: 26-31, 2005.

Ouwehand AJ, Mollema-Schelwald BM, Knegtering H. The relationship between antipsychotic-induced hyperprolactinemia and menstrual disorders in women with schizophrenia; a systematic review. Tijdschr Psychiatr. 54: 861-8, 2012.

Research Units on Pediatric Psychopharmacology Autism Network: Risperidone in children with autism and serious behavioral problems. New Eng. J Med. 347: 314-321, 2002.

Reyes M, Croonenberghs J, Augustyns I, Eerdekens M. Long-term use of risperidone in children with disruptive behavior disorders and subaverage intelligence: efficacy, safety, and tolerability. J Child Adolesc Psychopharmacol. 16: 260-72, 2006.

Roke Y, Van Harten PN, Boot AM, Buitelaar JK. Antipsychotic medication in children and adolescents: A descriptive review of the effects on prolactin level and associated side effects.J Child Adolesc Psychopharmacol. 19: 403-1, 2009. 
Roke Y, Buitelaar JK, Boot AM, Tenback D, van Harten PN. Risk of hyperprolactinemia and sexual side effects in males 10-20 years old diagnosed with autism spectrum disorders or disruptive behavior disorder and treated with risperidone. J Child Adolesc Psychopharmacol. 22: 432-9, 20121.

Roke Y, van Harten P, Buitelaar J, Tenback D, de Rijke Y, Boot AM. Antipsychotic-induced hyperprolactinemia and testosterone levels in boys. Horm Res Paediatr. 77: 235-40, 20122.

Rosen D, Foster C. Delayed Puberty. Pediatrics in Review. 22: 309-315, 2001.

Saranac L, Zivanovic S, Radovanovic Z, Kostic G, Markovic I, Miljkovic P. Hyperprolactinemia: different clinical expression in childhood. Horm Res Paediatr. 73: 187-92, 2010.

Sachse C, Brockmöller J, Bauer S, Roots I. Cytochrome P450 2D6 variants in a Caucasian population: allele frequencies and phenotypic consequences. Am J Hum Genet. 60:284-95, 1997.

Schwetz V, Pieber T, Obermayer-Pietsch B. Mechanisms in endocrinology: The endocrine role of the skeleton: background and clinical evidence. Eur J Endocrinol. 166: 959-967, 2012.

Seriwatanachai D, Thongchote K, Charoenphandhu N, Pandaranandaka J, Tudpor K, Teerapornpuntakit J, Suthiphongchai T, Krishnamra N. Prolactin directly enhances bone turnover by raising osteoblastexpressed receptor activator of nuclear factor kappaB ligand/osteoprotegerin ratio. Bone. 42: 53546, 2008.

Sikich L, Hamer RM, Bashford RA, Sheitman BB, Lieberman JA. A pilot study of risperidone, olanzapine, and haloperidol in psychotic youth: a double-blind, randomized, 8-week trial. Neuropsychopharmacology. 29: 133-45, 2004.

Singh J, Chen G, Canuso CM.Antipsychotics in the treatment of bipolar disorder. Handb Exp Pharmacol. 212:187-212, 2012.

Smith S, Wheeler MJ, Murray R, O'Keane V.The effects of antipsychotic-induced hyperprolactinaemia on the hypothalamic-pituitary-gonadal axis. J Clin Psychopharmacol. 22:109-14, 2012.

Snyder R, Turgay A, Aman M, Binder C, Fisman S, Carroll A. Effects of risperidone on conduct and disruptive behavior disorders in children with subaverage IQs. J Am Acad Child Adolesc Psychiatry. 41: 1026-36, 2002.

Staller J. The effect of long-term antipsychotic treatment on prolactin. J Child Adolesc Psychopharmacol. 16: 317-26, 2006.

Stevens JR, Kymissis PI, Baker AJ. Elevated prolactin levels in male youths treated with risperidone and quetiapine. J Child Adolesc Psychopharmacol.15: 893-900, 2005.

Stigler KA, Diener JT, Kohn AE, Li L, Erickson CA, Posey DJ, McDougle CJ. A prospective, open-label study of aripiprazole in youth with Asperger's disorder and pervasive developmental disorder not otherwise specified. Neuropsychopharmacology. 31:S194, 2006.

Szarfman A, Tonning JM, Levine JG, Doraiswamy PM. Atypical antipsychotics and pituitary tumors: a pharmacovigilance study. Pharmacotherapy. 26:748-58, 2006.

Taes Y, Lapauw B, Vanbillemont G, Bogaert V, De Bacquer D, Zmierczak H, Goemaere S. Fat Mass Is Negatively Associated with Cortical Bone Size in Young Healthy Male Siblings. J Clin Endocrinol Metab. 94: 2325-31, 2009.

Thompson J, Thomas N, Singleton A, Piggott M, Lloyd S, Perry EK, Morris CM, Perry RH, Ferrier IN, Court JA. D2 dopamine receptor gene (DRD2) Taq1 A polymorphism: reduced dopamine D2 receptor binding in the human striatum associated with the A1 allele. Pharmacogenetics. 7:479-84, 1997.

Troost PW, Lahuis BE, Hermans MH, Buitelaar JK, van Engeland H, Scahill L, Minderaa RB, Hoekstra PJ. Prolactin release in children treated with risperidone: impact and role of CYP2D6 metabolism. J Clin Psychopharmacol. 27: 52-7, 2007.

Turgay A, Binder C, Snyder R, Fisman S. Long-term safety and efficacy of risperidone for the treatment of disruptive behavior disorders in children with subaverage IQs. Pediatrics.110: e34, 2002.

Verhelst J, Abs R. Hyperprolactinemia: pathophysiology and management. Treat Endocrinol. 2: 23-32, 2003.

Vitiello B, Correll C, van Zwieten,Boot B, Zuddas A, Parellada M, Arango C. Antipsychotics in children and adolescents: increasing use, evidence for efficacy and safety concerns. Eur Neuropsychopharmacol.19: 629-35, 2009.

Wing L: The autistic spectrum. Lancet. 350:1761-1766, 1997. 


\section{CHAPTER I}

Wink LK, Erickson CA, McDougle CJ. Pharmacologic treatment of behavioral symptoms associated with autism and other pervasive developmental disorders. Curr Treat Opt Neurol. 12: 529-38, 2010.

Wu XY, Mao JF, Lu SY, Zhang Q, Shi YF. Testosterone replacement therapy improves insulin sensitivity and decreases high sensitivity C-reactive protein levels in hypogonadotropic hypogonadal young male patients. Chin Med J. 122: 2846-50, 2009.

Young RM, Lawford BR, Barnes M, Burton SC, Ritchie T, Ward WK, Noble EP. Prolactin levels in antipsychotic treatment of patients with schizophrenia carrying the DRD2*A1 allele. Br J Psychiatry 185:147-5, 2004. 


\section{PART 1}

\section{Descriptive review}

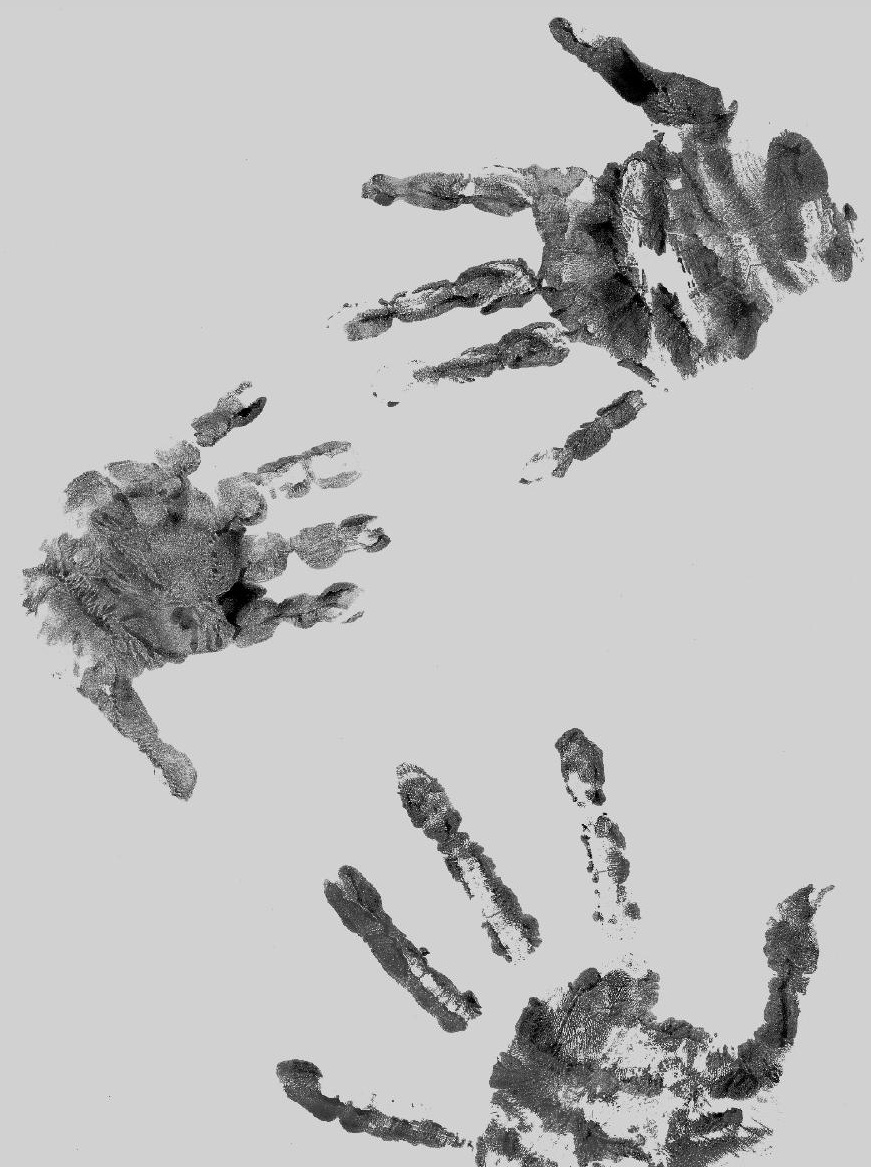





\section{CHAPTER 2}

\section{Antipsychotic medication in children and adolescents: effects on prolactin level and associated side effects. A descriptive review}

Yvette Roke, MD, Peter N. van Harten, MD, PhD, Annemieke M. Boot, MD, PhD, Jan K. Buitelaar, MD, PhD

J Child Adolesc Psychopharmacol. 2009 Aug;19(4):403-14.

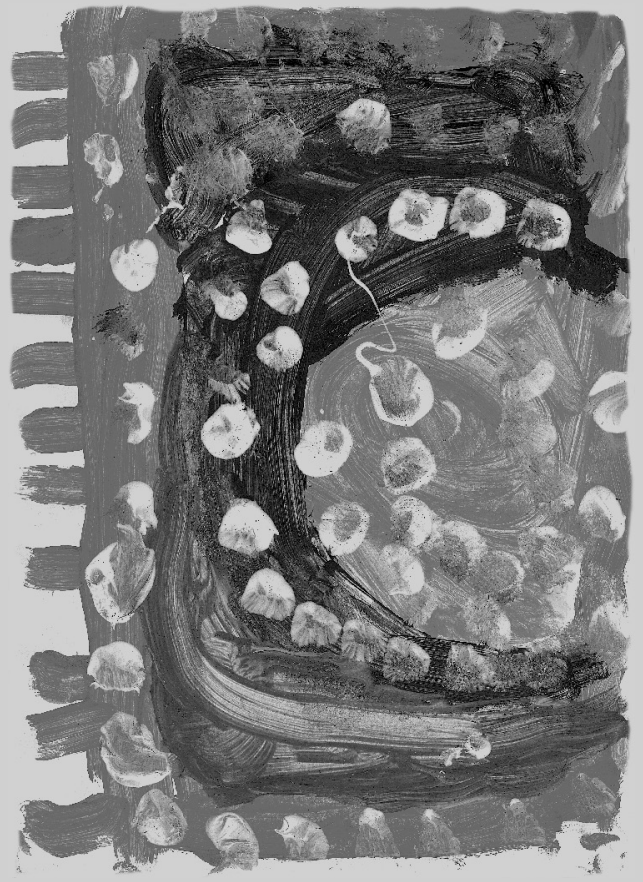




\section{Abstract}

Objective: This review reports the incidence of hyperprolactinaemia, its relation with genotype, and prolactin related side effects in children and adolescents treated with antipsychotics.

Method: Data on prolactin levels were available for haloperidol, pimozide, risperidone, olanzapine, clozapine, ziprasidone and quetiapine. Twenty-nine studies were selected after a literature search in the English Medline/ Embase/ Psychinfo/ EBM databases (1965- August 2008)

Results: All antipsychotics, except clozapine, ziprasidone and quetiapine, increase the mean prolactin level from baseline values of $8.0 \mathrm{ng} / \mathrm{ml}$ to $25-28 \mathrm{ng} / \mathrm{ml}$ after four weeks of treatment (reference range $0-15 \mathrm{ng} / \mathrm{ml}$ ). Most and best data are available for risperidone. Five risperidone studies $(n=577)$ show an increase of prolactin level from $7.8 \mathrm{ng} / \mathrm{ml}$ to $17.7 \mathrm{ng} / \mathrm{ml}$ after one year of treatment and two risperidone studies $(\mathrm{n}=60)$ show an increase from $7.4 \mathrm{ng} / \mathrm{ml}$ to $24.9 \mathrm{ng} / \mathrm{ml}$ after two years of treatment. Aggregated over all antipsychotics prolactin related side effects, such as gynaecomastia, galactorrhea, irregular menses and sexual dysfunction were reported by $4.8 \%$ of the children and adolescents. No data are available on bone mineral density in relation to antipsychotic-induced hyperprolactinaemia in children and adolescents. Prolactin levels may be influenced by the genetic differences that influence prolactin metabolism and D2 receptor density

Conclusion: Persistent elevation of prolactin for periods up to two years has been documented in the maintenance treatment with risperidone. Very limited long-term data of pimozide, olanzapine and quetiapine prohibit drawing conclusions for these antipsychotics. Systematic long-term observational studies including specific questionnaires as well as physical examination, are needed to investigate prolactin related side effects of antipsychotic treatment in children and adolescents.

Keywords: Adolescent, Child, Hyperprolactinaemia, Puberty, Bone mineral density, Antipsychotic agents, Genetics 


\section{Introduction}

The number of prescriptions for (a)typical antipsychotics to treat children and adolescents with both schizophrenia and other psychotic conditions and with nonpsychotic conditions such as autism spectrum disorders, disruptive behavioural disorders, tic disorders and behavioural problems associated with mental retardation has increased significantly (Schirm 2001) (Zito 2003) (Cooper 2004) (Correll 2008). This increase can be attributed largely to the introduction of new antipsychotics with fewer extra pyramidal side effects (Correll 2004), greater efficacy for broader target symptoms (Buckley 2001) and possibly improved compliance (Dolder 2002) (Menzin 2003).

In particular, low dosages of risperidone and olanzapine appear to be effective in the treatment of behavioural problems in autism spectrum disorders (Malone 2002) (McCracken 2002), conduct disorders (Findling 2000) (Aman 2002) (Snyder 2002) and acute psychotic symptoms (Arango 2004) (Sikich 2004). However, risperidone and olanzapine may have potential long-term side effects. There is increasing awareness of the impact of long-term side effects of antipsychotics in children and adolescents. Since these children and adolescents are in a continuous state of development and maturation they may be more vulnerable to these side effects than adults. The understanding of the complex interaction of these drugs with neurochemical systems, such as pre- and post synaptic receptor systems and binding to transporter sites or to secondary or tertiary messenger systems in the brain would explain these potential long term side effects. Many of these interactions have not yet been clarified. Our knowledge about these medication-brain interactions has been quite limited.

One side effect of antipsychotics is hyperprolactinaemia. The secretion of prolactin by the anterior pituitary gland is inhibited by the tubero-infundibular dopamine system. Hyperprolactinaemia is caused by blocking of the D2 dopaminereceptor at the anterior lobe of the pituitary gland, resulting in high prolactin levels. This may cause a decline in gonadotropins and a decrease in oestrogen- and testosterone-concentrations (Haddad 2004) (Halbreich 2003). Strong D2 dopaminereceptor blocking antipsychotics, such as amisulpiride, cause frequent hyperprolactinaemia in adults (Paparrigopoulos 2007) but data in children and adolescents are not available.

The tubero-infundibular D2 dopamine receptors are known to react more sensitively and fast to the D2 blocking effects of antipsychotics than the D2 receptors in the mesolimbic and mesocortical dopamine systems (Langer 1977) (Halbreich 2003). Prolactin is secreted intermittently, which may result in variation between single samples.

Hyperprolactinaemia associated with antipsychotic medication may be more prevalent in children and adolescents than in adults, because the density of D2 dopamine receptors in the central nervous system is higher in children and adolescents than in adults (Seeman 1987). 
Hyperprolactinaemia may cause gynaecomastia, galactorrhea, irregular menses and amenorrhea in women, sexual dysfunction (decreased sexual desire, erectile/ ejaculatory dysfunction, orgasmic dysfunction, vaginal dryness), and reduced fertility (Bobes 2003) (Costa 2007) (Knegtering 2003, 2004, 2006) (Nakonezny 2007).

The induced hypogonadotropic hypogonadism together with low oestrogen and testosterone levels may cause low bone mineral density and osteoporosis (Abraham and Halbreich 2003) (Abraham and Paing 2003) (Meaney 2004) (Hugenholtz 2005) (O'Keane 2005) (Becker 2006) (Howard 2007). This effect may be even more marked in adolescents because puberty is an important period for the attainment of peak bone mass (Davies 2005). Serum prolactin levels vary in time and betweenindividuals. There is reasonable consensus regarding the upper limit of the normal range (hyperprolactinaemia) being $500 \mathrm{mU} / \mathrm{L}$ in both men and women at adult age, which is approximately $15 \mathrm{ng} / \mathrm{ml}$ (Bevan 1991). However, some authors suggest an upper limit of $25 \mathrm{ng} / \mathrm{ml}$ for adults (Lenton 1979) (Marken 1992). Studies in children and adolescents show slightly lower values (Gässler 2000). There is individual variation in plasma prolactin level at which symptoms appear. Some symptoms, for example galactorrhea, reflect raised prolactin acting on target tissue while other symptoms, such as amenorrhoea, are due to secondary hypogonadism. Amenorrhoea usually appears at prolactin levels above $60 \mathrm{ng} / \mathrm{ml}$ (Haddad 2004).

A previous review on antipsychotic-induced hyperprolactinaemia in children and adolescents was published in 2004 and included 14 studies (Pappagallo 2004). Eighteen studies were published thereafter and are include in our review. Pappagallo (2004) reported an overall incidence of $20 \%$. Our review reports an incidence of respectively $90 \%, 80 \%, 62 \%, 31 \%$ and $12 \%$ with haloperidol, pimozide, risperidone, olanzapine and quetiapine during treatment. Recent reviews on hyperprolactinaemia did not include children and adolescents and were not comparable to the incidence numbers of this review (Byerly 2007). The objective of this review was to evaluate the incidence and severity of antipsychotic induced hyperprolactinaemia, the incidence of prolactin-related side effects, and the role of genetic vulnerability factors among children ( $\leq 12$ years of age) and adolescents (12 to18 years of age).

\section{Method}

A search was conducted in the English Medline/ Embase/ Psychinfo/ EBM databases (1965- August 2008) using the terms: "risperidone", "olanzapine", "pimozide", "clozapine", "quetiapine", "haloperidol", “aripiprazole”, “amisulpiride”, "ziprasidone”, “(a)typical antipsychotics”, "adverse effects”, “side effects”, ” hyperprolactinaemia", "bone mineral density", "children", "adolescents", "prolactinoma”, "osteoporosis", "prolactin", "hypogonadism", "bone density", "sex hormone”, "androgen", "estrogen", "metabolic", “endocrine”, "puberty disorders”, “delayed puberty", "polymorphism", "genetic" and "puberty". The terms were used alone or in 
various combinations. Data appearing only in abstracts of scientific meetings or in journals written in languages other than English were excluded. The results were based upon studies carried out with children and adolescents. All reports (except single case reports) with a duration longer than three weeks were included. Data about prolactin levels were available for haloperidol, pimozide, risperidone, olanzapine, clozapine, ziprasidone and quetiapine. Antipsychotics were converted to chloorpromazine equivalent doses (CPZ) (Woods 2003).

\section{Results}

\section{Data}

Twenty-nine publications with study durations longer than three weeks were found: risperidone $(n=20)$, olanzapine $(n=7)$, quetiapine $(n=5)$, haloperidol $(n=4)$, pimozide $(n=3)$, clozapine $(n=2)$ and ziprasidone $(n=1)$. These studies varied in terms of the duration of treatment which ranged from 3.3 to 106 weeks. Six papers were based on the same clinical sample and study (Wudarsky 1999) (Alfaro 2002) (Aman 2002) (Findling 2004) (Croonenberghs 2005) (Reyes 2006). The samples included children with disruptive disorders, conduct disorder, oppositional defiant disorder, autism, schizophrenia, schizoaffective disorder, schizophreniform disorder, psychotic disorders NOS, Tourette's syndrome, bipolar affective disorder with psychotic features, depression with psychotic features and children with normal and subnormal intelligence. The design of the studies varied. 17 studies had an open label design, four studies had an observational design (Frazier 1999) (Masi 2003) (Stevens 2005) (Staller 2006) and eight studies were double blind (Sallee 1996) (Wudarsky 1999) (Snyder 2002) (Alfaro 2002) (Aman 2002) (Sikich 2004) (Hellings 2005) (Luby 2006). Seven risperidone studies (Turgay 2002) (Findling 2004) (Croonenberghs 2005) (Stevens 2005) (Reyes 2006) (Staller 2006) (Anderson 2007) monitored prolactin for a period of 48 to 106 weeks. For olanzapine, quetiapine and pimozide one long-term study has been performed (Suwa 1984) (Staller 2006). Clozapine and ziprasidone were studied for six weeks.

The total number of patients studied for risperidone, olanzapine, quetiapine, haloperidol, pimozide, clozapine and ziprasidone were 1382, 170, 72, 56, 46, 30 and 12 respectively. The weighted average of the percentage of boys included in the studies ranged from 63-82.5\%. Ten of the 29 studies used a prospective design with prolactin as the principal outcome variable (Simeon 1979) (Sallee 1996) (Wudarsky 1999) (Masi 2001) (Alfaro 2002) (Masi 2003) (Saito 2004) (Hellings 2005) (Anderson 2007) (Troost 2007). Two studies had no medication-free baseline measurement (Saito 2004) (Sikich 2004) and six studies had no prolactin baseline measurement (Hardan 1996) (Frazier 1999) (McConville 2000) (Fegert 2003) (Stevens 2005) (Anderson 2007). Co-medication was permitted in 19 out of 29 
studies. In five studies (Wudarsky 1999) (Shaw 2001) (Alfaro 2002) (Anderson 2007) (Dittmann 2008) the use of co-medication was unknown and in six studies co-medication was not allowed (Simeon 1979) (Suwa 1984) (Sallee 1996) (Masi 2001, 2003) (Luby 2006). Eleven studies (Frazier 1999) (McConville 2000) (Shaw 2001) (Snyder 2002) (Findling 2004) (Saito 2004) (Sikich 2004) (Hellings 2005) (Stevens 2005) (Reyes 2006) (Staller 2006) allowed co-medication that can cause modest elevations of prolactin levels such as antidepressants (Molitch 2005) and melatonin (Blaicher 1999) and five studies allowed other co-medication, such as psycho stimulants, benzodiazepines and anticholinergics (Hardan 1996) (Aman 2002) (Turgay 2002) (Croonenberghs 2005) (Troost 2007) .

Most studies (17) used $0-18 \mathrm{ng} / \mathrm{ml}$ for boys and $0-30 \mathrm{ng} / \mathrm{ml}$ for girls, but four studies used 0-15 ng/ml for boys and girls (Frazier1999) (Masi 2001, 2003) (Stevens 2005) while eight studies did not give a reference value (Suwa 1984) (Shaw 2001) (Aman 2002) (Fegert 2003) (Sikich 2004) (Luby 2006) (Anderson 2007). All the data are summarized in Tables 1-4; the weighted averages were calculated by multiplication of the number of patients and the matching variable of the same study. The amounts of the different studies were added and then divided by the total number of patients. Medication-free prolactin baseline values were missing in two studies and seven studies had no prolactin baseline value measurement; these studies were left out of the prolactin baseline weighted average calculation.

\section{Prolactin level}

All antipsychotics, except clozapine, ziprasidone and quetiapine, increase the prolactin level from baseline values of $8.0 \mathrm{ng} / \mathrm{ml}$ to $25-28 \mathrm{ng} / \mathrm{ml}$ after four to eight weeks of treatment. Eight short-term risperidone studies $(n=739)$ with an average duration of 4.6 weeks showed an increase of prolactin from $7.9 \mathrm{ng} / \mathrm{ml}$ at baseline to $27.6 \mathrm{ng} / \mathrm{ml}$ at endpoint (Aman 2002) (Snyder 2002) (Masi 2001) (Turgay 2002) (Fegert 2003) (Croonenberghs 2005) (Anderson 2007) (Troost 2007). Further treatment shows a decrease to $17.7 \mathrm{ng} / \mathrm{ml}$ (male $15.8 \mathrm{ng} / \mathrm{ml}$ and female 20.8 $\mathrm{ng} / \mathrm{ml}$ ) after one year of treatment (Croonenberghs 2005) (Findling 2004) (Anderson 2007) (Stevens 2005) (Turgay 2002) and to $24.9 \mathrm{ng} / \mathrm{ml}$ (male $24.6 \mathrm{ng} / \mathrm{ml}$ and female $27.6 \mathrm{ng} / \mathrm{ml}$ ) after two years of treatment (Reyes 2006) (Staller 2006). Longterm prolactin level is still elevated compared to baseline and compared to reference value after one year and two year of treatment. A pimozide study $(n=13)$ showed an increase after one year of treatment from $12.4 \mathrm{ng} / \mathrm{ml}$ to $24.5 \mathrm{ng} / \mathrm{ml}$ (Suwa 1984), but one olanzapine study ( $n=7$ ) showed no increase of prolactin level after one year of treatment (Staller 2006).

The possibility to draw conclusions is limited by the small sample size, however. Thus, persistent elevation of prolactin has been clearly documented in the maintenance treatment with risperidone for up to two year. 
As shown in Tables 1-4, the incidence of hyperprolactinaemia during treatment with haloperidol, pimozide, risperidone, olanzapine and quetiapine was respectively $90 \%, 80 \%, 62 \%, 31 \%$ and $12 \%$.

It is not likely that the prolactin elevation is illness-related, since comparative populations, namely the one with disruptive disorder, conduct disorder and oppositional defiant disorder $(n=1060)$ treated with risperidone the one with autism treated with risperidone $(\mathrm{n}=158)$ showed no difference with respect to the severity or incidence of prolactin elevation. It is not possible to draw conclusions about illness-related prolactin elevation for the populations with affective, tic and psychotic disorders because of their small sample size. 


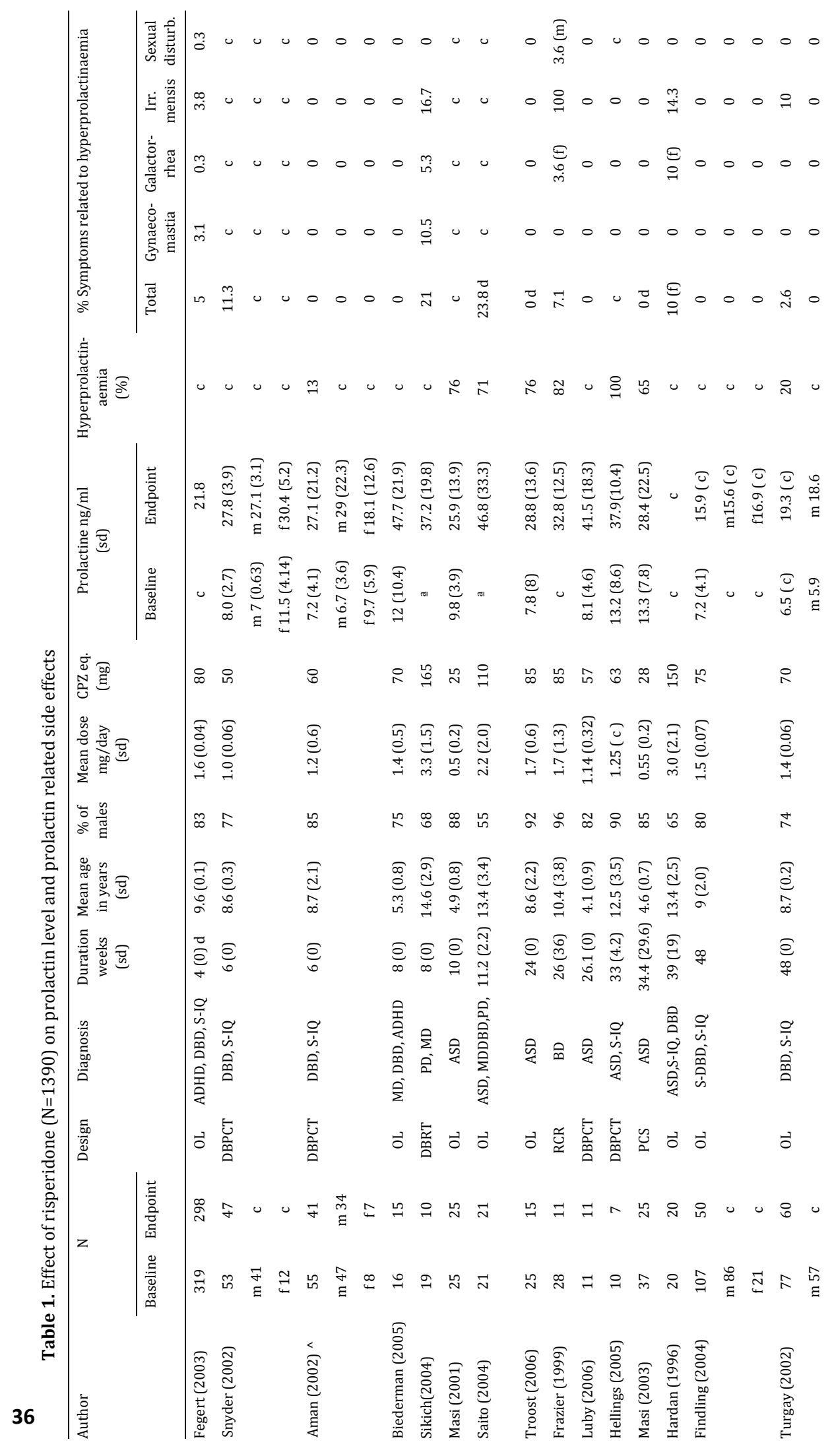




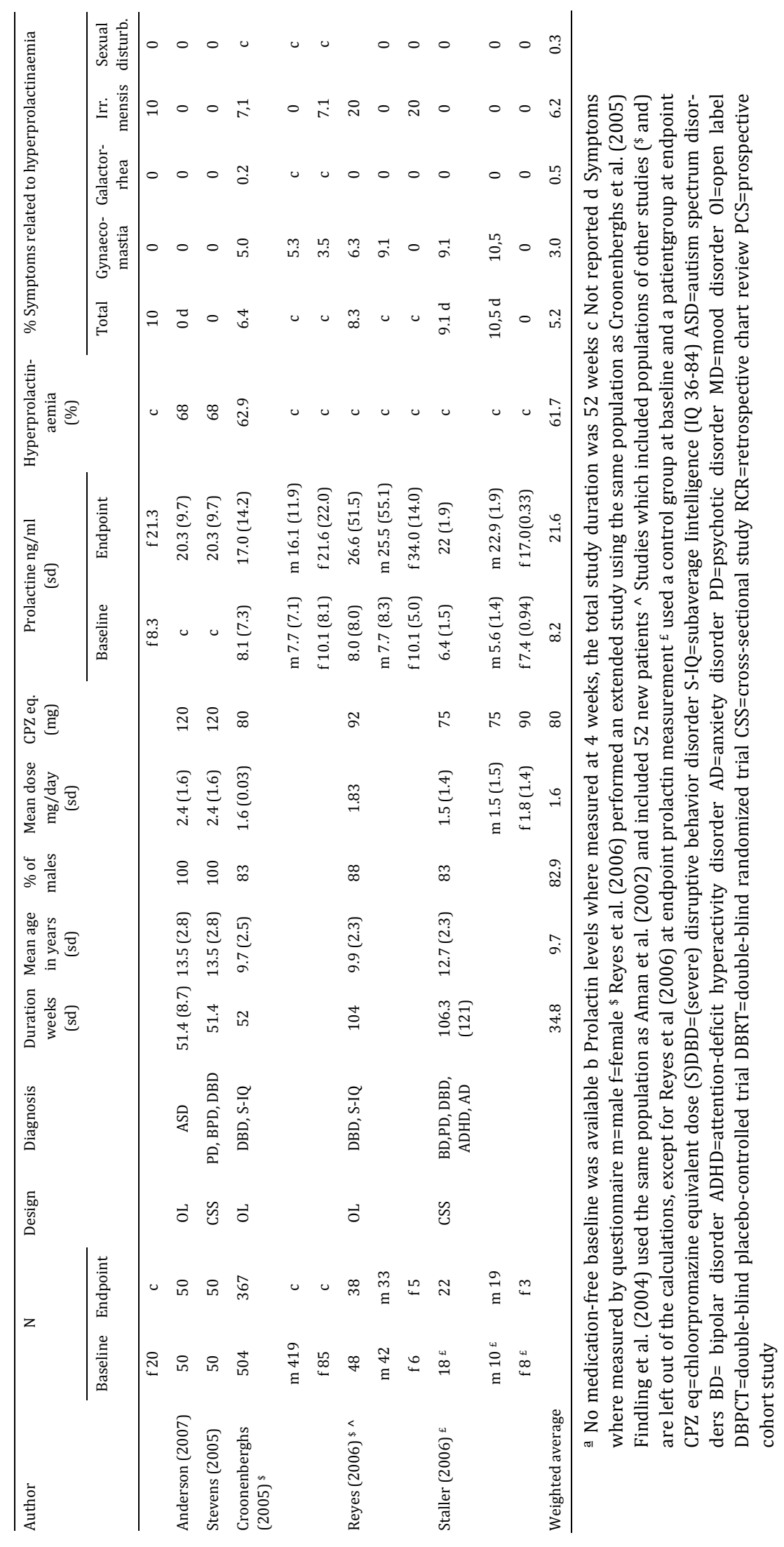

REVIEW 


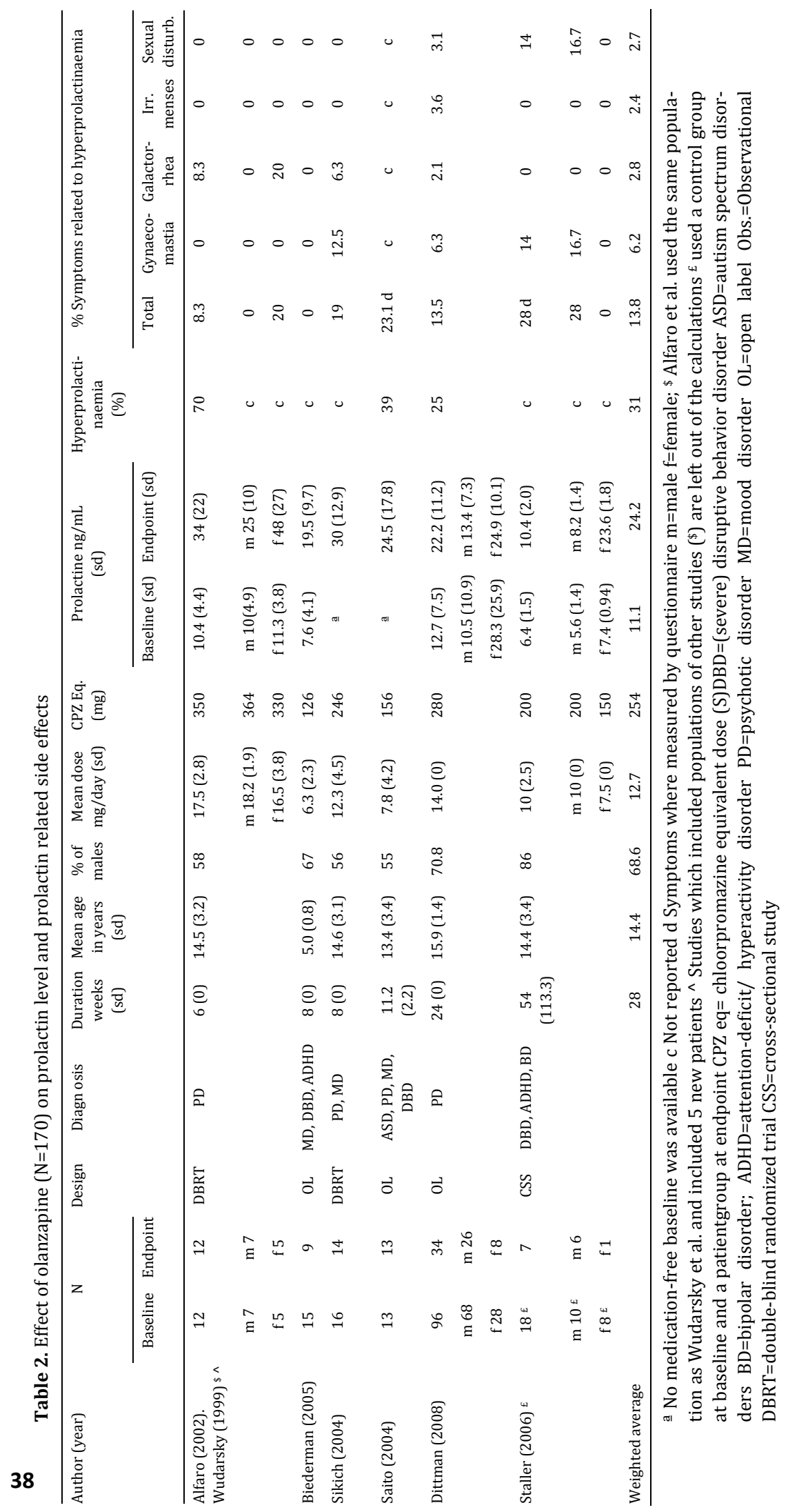




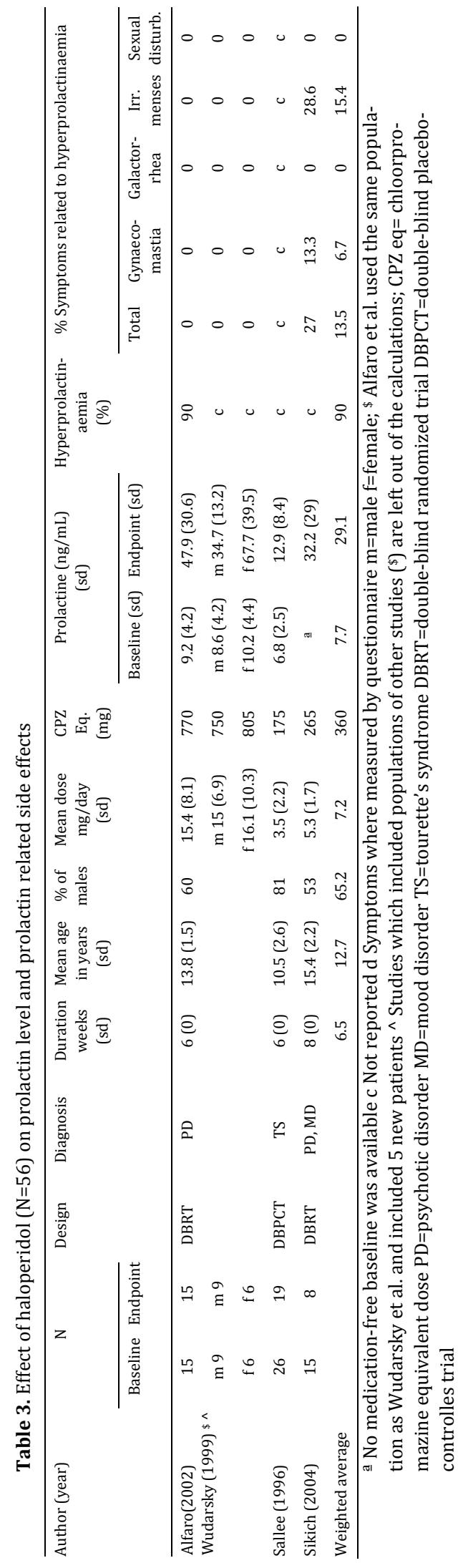




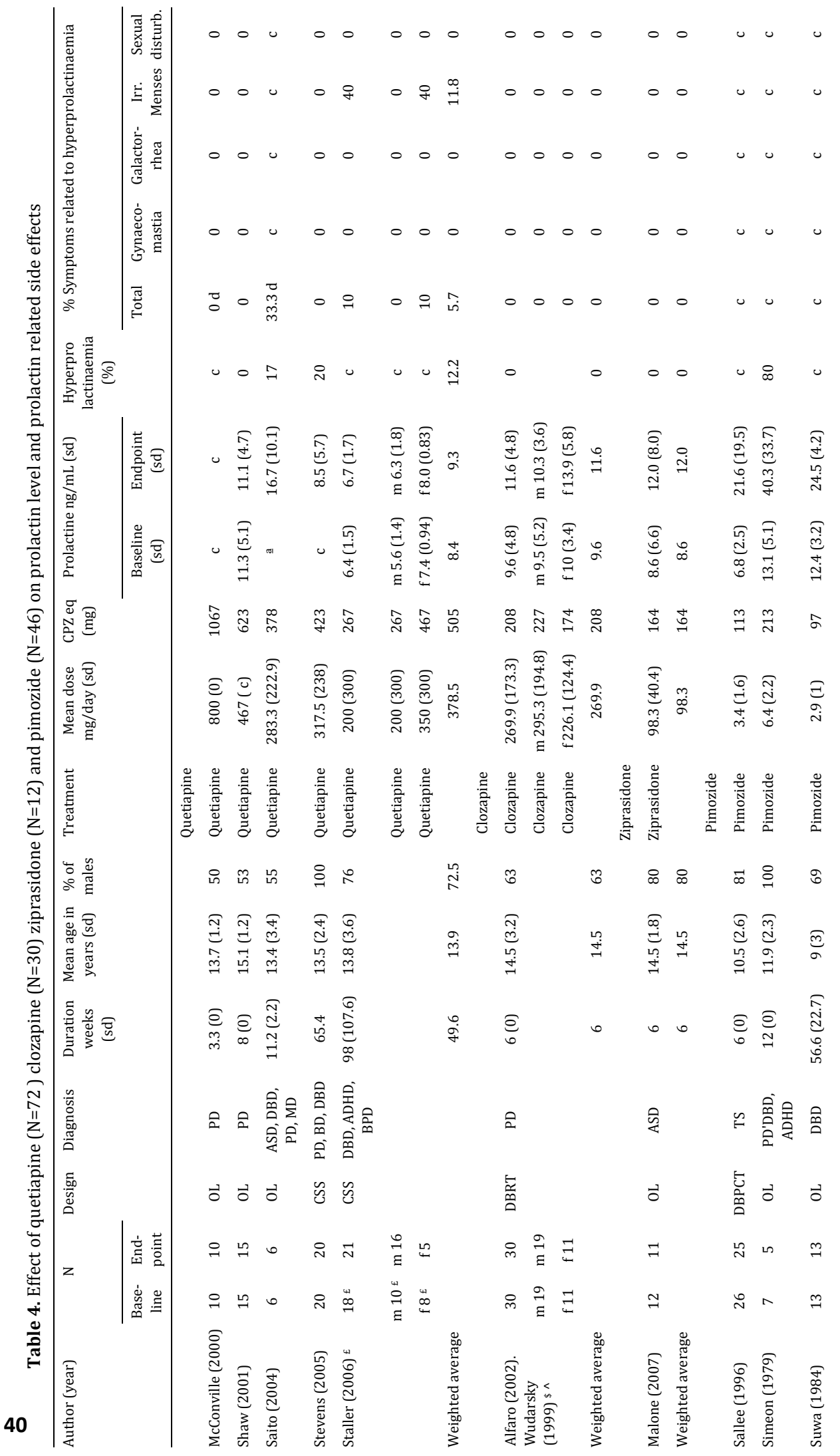




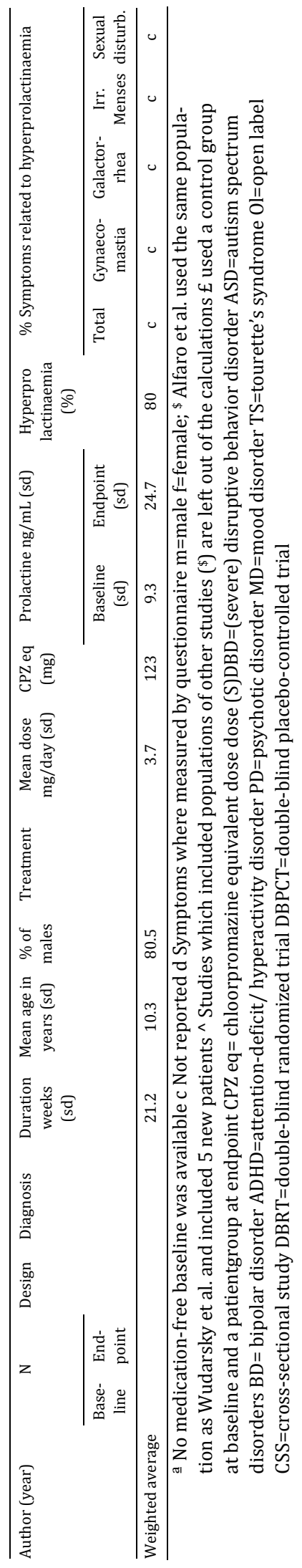




\section{Prolactin related side effects}

\section{Sex hormones}

As far as we know, no attention has yet been given on the prolactin-raising effect on sex steroid levels in children or adolescents receiving antipsychotic medication.

\section{Pubertal development}

Only two studies with duration of one year investigated the association between risperidone and the progression of puberty (Dunbar 2004, Reyes 2006). No effect was found on the progression of Tanner stages after one year follow-up.

\section{Neuroendocrine and sexual side effects}

Tables 1-4 show that children and adolescents treated with olanzapine, haloperidol, quetiapine and respectively risperidone report 13.8\%, 13.5\%, 5.7\% and 5.1\% symptoms related to hyperprolactinaemia. Most frequently reported are gynaecomastia (risperidone 3.0\%, olanzapine 6.2\%, haloperidol 6.7\%) and irregular menses (risperidone 6.3\%, haloperidol 15.4\%, quetiapine 11.8\%). In a prospective study of hyperprolactinaemia in children and adolescents $25 \%(10 / 40)$ reported a decrease in sexual performance, and in another double-blind randomized 8 week trial $22 \%$ of 50 adolescents treated with prolactin-raising atypical antipsychotics reported sexual side effects (Sikich 2004) (Saito 2004). Unfortunately, many studies did not report on sexual side effects.

\section{Bone mineral density (BMD)}

So far no studies have examined the effect of prolactin-raising antipsychotic medication on BMD in adolescents.

\section{Discussion}

The main conclusion from this review is that all antipsychotics except clozapine, ziprasidone and quetiapine, cause a rise in prolactin level to levels higher than two times the upper normal limit after four to eight weeks of treatment. Furthermore, long-term studies with adequate sample size have only been performed with risperidone and limited long-term data are available of pimozide, olanzapine and quetiapine which leads to cautiousness in drawing conclusions about these latter medications. Anyhow, available data show that risperidone and pimozide induce a persistent elevation in prolactin level above the upper limit, while with olanzapine the prolactin level normalizes to baseline value. Quetiapine did not increase the mean prolactin level (Shaw 2001, Staller 2006). The actual percentage of children or adolescents that had hyperprolactinaemia was measured in a few studies (Tables 1-4). The weighted average incidence of $12 \%$ hyperprolactinaemia in the 
quetiapine group was reported in the text of three studies. No baseline measurements were available, thus pre-existing hyperprolactinaemia could not be excluded. Furthermore, prolactin elevating co-medication was used in two out of three studies (Saito 2004, Stevens 2005).

Prolactin levels were averaged across the whole sample studied; including those whose prolactin levels were not raised. Therefore, group mean data shown in Tables1-4 are lower than the mean data of the subgroup of children and adolescents with prolactin levels above the upper limit. Little is known about the clinical consequences of a sustained higher prolactin level over years among children and adolescents.

Only two studies with duration of one year investigated the association between risperidone and the progression of puberty (Dunbar 2004, Reyes 2006). Although no effect was found on the progression of Tanner stages a one year follow-up may be too short to draw conclusions about the effect of pubertal development or later developmental processes. It is known that hyperprolactinaemia due to prolactinoma is associated with delayed puberty, but in those patients prolactin levels were much higher, in the range of $200 \mathrm{ng} / \mathrm{ml}$ or above, than in the child and adolescent psychiatric samples included in this study (Greenspan 1986) (Howlett 1989) (Kawano 2000) (Patton 1983) (Sack 1984). It is also known that prolactinoma-induced hyperprolactinaemia induces a decrease in testosterone levels in men/pubertal boys but no studies have been performed to examine the effect of antipsychotic-induced hyperprolactinaemia on the sex hormone levels. Studies in adult males show that the prolactin-raising effect of antipsychotics leads to a significant decline in Luteinizing Hormone, Follicle Stimulating Hormone and testosterone although the levels remained within the normal range (Carter 1982) (Siris 1980). Prolactin related side effects, such as gynaecomastia, galactorrhea, irregular menses and sexual side effects were reported by $4.8 \%$ of the total number of patients. In several adult studies $30 \%$ to $60 \%$ of adult patients using prolactin-raising antipsychotic medication reported sexual side effects, such as erection and ejaculatory and menstrual disturbances compared to about $10 \%$ of patients using prolactin-sparing antipsychotic medication (Knegtering 2003). In The Outcomes Research Study in schizophrenia (EIRE) (Bobes 2003), the prevalence of sexual dysfunction and reproductive side effects was investigated in 365 adult schizophrenic Spanish patients using prolactin-raising antipsychotics, risperidone and haloperidol, compared to 43 patients using quetiapine. The prolactin-raising antipsychotic treatment was associated with $40 \%$ sexual dysfunction compared to $18 \%$ in the quetiapine group. Several studies show a relationship between serum prolactin level and sexual functioning, strength of sex drive, penile erection and sexual arousal (Costa 2007) (Knegtering 2003, 2004, 2006) (Nakonezny 2007). The 4.8\% of the total number of patients in this review that reported sexual dysfunction is low in relation to the percentage of adult patients that report these side effects. This discrepancy can be partly explained by comparing the method of the different studies, spontaneous self report in adolescents and children versus questionnaires used in adult 
studies. Besides the method also the age of sexual development and the diagnosis play an important role. The adults were mainly adults with psychotic disorders whereas the children and adolescents had autistic or behavioural disorders.

The effect of antipsychotic-induced hyperprolactinaemia on BMD has not been studied in children and adolescents. Several adult studies have investigated antipsychotic-induced hyperprolactinaemia, and possibly related hypogonadism, and related effects on BMD. These studies show a relation between antipsychoticinduced hypogonadism and a decrease in BMD (Abraham and Halbreich 2003) (Abraham and Paing 2003) (Meaney 2003, 2004) (O'Keane 2005) (Becker 2006). Furthermore, two large case-control studies $(44,500$ patients and 16,341 patients) showed that prolactin-raising antipsychotic medication was associated with a twofold increased risk of hip or femur fractures. The validity of this finding was supported by a dose increase relationship, i.e. the longer duration of antipsychotic use the higher the risk (Howard 2007) (Hugenholtz 2005).

The relation between hyperprolactinaemia and BMD loss in adolescents was studied in patients with prolactinomas. The effect of hyperprolactinaemia on BMD was studied by comparing the results for two groups of patients with prolactinomas, one group of 20 adolescents and one group of 20 adults. The adolescents had more severe bone loss than the adults. After two years of treatment with dopaminergic drugs, the bone mass and bone turnover in the adolescent group were still not restored to normal values (Colao 2000). Prolactin levels above $60 \mathrm{ng} / \mathrm{ml}$ are likely to be associated with hypogonadism in adult studies (Haddad 2004). The occurrence of osteopenia or osteoporosis correlates with the presence and duration of hypogonadism rather than the degree of hyperprolactinaemia ( $O$ 'Keane 2005) (Greenspan 1989) (Misra 2004). Adolescence is an important period for the attainment of peak bone mass (Davies 2005) and disturbances in this process during puberty may influence the risk of osteoporosis later in life. The bone cortical thickness was reported to be significant reduced in 75 boys, aged 4 to 8 years, with autism or autism spectrum disorders, indicating that bone development should be monitored in these patients (Hediger 2008). Besides the dose and duration of antipsychotic medication, prolactin levels may be influenced by the genetic differences that influence prolactin metabolism and D2 receptor density. However, the genetic studies performed so far; by Anderson et al, (Anderson 2007) and Troost et al, (Troost 2007) included small number of patients, respectively 42 and 26 . In 2004 another review on prolactin and antipsychotic agents in children and adolescents was published (Pappagallo 2004) and in 2007 a review on prolactin elevation and antipsychotic treatment in adult patients with schizophrenia and bipolar disorders was published (Beyerly 2007). Pharmacovigilance studies indicate that, although very rarely, hyperprolactinaemia due to D2 blocking antipsychotics may be associated with increased risk for pituitary tumours (Koves 2004, Szarfman 2006). 


\section{Prolactin level and mediators}

Post pubertal status (Duval 2007), female gender, higher relative doses of antipsychotic medication and genetic differences are all known risk factors for prolactin elevation. Adolescent women of reproductive age have greater prolactin response to antipsychotics than prepubertal girls or males. Estrogen stimulates prolactin synthesis and enhances prolactin response to neuroleptic medication (Sallee 2000, Alfaro 2002, Saito 2004). Age related decrease in dopamine receptors (Seeman 1987) also gives a more pronounced effect in post pubertal adolescents and children compared to adults (Wudarsky 1999). Genetic differences may explain individual variation in whether hyperprolactinaemia leads to clinical consequences. The Taq1 A1 allele of the D2 dopamine receptor gene (DRD2) is associated with a significantly reduced density of $\mathrm{D} 2$ receptors. Also the metabolization rate of prolactin-inducing antipsychotics may influence prolactin

levels.

\section{Limitations}

The conclusions of this review are limited by the design and limitations of the original studies such as the use of concomitant prolactin-elevating medication, the short overall study duration of most studies, differences in the diagnosis, age and pubertal status and the lack of prolactin baseline values in 7 out of 29 studies (Stevens 2005) (Anderson 2007) (Hardan 1996) (Frazier 1999) (McConville 2000) (Fegert 2003), an overlap in populations or the missing of medication-free baseline values in 2 out of 29 studies(Sikich 2004) (Saito 2004) they were excluded from the analysis. Further, publication bias likely exists in that not all data on prolactin levels available in drug companies' files, have been published.

Furthermore, since prolactin-related side effects were mainly based on spontaneous self-report, the actual percentage of prolactin-related side effects may have been underestimated. In addition it may be impossible in some patients to distinguish between prolactin-related side effects and common physiological processes such as gynaecomastia in early pubertal boys and irregular menstrual cycles in females during the first few years after menarche (Bembo 2004) (Hanavadi 2006).

Higher age, post pubertal status (Duval 2007), female gender and higher relative doses of antipsychotic medication are all known risk factors for prolactin elevation. The mean age of the risperidone and respectively pimozide studies was 9.7 and 10.3 years, of which most patients were pre-pubertal, while the mean age in the olanzapine, quetiapine, haloperidol, pimozide, ziprasidone and clozapine studies was respectively $14.4,13.9,12.7,14.5$ and 14.5 years and the patients were mainly post-pubertal. The relative CPZ dose of the antipsychotic used was $80 \mathrm{mg}$ for risperidone versus $254 \mathrm{mg}, 123 \mathrm{mg}, 505 \mathrm{mg}, 208 \mathrm{mg}, 164 \mathrm{mg}$ and $360 \mathrm{mg}$ for olanzapine, pimozide, quetiapine, clozapine, ziprasidone and haloperidol respectively. The percentage male vs. female among the different studies was also roughly the 
same for quetiapine, olanzapine, clozapine and haloperidol, where as for risperidone, ziprasidone and pimozide the percentage of males was slightly higher. Lower overall age, low relative CPZ dose, higher percentage of males and pre-pubertal status may have masked an actual higher elevation of prolactin in the risperidone group.

The CPZ dose varied among the different studies. The overall quetiapine and haloperidol dose used were respectively five and four times higher than the risperidone dose used. The dose of olanzapine and clozapine were two fold higher and of pimozide one and a half times higher than the risperidone dose. This may have biased the comparison of these medications in terms of side-effects and elevation of prolactin.

Prolactin reference values differed between the studies and that influenced the percentage of hyperprolactinaemia. Most studies (17) used 0-18 ng/ml for boys and $0-30 \mathrm{ng} / \mathrm{ml}$ for girls, but 4 studies used $0-15 \mathrm{ng} / \mathrm{ml}$ for boys and girls (Stevens 2005) (Masi 2001, 2003) (Frazier1999) while 8 studies did not give a reference value (Aman 2002) (Sikich 2004) (Anderson 2007) (Suwa 1984) (Fegert 2003) (Shaw 2001) (Luby 2006). Furthermore, only 15 out of 29 studies reported the incidence of hyperprolactinaemia (table 1-4).

\section{Clinical Implications}

The clinical value is related to the consequences of long-term hyperprolactinaemia such as a decline in sexual function (Costa 2007) (Knegtering 2003, 2004, 2006) (Nakonezny 2007) and decreased bone mineral density (Abraham and Halbreich 2003) (Abraham and Paing 2003) (Meaney 2003, 2007) (O'Keane 2005) (Becker 2006). Children and adolescents may be more vulnerable to the adverse effects of hyperprolactinaemia.

Therefore, prolactin-related side effects should be systematically investigated e.g. with the help of a side effect checklist for children and adolescents (Saito 2004) and with a physical examination.

This review suggests that prolactin levels should be monitored in children or adolescents with sexual dysfunctions, gynaecomastia galactorrhea or hypogonadotrophic hypogonadism. The antipsychotic-induced hyperprolactinaemia can be treated by lowering the dose or by switching to a prolactin sparing antipsychotic. If both strategies fail a dopamine agonist may be added (amantadine, carbergoline) (Correll 2008).

\section{References}

Abraham G, Halbreich U, Friedman RH, Josiassen RC: Bone mineral density and prolactin associations in patients with chronic schizophrenia. Schizophr Res 59(1): 17-8, 2003. 
Abraham G, Paing WW, Kaminski J, Joseph A, Kohegyi E, Josiassen RC: Effects of elevated serum prolactin on bone mineral density and bone metabolism in female patients with schizophrenia: a prospective study. Am J Psychiatry 160(9): 1618-20m, 2003.

Aklillu E, Kalow W, Endrenyi L, Harper P, Miura J, Ozdemir V: CYP2D6 and DRD2 genes differentially impact pharmacodynamic sensitivity and time course of prolactin response to perphenazine. Pharmacogenet Genomics 17(11): 989-93, 2007.

Alfaro CL, Wudarsky M, Nicolson R, Gochman P, Sporn A, Lenane M: Correlation of antipsychotic and prolactin concentrations in children and adolescents acutely treated with haloperidol, clozapine, or olanzapine. J Child Adolesc Psychopharmacol 12(2): 83-91, 2002.

Aman MG, De Smedt G, Derivan A, Lyons B, Findling RL: Double-blind, placebo-controlled study of risperidone for the treatment of disruptive behaviors in children with subaverage intelligence. Am J Psychiatry 159(8): 1337-46, 2002.

Anderson GM, Scahill L, McCracken JT, McDougle CJ, Aman MG, Tierney E: Effects of short- and long-term risperidone treatment on prolactin levels in children with autism. Biol Psychiatry 61(4): 545-50, 2007.

Arango C, Parellada M, Moreno DM: Clinical effectiveness of new generation antipsychotics in adolescent patients. Eur Neuropsychopharmacol 14 Suppl 4: S471-9, 2004.

Becker AL, Epperson CN: Female puberty: clinical implications for the use of prolactin-modulating psychotropics. Child Adolesc Psychiatr Clin N Am 15(1): 207-20, 2006.

Bembo SA, Carlson HE: Gynecomastia: its features, and when and how to treat it. Cleve Clin J Med 71(6): 511-7, 2004.

Bevan JS: Interpreting prolactin levels: implications for the management of large pituitary lesions. $\mathrm{Br}$ J Neurosurg 5(1): 3-6, 1991.

Blaicher W, Imhof MH, Gruber DM, Schneeberger C, Sator MO, Huber JC: Endocrinological disorders. Focusing on melatonin's interactions. Gynecol Obstet Invest 48(3): 179-82, 1999.

Bobes J, Garc APMP, Rejas J, Hernandez G, Garcia-Garcia M, Rico-Villademoros F: Frequency of sexual dysfunction and other reproductive side-effects in patients with schizophrenia treated with risperidone, olanzapine, quetiapine, or haloperidol: the results of the EIRE study. J Sex Marital Ther 29(2): 125-47, 2003.

Buckley PF: Broad therapeutic uses of atypical antipsychotic medications. Biol Psychiatry 50(11): 91224, 2001.

Byerly M, Suppes T, Tran QV, Baker RA: Clinical implications of antipsychotic-induced hyperprolactinaemia in patients with schizophrenia spectrum or bipolar spectrum disorders: recent developments and current perspectives. J Clin Psychopharmacol 27 (6): 639-61, 2007

Carter DA, McGarrick GM, Norton KR, Paykel ES, Prysor-Jones RA, Whitehead SA: The effect of chronic neuroleptic treatment on gonadotrophin release. Psychoneuroendocrinology 7(2-3): 201-7, 1982.

Colao A, Di Somma C, Loche S, Di Sarno A, Klain M, Pivonello R: Prolactinomas in adolescents: persistent bone loss after 2 years of prolactin normalization. Clin Endocrinol (Oxf) 52(3): 319-27, 2000.

Cooper WO, Hickson GB, Fuchs C, Arbogast PG, Ray WA: New users of antipsychotic medications among children enrolled in TennCare Arch Pediatr Adolesc Med 158(8): 753-9, 2004.

Correll CU: Antipsychotic use in children and adolescents: minimizing adverse effects to maximize outcomes. J Am Acad Child Adolesc Psychiatry 47(1): 9-20, 2008.

Correll CU: Monitoring and management of antipsychotic-related metabolic and endocrine adverse events in pediatric patients. International Review of Psychiatry, 20(2): 195-201, 2008.

Correll CU, Leucht S, Kane JM: Lower risk for tardive dyskinesia associated with second-generation antipsychotics: a systematic review of 1-year studies. Am J Psychiatry 161(3): 414-25, 2004.

Costa AM, de Lima MS, Faria M, Filho SR, de Oliveira IR, de Jesus Mari J : A naturalistic, 9-month followup, comparing olanzapine and conventional antipsychotics on sexual function and hormonal profile for males with schizophrenia. J Psychopharmacol 21(2): 165-70, 2007.

Croonenberghs J, Fegert JM, Findling RL, De Smedt G, Van Dongen S: Risperidone in children with disruptive behavior disorders and subaverage intelligence: a 1-year, open-label study of 504 patients. J Am Acad Child Adolesc Psychiatry 44(1): 64-72, 2005. 
Davies JH, Evans BA, Gregory JW: Bone mass acquisition in healthy children. Arch Dis Child 90(4): 373-8, 2005.

Dittmann RW, Meyer E, Freisleder FJ, Remschmidt H, Mehler-Wex C, Junghanss J: Effectiveness and tolerability of olanzapine in the treatment of adolescents with schizophrenia and related psychotic disorders: results from a large, prospective, open-label study. J Child Adolesc Psychopharmacol 18(1): 54-69, 2008.

Dolder CR, Lacro JP, Dunn LB, Jeste DV: Antipsychotic medication adherence: is there a difference between typical and atypical agents? Am J Psychiatry 159(1): 103-8, 2002.

Duval F, Guillon MS, Mokrani MC, Crocq MA, Garcia Duarte, F: Relationship between prolactin secretion, and plasma risperidone and 9-hydroxyrisperidone concentrations in adolescents with schizophreniform disorder. Psychoneuroendocrinology, Nov 27, 2007.

Fegert JM, Findling RL, deSmedt G: Risperidon zur Behandlung aggressiv-impulsiven Verhaltens bei Kindern und Jugendlichen mit Intelligenz im unteren Durchschnittsbereich, Lernbehinderung und leichter geistiger Behinderung. Nervenheilkunde 22(2): 93-97, 2003.

Findling RL, McNamara NK: Atypical antipsychotics in the treatment of children and adolescents: clinical applications. J Clin Psychiatry 65 Suppl 6: 30-44, 2004.

Findling R. L, McNamara, NK, Gracious BL: Paediatric uses of atypical antipsychotics. Expert Opin Pharmacother 1(5): 935-45, 2000.

Frazier JA, Meyer MC, Biederman J, Wozniak J, Wilens TE, Spencer TJ: Risperidone treatment for juvenile bipolar disorder: a retrospective chart review. J Am Acad Child Adolesc Psychiatry 38(8): 960-5, 1999.

Gässler N, Peuschel T, Pankau R: Pediatric reference values of estradiol, testosterone, lutropin, follitropin and prolactin.Clin Lab 46:553-560, 2000.

Greenspan SL, Neer RM, Ridgway EC, Klibanski A: Osteoporosis in men with hyperprolactinemic hypogonadism. Ann Intern Med 104(6): 777-82,1986.

Greenspan SL, Oppenheim DS, Klibanski A: Importance of gonadal steroids to bone mass in men with hyperprolactinemic hypogonadism. Ann Intern Med 110(7): 526-31, 1989.

Haddad PM, Wieck A: Antipsychotic-induced hyperprolactinaemia: mechanisms, clinical features and management." Drugs 64(20): 2291-314, 2004.

Halbreich U, Kinon BJ, Gilmore JA, Kahn LS: Elevated prolactin levels in patients with schizophrenia: mechanisms and related adverse effects. Psychoneuroendocrinology 28 Suppl 1: 53-67, 2003.

Hanavadi S, Banerjee D, Monypenny IJ, Mansel RE: The role of tamoxifen in the management of gynaecomastia. Breast 15(2): 276-80, 2006.

Hardan A, Johnson K, Johnson C, Hrecznyj B: Case study: risperidone treatment of children and adolescents with developmental disorders. J Am Acad Child Adolesc Psychiatry 35(11): 1551-6, 1996.

Hediger ML, England LJ, Molloy CA, Yu KF, Manning-Courtney P, Mills JL: Reduced bone cortical thickness in boys with autism or autism spectrum disorders. J Autism Dev Disord 38: 848-856, 2008.

Hellings JA, Zarcone JR, Valdovinos MG, Reese RM, Gaughan E, Schroeder SR: Risperidone-induced prolactin elevation in a prospective study of children, adolescents, and adults with mental retardation and pervasive developmental disorders. J Child Adolesc Psychopharmacol 15(6): 885-92, 2005.

Howard L, Kirkwood G, Leese M: Risk of hip fracture in patients with a history of schizophrenia. Br J Psychiatry 190: 129-34, 2007.

Howlett TA, Wass JA, Grossman A, Plowman PN, Charlesworth M, Touzel R: Prolactinomas presenting as primary amenorrhoea and delayed or arrested puberty: response to medical therapy. Clin Endocrinol (Oxf) 30(2): 131-40, 1989.

Hugenholtz GWK: Antipsychotic in daily clinical practice : patterns, choices and consequences. Universiteit Utrecht. Utrecht, Utrecht. Doctor: 172, 2005.

Kawano Y, Kamihigashi S, Nakamura S, Miyakawa I: Delayed puberty associated with hyperprolactinemia caused by pituitary microadenoma. Arch Gynecol Obstet 264(2): 90-2, 2000.

Knegtering H: Antipsychotic treatment and sexual functioning : role of prolactin. Rijksuniversiteit Groningen. Groningen, Rijksuniversiteit Groningen. Dr.: 169, 2003. 
Knegtering H, van der Moolen AE, Castelein S, Kluiter H, van den Bosch RJ: What are the effects of antipsychotics on sexual dysfunctions and endocrine functioning? Psychoneuroendocrinology 28 Suppl 2: 109-23, 2003.

Knegtering R, Castelein S, Bous H, Van Der Linde J, Bruggeman R, Kluiter H: A randomized open-label study of the impact of quetiapine versus risperidone on sexual functioning. J Clin Psychopharmacol 24(1): 56-61, 2004.

Knegtering R, Baselmans P, Castelein S, Bosker F, Bruggeman R, van den Bosch RJ: Predominant role of the 9-hydroxy metabolite of risperidone in elevating blood prolactin levels. Am J Psychiatry 162(5): 1010-2, 2005.

Knegtering H, Boks M, Blijd C, Castelein S, van den Bosch RJ, Wiersma D: A randomized open-label comparison of the impact of olanzapine versus risperidone on sexual functioning. J Sex Marital Ther 32(4): 315-26, 2006.

Langer G, Sachar EJ, Halpern FS, Gruen PH, Solomon M: The prolactin response to neuroleptic drugs. A test of dopaminergic blockade: neuroendocrine studies in normal men. J Clin Endocrinol Metab 45(5): 996-1002, 1977.

Lenton EA, Brook LM, Sobowale 0, Cooke ID: Prolactin concentrations in normal menstrual cycles and conception cycles. Clin Endocrinol (Oxf) 10(4): 383-91, 1979.

Luby J, Mrakotsky C, Stalets MM, Belden A, Heffelfinger A, Williams M: Risperidone in preschool children with autistic spectrum disorders: an investigation of safety and efficacy. J Child Adolesc Psychopharmacol 16(5): 575-87, 2006.

Malone RP, Maislin G, Choudhury MS, Gifford C, Delaney MA: Risperidone treatment in children and adolescents with autism: short- and long-term safety and effectiveness. J Am Acad Child Adolesc Psychiatry 41(2): 140-7, 2002.

Malone RP, Delany MA, Hyman SB, Cater JR: Ziprasidone in adolescents with autism: an open-label pilot study. J Child Adolesc Psychopharmacol 17(6): 779-90, 2007.

Marken PA, Haykal RF, Fisher JN: Management of psychotropic-induced hyperprolactinemia." Clin Pharm 11(10): 851-6, 1992.

Masi G, Cosenza A, Mucci M: Prolactin levels in young children with pervasive developmental disorders during risperidone treatment. J Child Adolesc Psychopharmacol 11(4): 389-94, 2001.

Masi G, Cosenza A, Mucci M, Brovedani P: A 3-year naturalistic study of 53 preschool children with pervasive developmental disorders treated with risperidone. J Clin Psychiatry 64(9): 1039-47, 2003.

McConville BJ, Arvanitis LA, Thyrum PT, Yeh C, Wilkinson LA, Chaney RO: Pharmacokinetics, tolerability, and clinical effectiveness of quetiapine fumarate: an open-label trial in adolescents with psychotic disorders. J Clin Psychiatry 61(4): 252-60, 2000.

McCracken JT, McGough J, Shah B, Cronin P, Hong D, Aman MG: Risperidone in children with autism and serious behavioral problems. N Engl J Med 347(5): 314-21, 2002.

Meaney AM, O'Keane V: Reduced bone mineral density in patients with schizophrenia receiving prolactin raising anti-psychotic medication. J Psychopharmacol 17(4): 455-8, 2003.

Meaney AM, Smith S, Howes OD, O'Brien M, Murray RM, O'Keane V: Effects of long-term prolactin-raising antipsychotic medication on bone mineral density in patients with schizophrenia." Br J Psychiatry 184: 503-8, 2004.

Meaney AM, O'Keane V: Bone mineral density changes over a year in young females with schizophrenia: relationship to medication and endocrine variables. Schizophr Res 93(1-3): 136-43, 2007.

Menzin J, Boulanger L, Friedman M, Mackell J, Lloyd JR: Treatment adherence associated with conventional and atypical antipsychotics in a large state Medicaid program. Psychiatr Serv 54(5): 719-23, 2003.

Mihara K, Suzuki A, Kondo T, Yasui-Furukori N, Ono S, Otani K: Relationship between Taq1 A dopamine D2 receptor (DRD2) polymorphism and prolactin response to bromperidol. Am J Med Genet 105(3): 271-4, 2001.

Misra M, Papakostas G I, Klibanski A: Effects of psychiatric disorders and psychotropic medications on prolactin and bone metabolism. J Clin Psychiatry 65(12): 1607-18; quiz 1590, 1760-1, 2004.

Moleman P: Praktische psychofarmacologie. Bohn Stafleu van Loghum, Houten 2005.

Molitch ME: Medication-induced hyperprolactinemia. Mayo Clin Proc 80(8): 1050-7, 2005. 
Nakonezny PA, Byerly MJ, Rush AJ: The relationship between serum prolactin level and sexual functioning among male outpatients with schizophrenia or schizoaffective disorder: a randomized doubleblind trial of risperidone vs. quetiapine. J Sex Marital Ther 33(3): 203-16, 2007

O'Keane V, Meaney AM: Antipsychotic drugs: a new risk factor for osteoporosis in young women with schizophrenia? J Clin Psychopharmacol 25(1): 26-31, 2005.

Pappagallo M, Silva R: The effects of atypical antipsychotic agents on prolactin levels in children and adolescents. J Child Adolesc Psychopharmacol 14 (3): 359-71, 2004.

Papparigopoulos T, Liappas J, Tzavellas E, Mourikis I, Soldatos C: Amisulpiride-induced hyperprolactinaemia is reversible following discontinuation. Prog Neuropsychopharmacol Biol Psychiatry 31(1): 92-6, 2007.

Patton ML, Woolf PD: Hyperprolactinemia and delayed puberty: a report of three cases and their response to therapy. Pediatrics 71(4): 572-5, 1983.

Reyes M, Croonenberghs J, Augustyns I, Eerdekens M: Long-term use of risperidone in children with disruptive behavior disorders and subaverage intelligence: efficacy, safety, and tolerability. J Child Adolesc Psychopharmacol 16(3): 260-72, 2006.

Sack J, Friedman E, Tadmor R, Sahar A, Katznelson D: Growth and puberty arrest due to prolactinoma. Acta Paediatr Scand 73(6): 863-7, 1984.

Saito E, Correll CU, Gallelli K, McMeniman M, Parikh UH, Malhotra AK: A prospective study of hyperprolactinemia in children and adolescents treated with atypical antipsychotic agents. J Child Adolesc Psychopharmacol 14(3): 350-8, 2004.

Sallee FR, Dougherty D, Sethuraman G, Vrindavanam N: Prolactin monitoring of haloperidol and pimozide treatment in children with Tourette's syndrome. Biol Psychiatry 40(10): 1044-50, 1996.

Schirm E, Tobi H, Zito JM, de Jong-van den Berg LT: Psychotropic medication in children: a study from the Netherlands. Pediatrics 108(2): E25, 2001.

Seeman P, Bzowej NH, Guan HC, Bergeron C, Becker LE, Reynolds GP: Human brain dopamine receptors in children and aging adults. Synapse 1(5): 399-404, 1987.

Shaw JA, Lewis JE, Pascal S, Sharma RK, Rodriguez RA, Guillen R: A study of quetiapine: efficacy and tolerability in psychotic adolescents. J Child Adolesc Psychopharmacol 11(4): 415-24, 2001.

Sikich L, Hamer RM, Bashford RA, Sheitman BB, Lieberman JA: A pilot study of risperidone, olanzapine, and haloperidol in psychotic youth: a double-blind, randomized, 8-week trial. Neuropsychopharmacology 29(1): 133-45, 2004.

Simeon J, Lawrence S, Simeon S: Effects of pimozide on prolactin in children [proceedings]. Psychopharmacol Bull 15(2): 40-2, 1979.

Siris SG, Siris ES, van Kammen DP, Docherty JP, Alexander PE, Bunney WE: Effects of dopamine blockade on gonadotropins and testosterone in men. Am J Psychiatry 137(2): 211-4, 1980.

Snyder R, Turgay A, Aman M, Binder C, Fisman S, Carroll A: Effects of risperidone on conduct and disruptive behavior disorders in children with subaverage IQs. J Am Acad Child Adolesc Psychiatry 41(9): 1026-36, 2002.

Staller J: The effect of long-term antipsychotic treatment on prolactin. J Child Adolesc Psychopharmacol 16(3): 317-26, 2006.

Stevens JR, Kymissis PI, Baker AJ: Elevated prolactin levels in male youths treated with risperidone and quetiapine. J Child Adolesc Psychopharmacol 15(6): 893-900, 2005.

Suwa S, Naruse H, Ohura T, Tsuruhara T, Takesada M, Yamazaki K: Influence of pimozide on hypothalamo-pituitary function in children with behavioral disorders. Psychoneuroendocrinology 9(1): 3744, 1984.

Tamminga WJ, Wemer J, Oosterhuis B, Weiling J, Wilffert B, de Leij LF: CYP2D6 and CYP2C19 activity in a large population of Dutch healthy volunteers: indications for oral contraceptive-related gender differences. Eur J Clin Pharmacol 55(3): 177-84, 1999.

Troost PW, Lahuis BE, Hermans MH, Buitelaar JK, van Engeland H, Scahill L: Prolactin release in children treated with risperidone: impact and role of CYP2D6 metabolism. J Clin Psychopharmacol 27(1): 527, 2007. 
Troost PW, Lahuis BE, Steenhuis MP, Ketelaars CE, Buitelaar JK, van Engeland H, Scahill L, Minderaa RB, Hoekstra PJ: Long-term effects of risperidone in children with autism spectrum disorders: a placebo discontinuation study. J Am Acad Child Adolesc Psychiatry 44: 1137-1144, 2005.

Turgay A, Binder C, Snyder R, Fisman S: Long-term safety and efficacy of risperidone for the treatment of disruptive behavior disorders in children with subaverage IQs. Pediatrics 110(3): e34, 2002.

Woods SW: Chlorpromazine equivalent doses for the newer atypical antipsychotics. J Clin Psychiatry 64(6): 663-7, 2003.

Wudarsky M, Nicolson R, Hamburger SD, Spechler L, Gochman P, Bedwell J: Elevated prolactin in pediatric patients on typical and atypical antipsychotics. J Child Adolesc Psychopharmacol 9(4): 239-45, 1999.

Young RM, Lawford BR, Barnes M, Burton SC, Ritchie T, Ward WK: Prolactin levels in antipsychotic treatment of patients with schizophrenia carrying the DRD2*A1 allele. Br J Psychiatry 185: 147-51, 2004.

Zito JM, Safer DJ, DosReis S, Gardner JF, Magder L, Soeken K: Psychotropic practice patterns for youth: a 10-year perspective. Arch Pediatr Adolesc Med 157(1): 17-25, 2003. 

Antipsychotic-induced hyperprolactinemia in children and adolescents

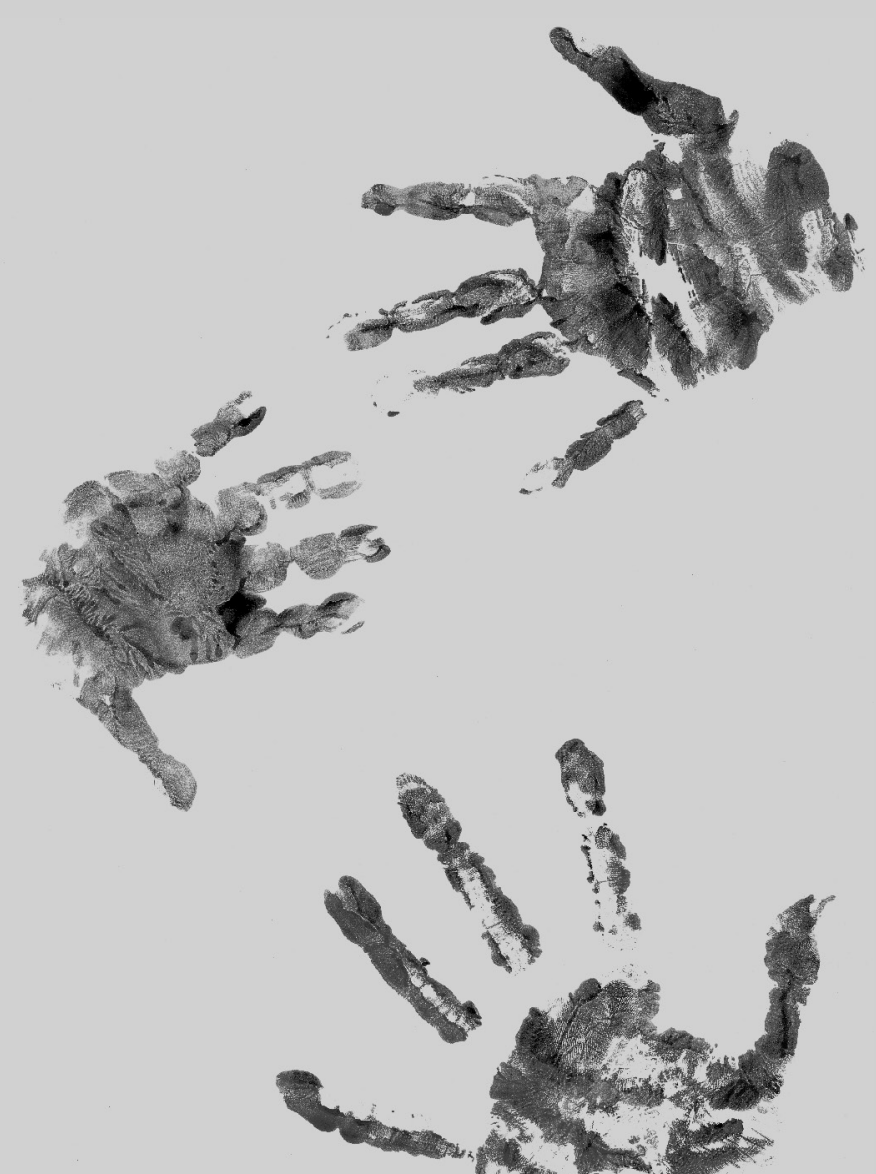





\section{Chapter 3}

\section{Risk of hyperprolactinemia and sexual side effects in boys aged 10-20 years old with autism spectrum disorders or disruptive behavior disorder treated with risperidone.}

Yvette Roke, M.D., Jan K. Buitelaar, M.D., Ph.D., Annemieke M. Boot, M.D., Ph.D., Diederik Tenback, M.D., Ph.D., Peter N. van Harten, M.D., Ph.D.

J Child Adolesc Psychopharmacol. 2012 Dec;22(6):432-9.

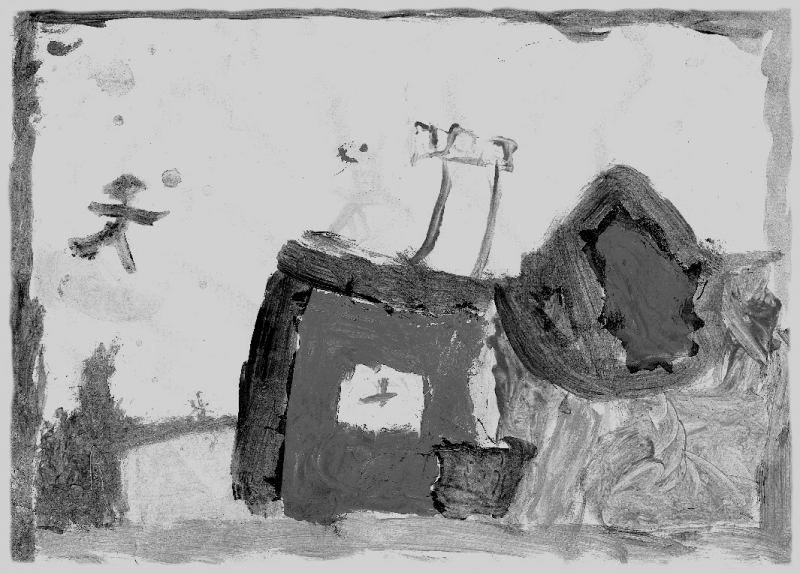




\section{Abstract}

Objective: The aim of this study was to investigate the long-term treatment effects of risperidone on prolactin levels and prolactin-related side effects in pubertal boys with autism spectrum disorders (ASD) and disruptive behavior disorders (DBD).

Method: Physical healthy 10- to 20-year-old boys with ASD $(\mathrm{N}=89)$ and/ or DBD ( $\mathrm{N}=10)$ chronically treated (mean 52 months, range 16-126 months) with risperidone (group 1, N=51) or not treated with any antipsychotic (group 2, $\mathrm{N}=47$ ) were recruited to this observational study from the child psychiatry outpatient clinic. Morning non-fasting serum prolactin levels were measured and prolactinrelated side effects were assessed by means of questionnaires and physical examination. Group differences were tested with Student's t-, Chi-square-, Fisher exact tests, Mann-Whitney tests, and logistic regression anal ysis, according to the type and distribution of data.

Results: Hyperprolactinemia was present in $47 \%$ of boys in group 1 but only in $2 \%$ of boys in group 2 (odds ratio $71.9,95 \% \mathrm{CI}, 7.7 ; 676.3$ ). $46 \%$ of boys in group 1 had asymptomatic hyperprolactinemia.

Current risperidone dose and 9-OH risperidone plasma level were significant predictors of hyperprolactinemia $(\mathrm{p}=0.035$ and $\mathrm{p}=0.03)$. Gynecomastia and sexual dysfunction were present in $43 \%$ and $14 \%$ of the boys in group1, respectively, compared with $21 \%$ and $0 \%$ of boys in group 2 ( $p=0.05$ and $p=0.01)$. Gynecomastia was not significantly associated with hyperprolactinemia.

Conclusion: Hyperprolactinemia is a common side effect in boys treated long term with risperidone. Boys treated with risperidone are more likely to report diminished sexual functioning than are boys not treated with antipsychotics.

Key words: Prolactin, Hyperprolactinemia, Adolescents, Risperidone, Sexual dysfunction 


\section{Introduction}

Second-generation antipsychotics (AP) are increasingly prescribed to children and adolescents with psychiatric disorders and have been used successfully to reduce maladaptive behaviours, such as irritability, self-injury, stereotypies and hyperactivity in children and adolescents with autism spectrum disorders (ASD) and irritability and aggressive behaviour in children and adolescents with disruptive behavior disorder (Aman 2009).

While risperidone and aripiprazole have been approved by the United States Food and Drug Administration (FDA) for the treatment of children and adolescents with irritability associated with ASD (RUPP 2002, Stigler 2006, Wink 2010), these drugs have not yet been approved for this indication in Europe. Antipsychotics are also frequently used, off-label, to treat severe aggression in children and adolescents with disruptive behavior disorder. Despite their efficacy (Wink 2010), there are concerns about the widespread use of these drugs given their side effect profile, such as, weight gain, metabolic adverse effects (dyslipidemia, hyperglycemia and diabetes), cardiac side effects (QTc prolongation), extrapyramidal side effects and increased prolactin levels (Molitch 2005, Correll 2008, Vitiello 2009). The side effects of antipsychotics are well described in adults but less well studied in children and adolescents. There are indications that children are more sensitive than adults to the metabolic adverse effects of antipsychotics (Correll 2006) and tend to gain proportionately more weight and do so more rapidly during treatment than do adults (Correll 2006).

This study investigated the prevalence of hyperprolactinemia and prolactinrelated side effects in children and adolescents on long-term risperidone treatment. Hyperprolactinemia is caused by dopamine 2 blockade in the tuberoinfundibular pathway and may decrease gonadotropin levels and thereby estrogen and testosterone concentrations (Halbreich 2003, Haddad 2004). Estrogen and testosterone have important roles in sexual functioning, bone mineralization and puberty (Saranac 2010), such that decreased levels may result in disorders of sexual functioning disorders (Cutler 2003, Knegtering 2003), and may delay puberty. One study reported antipsychotic-induced hyperprolactinemia not to affect puberty, in prepubertal children (Reyes 2006), whereas another reported diminished bone mineral density in boys on long-term prolactin-elevating antipsychotics (Calarge 2010). It is not known what the threshold prolactin level is for adverse effects on sexual functioning, puberty, and bone mineralization.

In fact, little is known about the consequences of persistently elevated prolactin levels in children and adolescents, and in particular about the effects of elevated but still subclinical levels of prolactin. A systematic review showed that maintenance treatment of children and adolescents with risperidone results in persistently elevated prolactin levels for up to 2 years (Roke 2009).

When investigating the effects of antipsychotic-induced hyperprolactinemia, it is important to be able to distinguish between the effect of the mental condition for 
which the antipsychotic is used and the effects of hyperprolactinemia on sexual functioning, puberty, and bone mineralization. For this reason, it is important to recruit a psychiatric control group that is not treated with antipsychotics to monitor side effects before and during treatment, to use validated instruments, to physically examine participants, and to use appropriate age and gender-based reference data for endocrine variables. Self-report data are less appropriate because children and adolescents may feel embarrassed or are not able to express problems of sexual functioning, and they might not notice physical changes, such as gynecomastia or galactorrhea.

In this study, we investigated the consequences of long-term treatment with risperidone on prolactin levels and sexual functioning in boys with ASD and DBD. We add to the current literature by recruiting a sample of patients using risperidone for longer than 16 months, using a validated questionnaire for assessing sexual dysfunction, using appropriate age and gender-based endocrine reference values, and using a physical examination to assess gynaecomastia. We compared boys with ASD and DBD treated with risperidone (group 1) with boys with ASD and DBD not treated with antipsychotics (group 2).

\subsection{Methods}

All participants were recruited from the total patient population of the outpatient adolescent clinic of the GGz Central Psychiatric Centre, The Netherlands, from October 2006 to November 2009. The GGz Central Psychiatric Centre hardly ever sees children and adolescents with psychotic or bipolar disorders, because these individuals tend to be referred to the nearby university hospital.

Inclusion criteria for the medication group (group 1) were: (i) an age between 10 and 20 years, (ii) diagnoses of any psychiatric disorder, (iii) an IQ above 85, and (iv) treatment with any antipsychotic medication continuously for more than 16 months. Inclusion criteria for the comparison group (group 2) were the same except for the use of antipsychotic medication, this group had to be AP naïve. Participants were excluded if they had a history of thyroid disorders, syndromes or other chronic diseases affecting puberty, endocrine disorders, if they used oral corticosteroids or anticonvulsants, or if they had a known cause of hyperprolactinemia (Verhelst 2003, Melmed 2011).

The first author contacted all children and adolescents that met the inclusion criteria by telephone and letter.

$80 \%$ of the contacted group 1 patients ( 56 boys, 6 girls) participated in the study compared to $50 \%$ of the group 2 patients ( 47 boys, 10 girls). All participants had a diagnosis of ASD or disruptive behaviour disorder (DBD). The main reason for not participating was fear of venipuncture.

Data of female participants (16 in a total study sample of 119), two boys in the AP group using concomitant SSRI medication and three boys treated with pimozide 
instead of risperidone were not analyzed. Thus the risperidone group (group 1) consisted of 51 boys with ASD or DBD treated long-term with risperidone and the comparison group (group 2) consisted of 47 boys with ASD or DBD but never been treated with an AP.

Use of other concomitant medication, such as, psychostimulants, melatonin, and atomoxetine was permitted (Table 1). The Local Medical Ethics Committee approved this study and written informed consent was obtained from the patient and the subject's parents/ legal guardians after a clear explanation of the study procedures.

\subsection{Procedures}

The clinical diagnosis was obtained from the patients' chart.

Pubertal stage was established by showing the boys different Tanner stage photographs of genitals ( $\mathrm{G}$ stage) and pubic hair (P stage) and then asking them to select the photographs that most accurately reflected their appearance (Duke 1980). One of the parents/ legal guardians was present during the self-assessment and confirmed the stages pointed out. Sexual functioning was investigated using the items (change in sex interest, change in orgasm ability, change in erection ability, and change in the amount of ejaculate) of the Antipsychotics and Sexual Functioning Questionnaire (ASFQ) (Wolters 2003). This instrument has been developed and validated to study antipsychotic -related sexual side effects. The first author explained what change in orgasm, change in erection, change in sex interest, and change in amount of ejaculate meant. If the boys did not remember or did not know if there was a difference, then relevant items were scored as unknown.

The first author, who was not aware of the prolactin data, systematically investigated prolactin-related side effects with the help of a checklist for children and adolescents (Saito 2004) and with a physical examination (breast palpitation); after first being trained by a pediatric-endocrinologist to detect the presence of gynecomastia and galactorrhea. The first author also measured the participants' height (without shoes to the nearest $0.1 \mathrm{~cm}$ using a stadiometer, Seca 206, the Netherlands) and weight (participant wearing underwear, to the nearest $0.1 \mathrm{~kg}$ using an analogue scale, Seca 761, the Netherlands). Age- and gender-specific height, weight and body mass index (BMI) Z-scores were calculated using normative data for Dutch children (Fredriks 20001, Fredriks 20002).

A non-fasting morning blood sample was obtained around 9.30 a.m. after a light breakfast was eaten at around 7.30. Serum prolactin was measured with an automated chemiluminescence assay system (Immulite 2000, Siemens Healthcare Diagnostics) calibrated on the 3rd IS 84/500. As macroprolactin, a complex of prolactin and IgG without biological activity, accounts for $10 \%$ of cases of hyperprolactinemia (McKenna 2009), seven samples with prolactin concentrations higher than 37 $\mathrm{ng} / \mathrm{mL}$ were assessed for the presence of macroprolactin. Polyethylene glycol 6000, $200 \mu \mathrm{L},(25 \% \mathrm{w} / \mathrm{w})$ was added to $200 \mu \mathrm{L}$ of serum and, after thorough vortex mix- 
ing, the mixture was centrifuged at $2200 \mathrm{~g}$ for $30 \mathrm{~min}$ at $4{ }^{\circ} \mathrm{C}$. Subsequently, prolactin was measured in the supernatant and the untreated serum. The recovery of prolactin after precipitation with polyethylene glycol 6000 was $101.4 \pm 9.6$ (mean \pm SD), which excluded the presence of macroprolactin. TSH was measured to exclude boys with hyperprolactinemia due to thyroid disorders. Plasma levels of risperidone and 9-hydroxyrisperidone were measured to evaluate compliance.

\subsection{Data-analysis}

To test for differences between groups 1 and 2, Student's t-test, Chi-square, MannWhitney tests, Fisher Exact tests, and logistic regression were used according to the type and distribution of data. Hyperprolactinemia was defined as a prolactin level above the 97.5th percentile based on normative data for age and gender (Emlinger 2002) (see Table 3).

Logistic regression analysis was used to investigate whether risperidone was associated with hyperprolactinemia. The following covariates were examined based on previous literature: age, BMI Z-score and Tanner stage. A subsequent logistic regression analysis was performed to evaluate the influence of type of medication, duration of antipsychotic use, use of dosage, risperidone levels, and 9$\mathrm{OH}$ risperidone levels on hyperprolactinemia in the patients using risperidone, corrected for age and BMI Z-score.

Sexual dysfunction was measured with four items of the ASFQ, scored 0-5 as follows: unknown (0), strongly diminished (1), diminished (2), unchanged (3), increased (4) and strongly increased (5), The ASFQ item scores were grouped, to increase power, as follows: unknown or not applicable, diminished, unchanged and increased.

Sexual dysfunction was present if a patient scored diminished on one or more of the four ASFQ items.

\section{Results}

Ninety-eight boys with ASD or DBD took part in the study. There was no difference in mean height Z-score, BMI Z-score, pubertal stage, ethnicity, and use of concomitant medication between the boys in groups 1 and 2: however, there were more boys with DBD in group 2 than in group 1 (4\% versus $15 \%, \mathrm{p}=0.05$ ). Forty-seven boys were not using an antipsychotic, but 51 boys were using risperidone (mean \pm SD daily dose, $1.5 \pm 0.9 \mathrm{mg}$, range $0.25-4 \mathrm{mg}$ ) long term (mean \pm SD duration, $53 \pm$ 27.8 months, range $16-126$ months), and 36 boys had used risperidone continuously for 3 or more years. 
At the time of measurement $14(27 \%)$ of all boys in group 1 had undetectable levels of risperidone $(0 \mu \mathrm{g} / \mathrm{L})$ and $4(8 \%)$ of these boys had also undetectable $9-\mathrm{OH}$ risperidone levels (Table 1 ).

Table 2 presents data on prolactin levels and the prevalence of hyperprolactinemia, asymptomatic hyperprolactinemia, and prolactin-related side effects in the two groups, as well as the number of boys in each Tanner stage. Hyperprolactinemia was significantly more common among the boys treated with risperidone than among the boys not treated with antipsychotic (24 versus 1 boy, $47 \%$ versus $2 \%$, $\mathrm{p}<0.0001$ ). In none of the boys was hyperprolactinemia due to macroprolactin or thyroid disorders.

The prolactin levels of the boys with hyperprolactinemia were in 18 out of 24 patients (75\%) between the 97.5 percentile level and $30 \mathrm{ng} / \mathrm{ml}$, in 2 out of $24(8 \%)$ between 30-50 ng/mL and in 4 out of 24 (17\%) higher than $50 \mathrm{ng} / \mathrm{mL}$.

Among the boys treated with risperidone, hyperprolactinemia was present in 5 of 7 boys in Tanner stage II (71\%), in 6 of 15 boys in Tanner stage III (40\%), in 8 of 21 boys in Tanner stage IV (38\%), and in 5 of 8 boys in Tanner stage V (63\%).

Hyperprolactinemia was asymptomatic in 11 boys (46\%). The odds ratio of having hyperprolactinemia with risperidone treatment was 71.9 (95\% CI, 7.7; 676.3). Adjustment for age and BMI Z-score did not influence the results. Gynecomastia was detected in 24 (47\%, measured by questionnaire) and 22 (43\%, measured by physical examination) boys in group 1 and in 10 boys (21\%) in group 2 $(\mathrm{p}=0.05)$ : this difference remained after adjustment for age and BMI Z-score $(\mathrm{p}=0.02)$. Of the boys with hyperprolactinemia, 8 (36\%) $(\mathrm{N}=8)$ had gynecomastia on physical examination (OR=2.86, 95\% CI 1.16, 7.06, $\mathrm{p}=0.26)$.

Sexual functioning was diminished in 7 of the boys in group1 (14\%), with 2 (4\%), $4(8 \%), 5(10 \%)$, and 1 (2\%) of the boys reporting diminished sexual interest, diminished ability to have an orgasm, diminished ejaculation and, lower ability to have an erection, respectively, compared to none of the boys in group $2(p=0.01)$. Five of the 7 boys scored their sexual functioning as strongly diminished, and 4 of these boys were, Tanner stage IV. Fifteen boys in group 1 (29\%) reported their change in sexual functioning as unknown and 10 (20\%) as unchanged compared with 19 (40\%) unknown and 5 (10\%) unchanged in group 2.

Sexual dysfunction tended to occur more often in boys with hyperprolactinemia $(\mathrm{N}=27)(21 \%$ vs. $8 \%, \mathrm{p}=0.07)$. Five of the seven boys with sexual dysfunction had hyperprolactinemia.

Table 4 shows predictors of hyperprolactinemia in boys treated with risperidone. The current dose of risperidone and the 9-OH risperidone plasma level both predicted hyperprolactinemia $(\mathrm{OR}=2.495 \%$, CI 1.1, 5.5, $\mathrm{p}=0.035$ and $\mathrm{OR}=1.15$, CI $1.02,1.09, \mathrm{p}=0.03$, respectively), whereas the mean dose of risperidone over the period, the risperidone plasma level and the duration of treatment did not (Table 4). 
Table 1. Characteristics of male children and adolescents with autism spectrum disorders or disruptive behaviour disorders with long-term risperidone treatment $(\mathrm{N}=51)$ and without antipsychotic treatment $(\mathrm{N}=47)$.

\begin{tabular}{|c|c|c|c|c|c|}
\hline & \multicolumn{2}{|l|}{$\begin{array}{l}\text { Cases } \\
(\mathrm{N}=51)\end{array}$} & \multicolumn{2}{|c|}{$\begin{array}{l}\text { Comparison subjects } \\
(\mathrm{N}=47)\end{array}$} & \multirow[t]{2}{*}{$P$ value } \\
\hline & $\mathrm{N}(\%)$ & Mean (SD; range) & N (\%) & Mean (SD; range) & \\
\hline Age, years & & $14.7(2.1 ; 10,19)$ & & $15.1(1.6 ; 11,18)$ & $0.27^{c}$ \\
\hline Height z-score & & $0.40(1.1 ;-2.4,2.1)$ & & $0.35(0.9 ;-1.5,2.9)$ & $0.79^{c}$ \\
\hline Weight z-score & & $0.49(1.1 ;-2.5,3.2)$ & & $0.34(1.2 ;-2,3.9)$ & $0.52^{\mathrm{c}}$ \\
\hline BMI & & $20.3(3.3 ; 14.6,29.5)$ & & $20.4(4 ; 15,32)$ & $0.94^{\mathrm{c}}$ \\
\hline Underweight & $3(6)$ & & $6(13)$ & & \\
\hline Normal & $41(80)$ & & $32(68)$ & & \\
\hline Overweight & $7(14)$ & & $8(17)$ & & \\
\hline Obese & 0 & & $2(4)$ & & \\
\hline BMI z & & $0.21(0.87 ;-1.8,1.8)$ & & $-0.0 .9(1.2 ;-3.3,2.3)$ & $0.16^{c}$ \\
\hline \multicolumn{6}{|l|}{ Tanner stages } \\
\hline I & 0 & & 0 & & \\
\hline II & $7(14)$ & & $9(19)$ & & \\
\hline III & $15(29)$ & & $13(28)$ & & \\
\hline IIII & $21(41)$ & & $20(43)$ & & \\
\hline V & $8(16)$ & & $6(13)$ & & \\
\hline \multicolumn{6}{|l|}{ Primary diagnosis } \\
\hline ASD* $^{*}$ & $49(96)$ & & $40(85)$ & & $0.11^{\mathrm{b}}$ \\
\hline DBD* & $2(4)$ & & $8(15)$ & & $0.05^{\mathrm{d}}$ \\
\hline Risperidone (mg/day) & & $1.5(0.9 ; 0.25,4)$ & & & - \\
\hline $\mathrm{RIS}^{*} \mu \mathrm{g} / \mathrm{L}$ & & $2.7(5 ; 0,28)$ & & & - \\
\hline 9-OH RIS* $\mu \mathrm{g} / \mathrm{L}$ & & $8.4(7.5 ; 0-36)$ & & & - \\
\hline Duration of use (months) & & $53(27.8 ; 16-126)$ & & & - \\
\hline \multicolumn{6}{|l|}{ Concomitant medication } \\
\hline Melatonin & $4(8)$ & & $3(6)$ & & \\
\hline Psychostimulants & $10(20)$ & & $13(30)$ & & \\
\hline Atomoxetine & $2(4)$ & & 0 & & \\
\hline Total & $13(25)$ & & $13(30)$ & & $0.17^{\mathrm{d}}$ \\
\hline Caucasian ethnicity & $49(96)$ & & $45(96)$ & & $0.44^{\mathrm{b}}$ \\
\hline
\end{tabular}

a Mann Whitney; ${ }^{\text {b }}$ Chi square; c Student t-test; ${ }^{\text {d }}$ Fisher Exact test; ${ }^{*} A S D=$ autism spectrum disorders; *DBD=disruptive behavior disorder; *RIS=plasma levels of risperidone; *9-OH RIS=plasma levels of 9$\mathrm{OH}$ risperidone 
Table 2. Prevalence of hyperprolactinemia and prolactin related side effects in male children and adolescents with mainly autism spectrum disorders with risperidone treatment $(\mathrm{N}=51)$ compared to male patients without antipsychotic treatment $(\mathrm{N}=47)$.

\begin{tabular}{|c|c|c|c|c|c|}
\hline & \multicolumn{2}{|l|}{$\begin{array}{c}\text { Cases } \\
\mathrm{N}=51\end{array}$} & \multicolumn{2}{|c|}{$\begin{array}{l}\text { Comparison subjects } \\
\mathrm{N}=47\end{array}$} & \multirow[t]{2}{*}{$P$ value } \\
\hline & N (\%) & Mean (SD, range) & $\mathrm{N}(\%)$ & Mean (SD, range) & \\
\hline Prolactin ng/ml* & & $19.3(16.8,2.4-92.5)$ & & $8.0(2.8,3.8-15.1)$ & $<0.0001^{\mathrm{a}}$ \\
\hline Tanner stage II & & $21.2(10.4,11.8,41.0)$ & & $7.7(2.5,5.7,10.8)$ & \\
\hline Tanner stage III & & $18.9(21.2,5.7,92.4)$ & & $7.3(3.3,3.8,15.1)$ & \\
\hline Tanner stage IV & & $17.9(16.9,2.3,77.8)$ & & $8.5(4.7,5.2,13.2)$ & \\
\hline Tanner stage V & & $21.7(13.7,6.6,48.6)$ & & $8.5(3.5,5.2,15.1)$ & \\
\hline Hyperprolactinemia & $24(47)$ & & $1(2)$ & & $<0.0001^{\mathrm{b}}$ \\
\hline \multicolumn{6}{|l|}{ Tanner stage } \\
\hline II/III/IV/V & $5 / 6 / 8 / 5$ & & $0 / 1 / 0 / 0$ & & \\
\hline $\begin{array}{l}\text { Asymptomatic } \\
\text { hyperprolactinemia }\end{array}$ & $\begin{array}{l}11 \text { out of } \\
24(46)\end{array}$ & & $\begin{array}{l}1 \text { out of } 1 \\
(100)\end{array}$ & & $<0.0001^{\mathrm{b}}$ \\
\hline \multicolumn{6}{|l|}{ Tanner stage } \\
\hline II/III/IV/V & $3 / 4 / 2 / 2$ & & $0 / 1 / 0 / 0$ & & \\
\hline \multicolumn{6}{|l|}{ Prolactin related side effects } \\
\hline $\begin{array}{l}\text { Gynecomastia } \\
\text { Questionnaire }\end{array}$ & $24(47)$ & & $10(21)$ & & $0.01^{\mathrm{b}}$ \\
\hline \multicolumn{6}{|l|}{ Tanner stage } \\
\hline II/III/IV/V & $3 / 5 / 12 / 4$ & & $2 / 4 / 4 / 0$ & & \\
\hline $\begin{array}{l}\text { Gynecomastia } \\
\text { physical examination }\end{array}$ & $22(43)$ & & $10(21)$ & & $0.05^{\mathrm{b}}$ \\
\hline \multicolumn{6}{|l|}{ Tanner stage } \\
\hline II/III/IV/V & $1 / 8 / 11 / 2$ & & $3 / 4 / 3 / 0$ & & \\
\hline Galactorrhea & 0 & & 0 & & - \\
\hline Diminished sexual functioning & $7(14)$ & & 0 & & $0.013^{\mathrm{c}}$ \\
\hline -sex interest & $2(4)$ & & 0 & & \\
\hline -orgasm & $4(8)$ & & 0 & & \\
\hline -ejaculate & $5(10)$ & & 0 & & \\
\hline -erection & $1(2)$ & & 0 & & \\
\hline
\end{tabular}

${ }^{*}$ reference value changes with age and gender (Emlinger et al 2002), see Table 3; a Mann Whitney; ${ }^{\text {b }}$ Chi square; ${ }^{c}$ Fisher Exact test 
Table 3. 97.5 th percentile of prolactin for age and gender in $\mathrm{ng} / \mathrm{ml}$ (Emlinger 2002)

\begin{tabular}{llllll}
\hline Age, (years) & N & Female & Age (years) & N & Male \\
\hline & & 97.5 th & & & 97.5 th \\
11 & 23 & 44.20 & 11 & 22 & 16.37 \\
12 & 18 & 15.47 & 12 & 17 & 12.93 \\
13 & 25 & 22.78 & 13 & 21 & 18.63 \\
14 & 30 & 31.13 & 14 & 32 & 17.55 \\
15 & 48 & 20.52 & 15 & 40 & 19.81 \\
16 & 40 & 20.71 & 16 & 31 & 15.09 \\
17 & 30 & 17.78 & 17 & 22 & 16.51 \\
$18-19$ & 12 & 39.53 & $18-19$ & 8 & 15.71 \\
$17-19$ & 42 & 32.78 & $17-19$ & 30 & 16.23 \\
\hline
\end{tabular}

Table 4. Predictors of hyperprolactinemia in an children and adolescent population using risperidone.

\begin{tabular}{lllll}
\hline & \multicolumn{2}{l}{ Hyperprolactinemia } & OR (CI) & p-value \\
& No, N=27 & Yes, N=24 & & \\
& Mean (SD) & Mean (SD) & & \\
\hline Current dose of risperidone (mg/day) & $1.25(0.84)$ & $1.83(0.95)$ & $2.42(1.07,5.50)$ & $0.035^{\mathrm{a}}$ \\
$\mathrm{RIS}^{*} \mu \mathrm{g} / \mathrm{L}$ & $1.48(2.14)$ & $4.30(6.86)$ & $1.19(0.97,1.44)$ & $0.090^{\mathrm{a}}$ \\
9-OH RIS* $\mu \mathrm{g} / \mathrm{L}$ & $6.26(5.32)$ & $11.35(8.70)$ & $1.15(1.02,1.29)$ & $0.030^{\mathrm{a}}$ \\
Mean dose of the treatment period (mg/day) & $1.41(0.76)$ & $1.68(0.53)$ & $1.98(0.79,4.97)$ & $0.14^{\mathrm{a}}$ \\
Duration of treatment (months) & $50.21(27.24)$ & $55.67(28.51)$ & $0.99(0.97,1.01)$ & $0.40^{\mathrm{a}}$ \\
\hline
\end{tabular}

a Logistic regression, corrected for age and BMI-Z; OR=odds ratio; CI=95\% confidence interval; ${ }^{*} \mathrm{RIS}=$ plasma levels of risperidone ; ${ }^{9}$-OH RIS=plasma levels of 9-0H risperidone

\section{Discussion}

Almost half of the boys treated long-term with risperidone but only $2 \%$ of the patients not treated with an antipsychotic agent had hyperprolactinemia. Although prolactin levels were only measured once, it is very likely that hyperprolactinemia is a common side effect in children and adolescents treated long-term with risperidone. Previous short-term studies have shown a steep increase in the prolactin level within the first 6 weeks, with levels stabilizing in the first 3 months (Aman 2002, Snyder 2002, Findling 2004, Biedereman 2005), followed by a slow decline after 1 year (Turgay 2002, Findling 2004, Croonenberghs 2005, Stevens 2005, Anderson 2007). Average prolactin levels were found to be above the reference value after 2 (Reyes 2006, Staller 2006) and 3 years of continued risperidone treatment (Calarge 2010), although two studies reported that prolactin levels tended to normalize after 12 months (Migliardi 2009) and 22 months (Anderson 2007) of antipsychotic use. Our results, obtained for pubertal boys with long-term risperidone use, show that half of the patients still have hyperprolactinemia after 
53 months. In previous studies hyperprolactinemia was defined using adult reference ranges, primarily $0-18 \mathrm{ng} / \mathrm{mL}$ and $0-30 \mathrm{ng} / \mathrm{mL}$ for male and female patients, respectively. Our study is the first to use age- and gender-appropriate reference ranges (Emlinger 2002, see Table 3) to define hyperprolactinemia. This is important because prolactin levels change during childhood and adolescence.

Gynecomastia was five times more common in our study than in other studies (Sikich 2004, Reyes 2006, Staller 2006) (Table 2). Previous studies included mainly prepubertal children and used spontaneous self-report, rather than, physical examination, to establish the presence of gynecomastia, which probably led to underestimation of the prevalence of gynecomastia. The prevalence of gynecomastia in the antipsychotic-naïve-boys was 21\% (10 of 47 boys) comparable to the prevalence of gynecomastia in healthy pubertal boys, indicating that it is a normal transient phenomenon in pubertal boys; the lifetime prevalence of gynecomastia in males is about 50\% (Bembo 2004, Hanavadi 2006). None of the boys had galactorrhea, consistent with earlier findings from a systematic review showing that galactorrhea does not occur in pubertal boys whereas it occurs in $0.5 \%$ of post-pubertal females (Roke 2009).

Our study is the first to use a validated and standardized instrument to assess sexual dysfunction in male adolescents using long-term antipsychotics. We found that 1 in 8 boys reported sexual dysfunction in relation to risperidone treatment. An earlier study that used a specific questionnaire for sexual adverse events showed a similar prevalence of sexual dysfunction among adolescents (Staller 2006). In studies of adults with schizophrenia or mood disorders, the rate of diminished sexual functioning due to hyperprolactinemia was about 40\% (Bobes 2003, Knegtering 2004 and 2006). The boys with ASD included in our study may have other sexual behavior than patients with schizophrenia or mood disorders. The mean dose of risperidone used in our study population was similar to other studies (weighted average $1.6 \mathrm{mg}$ per day) (Roke 2009). However, as our participants were older than those of most previous studies (mean age 14.5 in this study versus weighted average of 9.7 years in earlier studies) (Roke 2009), the dose corrected for age was probably lower in our study.

\subsection{Limitations}

This study had some limitations that should be taken into account when interpreting the results and which should be addressed in future studies. First, our sample size was relatively small, but our findings are in agreement with those of larger studies (Calarge 2010). In addition prolactin-elevating concomitant medication was permitted, such as, atomoxetine and melatonin (Blaicher 1999, Molitch 2005, Coker 2010), which could have influenced the prolactin levels. However, use of these medications was similar in the two groups of boys and appears not to have confounded our results. The prolactin-elevating effect of this concomitant medication 
is considered to be minor compared with that of the antipsychotic used (Coker 2010).

Another limitation is the cross-sectional design of the study, so that we cannot establish causality and also do not know what baseline prolactin levels were. Instead, we compared boys treated with risperidone and boys not treated with antipsychotics. Fourteen boys (27\%) had undetectable risperidone levels, and 4 of these boys (8\%) had also undetectable $9-\mathrm{OH}$ risperidone levels. Risperidone has a short half-life of three hours compared to the longer half-life of at least 23 hours (dependent on the patients CYP2D6 polymorfism) of 9-OH risperidone, explaining the difference in blood level detectability. These data suggest that these fourteen boys did not take their risperidone as prescribed. The four boys with undetectable risperidone and 9-OH risperidone levels did probably not take their medication at all while the ten boys with undetectable risperidone but detectable 9-OH risperidone levels probably did not take their AP as prescribed.

These adherence problems could have led to an underestimation of the actual prevalence of hyperprolactinemia and prolactin-related side effects in our study.

The ASFQ data on sexual functioning may have been biased by recall and time. The children and adolescents had to think back to the time when they did not use risperidone. Moreover, some of the boys may have started risperidone before puberty and may have become sexually mature since, so that they might have considered their sexual functioning as unchanged $(20 \%$ cases and $10 \%$ comparison group) or unknown (30\% cases and 40\% comparison group) whereas it was, in fact, suppressed. Moreover, boys who were sexually inexperienced or inactive could not make a before and after comparison. Another limitation is the selfassessment of pubertal stage. However, self-assessment has proven to be a valid and reliable method in comparison to physical examination especially in non-obese adolescent boys in mid to late adolescence (Duke 1980, Wacharasindhu 2002, Leone 2007, Chan 2008). We found that the staging of pubic hair development was less reliable than staging genital development, and so we used the genital development as main measure. Self-assessment of puberty has not been investigated before in autistic adolescents, but has proven reliable, in adolescents with other chronic diseases such as Crohn's disease and diabetes mellitus (Schall 2003, Stephen 2008). The prevalence of gynecomastia could have been confounded by the presence of overweight/ obesity, however the boys' breasts were palpated to distinguish between fat and glandular tissue.

\subsection{Clinical implications}

Continuous use of risperidone for 16 months or longer induces hyperprolactinemia in about half of the boys and might diminish their sexual functioning. Although gynecomastia was two times more common in the risperidone group, hyperprolactinemia was not associated with gynecomastia. However, 46\% (11 out of 24) of the boys with risperidone-induced hyperprolactinemia did not have prolactin-related 
side effects. The long-term consequences of asymptomatic hyperprolactinemia are unknown, but theoretically, high prolactin levels could result in diminished bone mineral density, changes in sexual maturation, or an increased risk of benign prolactinomas (Sfarzman 2006) during periods of critical maturation. Long-term studies are needed to investigate the relevance of asymptomatic hyperprolactinemia.

Some experts recommend a "wait and see approach" for asymptomatic hyperprolactinemia and advise that prolactin levels should be monitored in the event of prolactin-related side effects, such as, sexual disorders, menstrual disturbances, gynecomastia or galactorrhea (Haddad 2004, Correll 2006 and 2008, Anderson 2007). Others suggest proactive monitoring of prolactin levels and possible side effects before and during treatment with prolactin-elevating antipsychotics (Staller 2006, Citrome 2008, Ho 2011). This study provides further support for the monitoring of prolactin levels in symptomatic patients only. Diminished sexual functioning was associated with long-term hyperprolactinemia whereas gynecomastia may be a normal phenomenon. Thus sexual function should be addressed before and during treatment, using a standardized questionnaire. If symptomatic antipsychotic-induced hyperprolactinemia occurs the antipsychotic should be stopped if this is clinically feasible. Prolactin levels should normalize within days dependent on the half-life (T 1/2) of the drug (Pollock 1998, Turrone 2002). Alternatively, the dosage should be reduced as there is a dose-response relation with prolactin levels (Knegtering 2005), or another antipsychotic agent without prolactin-elevating qualities should be tried (e.g. quetiapine, aripiprazol, clozapine) (Stevens 2005, Greenaway 2009). If the hyperprolactinemia persists despite these steps, further investigation of the patient is necessary (Ho 2011).

\section{References}

Aman MG, De Smedt G, Derivan A, Lyons B, Findling RL: Double-blind, placebo-controlled study of risperidone for the treatment of disruptive behaviors in children with subaverage intelligence. Am J Psychiatry 159:1337-46, 2002.

Aman MG, McDougle CJ, Scahill L, Handen B, Arnold LE, Johnson C, Stigler KA, Bearss K, Butter E, Swiezy NB, Sukhodolsky DD, Ramadan Y, Pozdol SL, Nikolov R, Lecavalier L, Kohn AE, Koenig K, Hollway JA, Korzekwa P, Gavaletz A, Mulick JA, Hall KL, Dziura J, Ritz L, Trollinger S, Yu S, Vitiello B, Wagner A: Medication and Parent Training in Children With Pervasive Developmental Disorders and Serious Behavior Problems: Results From a Randomized Clinical Trial. J Am Acad Child Adolesc Psychiatry 48:1143-54, 2009.

Anderson GM, Scahill L, McCracken JT, McDougle CJ, Aman MG, Tierney E: Effects of short- and long-term risperidone treatment on prolactin levels in children with autism. Biol Psychiatry 61: 545-50, 2007.

Biederman J, Mick E, Wozniak J, Aleardi M, Spencer T, Faraone SV: An open-label trial of risperidone in children and adolescents with bipolar disorder. J Child Adolesc Psychopharmacol 15:311-317, 2005.

Blaicher W, Imhof MH, Gruber DM, Schneeberger C, Sator MO, Huber JC: Endocrinological disorders. Focusing on melatonin's interactions. Gynecol Obstet Invest 48:179-82, 1999.

Bembo SA, Carlson HE: Gynecomastia: its features, and when and how to treat it. Cleve Clin J Med 71: 511-7, 2004. 
Bobes J, Garc APMP, Rejas J, Hernandez G, Garcia-Garcia M, Rico-Villademoros F: Frequency of sexual dysfunction and other reproductive side-effects in patients with schizophrenia treated with risperidone, olanzapine, quetiapine, or haloperidol: the results of the EIRE study. J Sex Marital Ther 29:125-47, 2003.

Calarge CA, Zimmerman B, Xie D, Kuperman S, Schlechte JA: A cross-sectional evaluation of the effect of risperidone and selective serotonine reuptake inhibitors on bone mineral density in boys. J Clin Psychiatry 1:338-347, 2010.

Chan NP, Sung RY, Kong AP, Goggins WB, So HK, Nelson EA: Reliability of pubertal self-assessment in Hong Kong Chinese children. J Paediatr Child Health. 44:353-8, 2008.

Citrome L: Current guidelines and their recommendations for prolactin monitoring in psychosis. J Psychopharmacol 22:90-7, 2008.

Coker F, Taylor D: Antidepressant-induced hyperprolactinaemia. CNS Drug 24:563-574, 2010

Correll CU, Penzer JB, Parikh UH, Mughal T, Javed T, Carbon M, Malhotra AK: Recognizing and monitoring adverse events of second-generation antipsychotics in children and adolescents. Child Adolesc Psychiatric Clin N Am. 15:177-206, 2006.

Correll CU, Carlson HE: Endocrine and metabolic adverse effects of psychotropic medication in children and adolescents. J Am Acad Child Adolesc Psychiatry. 45:771-91, 2006.

Correll CU: Monitoring and management of antipsychotic-related metabolic and endocrine adverse events in pediatric patients. Int Rev Psychiatry 20:195-201, 2008.

Correll CU: Assessing and maximizing the safety and tolerability of antipsychotics used in the treatment of children and adolescents. J Clin Psychiatry 69:26-36, 2008.

Croonenberghs J, Fegert JM, Findling RL, De Smedt G, Van Dongen S: Risperidone in children with disruptive behavior disorders and subaverage intelligence: a 1-year, open-label study of 504 patients. J Am Acad Child Adolesc Psychiatry 44:64-72, 2005.

Cutler AJ:Sexual dysfunction and antipsychotic treatment. Psychoneuroendocrinology. 28 :69-82, 2003.

Duke PM, Litt IF, Gross RT: Adolescents'self-assesment of sexual maturation. Pediatrics 66:918-20, 1980.

Emlinger MW, Kühnel W, Ranke MB: Reference ranges for serum concentrations of Lutotropin (LH), Follitropin (FSH), Estradiol (E2), Prolactin, Progesterone, Sex Hormone Binding Globuline (SHBG), Dehydroepiandrosterone sulfate (DHEAS), Cortisol and Ferritin in neonates, children and young adults. Clin Chem Lab Med 40:1151-1160, 2002.

Fredriks AM, van Buuren S, Burgmeijer RJ, Meulmeester JF, Beuker RJ, Brugman E, Roede MJ, VerlooveVanhorick SP, Wit JM: Continuing positive secular growth change in The Netherlands 1955-1997. Pediatr. Res 47:316-23, 20001.

Fredriks AM, van Buuren S, Wit JM, Verloove-Vanhorick SP: Body index measurements in 1996-7 compared with 1980. Arch Dis Child. 82(2):107-12, 20002.

Findling RL, Aman MG, Eerdekens M, Derivan A, Lyons B: Long-term, open-label study of risperidone in children with severe disruptive behaviors and below-average IQ. Am J Psychiatry 161:677-84, 2004.

Graham SM, Howgate D, Anderson W, Howes C, Heliotis M, Mantalaris A, Tsiridis E, Tsapakis E: Risk of osteoporosis and fracture incidence in patients on antipsychotic medication. Expert Opin Drug Saf. 10:575-602, 2011.

Greenaway M, Elbe D: Focus on aripiprazole: a review of its use in child and adolescent psychiatry. J Can Acad Child Psychiatry 18:250-60, 2009.

Haddad PM, Wieck A: Antipsychotic-induced hyperprolactinaemia: mechanisms, clinical features and management. Drugs 64:2291-314, 2004.

Halbreich U, Kinon BJ, Gilmore JA, Kahn LS: Elevated prolactin levels in patients with schizophrenia: mechanisms and related adverse effects. Psychoneuroendocrinology 28:53-67, 2003.

Hanavadi S, Banerjee D, Monypenny IJ, Mansel RE: The role of tamoxifen in the management of gynaecomastia. Breast 15:276-80, 2006.

Ho J, Panagiotopoulos C, McCrindle B, Grisaru S, Pringsheim T, CAMESA guideline group. The Canadian Alliance for Monitoring Effectiveness and Safety of Antipsychotics in Children (CAMESA) Guideline Project: Management Recommendations for Metabolic Complications Associated with Second Generation Antipsychotic Use in Children and Youth. J Can Acad Child Adolesc Psychiatry 20:234-41, 2011 
Knegtering H, van der Moolen AE, Castelein S, Kluiter H, van den Bosch RJ: What are the effects of antipsychotics on sexual dysfunctions and endocrine functioning? Psychoneuroendocrinology 28:109-23, 2003.

Knegtering R, Castelein S, Bous H, Van Der Linde J, Bruggeman R, Kluiter H: A randomized open-label study of the impact of quetiapine versus risperidone on sexual functioning. J Clin Psychopharmacol 24: 56-61, 2004

Knegtering R, Baselmans P: Predominant role of the 9-hydroxy metabolite of risperidone in elevating blood prolactin levels. Am J Psychiatry 162:1010-2, 2005.

Knegtering H, Boks M, Blijd C, Castelein S, van den Bosch RJ, Wiersma D: A randomized open-label comparison of the impact of olanzapine versus risperidone on sexual functioning. J Sex Marital Ther 32: 315-26, 2006.

Leone M, Comtois AS: Validity and reliability of self-assessment of sexual maturity in elite adolescent athletes. J Sports Med Phys Fitness, 47:361-5, 2007.

McDougle CJ, Stigler KA, Erickson CA, Posey DJ: Atypical antipsychotics in children and adolescents with autistic and other pervasive developmental disorders. J Clin Psychiatry 69:15-20, 2008.

McKenna T: Should macroprolactin be measured in all hyperprolactinaemic sera? Clin Endocrinol 71:466-9, 2009.

Melmed S, Casanueva FF, Hoffman AR, Kleinberg DL, Montori VM, Schlechte JA, Wass JA: Diagnosis and treatment of hyperprolactinemia: an Endocrine Society clinical practice guideline. J Clin Endocrinol Metab 96:273-88, 2011.

Migliardi G, Spina E, D'Arrigo C, Gagliano A, Germanò E, Siracusano R, Diaz FJ, de Leon J: Short- and longterm effects on prolactin of risperidone and olanzapine treatments in children and adolescents. Prog Neuropsychopharmacol Biol Psychiatry 33:1496-501, 2009.

Molitch ME: Medication-induced hyperprolactinemia. Mayo Clin Proc 80:1050-1057, 2005.

Pollock A, McLaren EH: Serum prolactin concentration in patients taking neuroleptic drugs. Clin Endocrinol 49:513-6, 1998.

Research Units on Pediatric Psychopharmacology Autism Network: Risperidone in children with autism and serious behavioral problems. New Eng. J Med. 347:314-321, 2002.

Reyes M, Croonenberghs J, Augustyns I, Eerdekens M: Long-term use of risperidone in children with disruptive behavior disorders and subaverage intelligence: efficacy, safety, and tolerability. J Child Adolesc Psychopharmacol 16:260-72, 2006.

Roke Y, Van Harten PN, Boot AM, Buitelaar JK: Antipsychotic medication in children and adolescents: A descriptive review of the effects on prolactin level and associated side effects.J Child Adolesc Psychopharmacol 19: 403-1, 2009.

Saito E, Correll CU, Gallelli K, McMeniman M, Parikh UH, Malhotra AK: A prospective study of hyperprolactinemia in children and adolescents treated with atypical antipsychotic agents. J Child Adolesc Psychopharmacol 14:350-8, 2004.

Saranac L, Zivanovic S, Radovanovic Z, Kostic G, Markovic I, Miljkovic P: Hyperprolactinemia: different clinical expression in childhood. Horm Res Paediatr 73:187-92, 2010.

Schall JI, Semeao EJ, Stallings VA, Zemel BS: Self-assessment of sexual maturity status in children with Crohn's disease. J Pediatr;141:223-9, 2002.

Sikich L, Hamer RM, Bashford RA, Sheitman BB, Lieberman JA: A pilot study of risperidone, olanzapine, and haloperidol in psychotic youth: a double-blind, randomized, 8-week trial. Neuropsychopharmacology 29:133-45, 2004.

Snyder R, Turgay A, Aman M, Binder C, Fisman S, Carroll A: Effects of risperidone on conduct and disruptive behavior disorders in children with subaverage IQs. J Am Acad Child Adolesc Psychiatry 41:1026-36, 2002.

Staller J: The effect of long-term antipsychotic treatment on prolactin. J Child Adolesc Psychopharmacol 16:317-26, 2006.

Stephen MD, Bryant WP, Wilson DP: Self-assessment of sexual maturation in children and adolescents with diabetes mellitus. Endocr Pract. 14:840-5, 2008.

Stevens JR, Kymissis PI, Baker AJ: Elevated prolactin levels in male youths treated with risperidone and quetiapine. J Child Adolesc Psychopharmacol 15:893-900, 2005. 
Stigler K.A., et al. A prospective, open-label study of aripiprazole in youth with Asperger's disorder and pervasive developmental disorder not otherwise specified. Neuropsychopharmacology. 31:S194, 2006.

Turgay A, Binder C, Snyder R, Fisman S: Long-term safety and efficacy of risperidone for the treatment of disruptive behavior disorders in children with subaverage IQs. Pediatrics 110: e34, 2002.

Turrone P, Kapur S, Seeman MV, Flint AJ: Elevation of prolactin levels by atypical antipsychotics. Am J Psychiatry 159: 133-135, 2002

Verhelst J, Abs R: Hyperprolactinemia: pathophysiology and management. Treat Endocrinol 2:23-32, 2003.

Vitiello B, Correll C, van Zwieten,Boot B, Zuddas A, Parellada M, Arango C: Antipsychotics in children and adolescents: increasing use, evidence for efficacy and safety concerns. Eur Neuropsychopharmacol.19:629-35, 2009.

Wacharasindhu S, Pri-Ngam P, Kongchonrak T: Self-assessment of sexual maturation in Thai children by Tanner photograph. J Med Assoc Thai, 85:308-19, 2002.

Wink LK, Erickson CA, McDougle CJ: Pharmacologic treatment of behavioral symptoms associated with autism and other pervasive developmental disorders. Curr Treat Opt Neurol 12:529-38, 2010.

Wolters HA, Knegtering H, Wiersma D, van den Bosch RJ: The spectrum of subjective effects of antipsychotic medication. Acta Neuropsychiatrica 15:274-79, 2003. 


\section{Chapter 4}

\section{Antipsychotic-induced hyperprolactinemia and testosterone levels in boys}

Yvette Roke, Peter N. van Harten, Jan K. Buitelaar, Diederik E. Tenback,

Yolanda B. de Rijke, Annemieke M. Boot

Horm Res Paediatr. 2012 Apr;77(4):235-40.

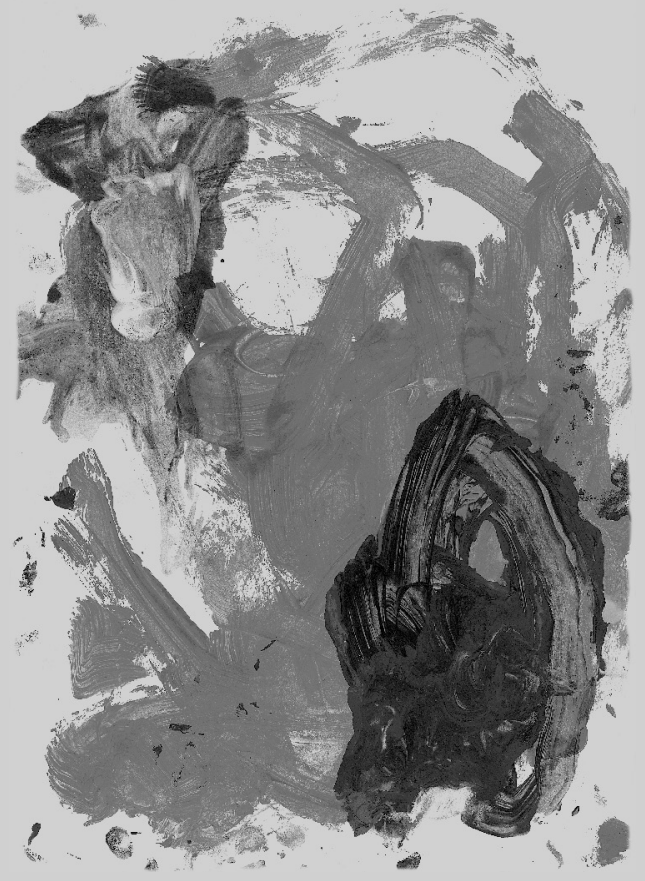




\section{Abstract}

Aims: This cross-sectional study investigates the effect of antipsychotic (AP) induced- hyperprolactinemia on testosterone, luteinizing hormone ( $\mathrm{LH}$ ), follicle stimulating hormone (FSH), Inhibin B, and puberty in boys with mainly autism spectrum disorders (ASD).

Method: One hundred and four physically healthy 10-to 19 year-old-boys with ASD or with disruptive behavior disorder (DBD) were recruited between October 2006 and November 2009. Fifty-six adolescents had been treated with AP for more than sixteen months; 48 had never been exposed to AP. Morning non-fasting levels of serum prolactin, testosterone, LH, FSH, and Inhibin B level were obtained and Tanner pubertal stage was determined. Patients with hyperprolactinemia $(\mathrm{N}=28)$ were compared to those without hyperprolactinemia $(\mathrm{N}=76)$ using non-parametric or parametric tests, as appropriate.

Results: Patients with AP-induced hyperprolactinemia had significantly lower testosterone levels with adjustment for age $(p=0.035)$ compared to patients without hyperprolactinemia and without AP treatment. The difference was not significant within the AP treated group, and the level of testosterone was within the reference range compared to age and gender matched normative data. There was no between-group difference for LH, FSH, Inhibin B or Tanner stages.

Conclusion: AP-induced hyperprolactinemia is related to significantly lower testosterone levels in pubertal boys with ASD and DBD.

Key words: Hyperprolactinemia, Adolescents, Testosterone, Puberty, Antipsychotics 


\section{Introduction}

Antipsychotics (AP) are commonly and increasingly prescribed to children and adolescents with autism spectrum disorders (ASD) and disruptive behavior disorder (DBD) [1]. AP reduce maladaptive behaviors such as irritability, self-injury, stereotypes and hyperactivity [2]. Hyperprolactinemia, a side effect caused by dopamine 2 blockade in the tuberoinfundibular pathway [3], is a common side effect of long-term AP treatment in children and adolescents [4]. Long-term hyperprolactinemia can cause suppression of the hypothalamic-pituitary gonadal axis, so a decrease of gonadotrophin-releasing hormone $(\mathrm{GnRH})$ and consequently of luteinizing hormone ( $\mathrm{LH}$ ) and testosterone may be observed in males. This may cause sexual dysfunction such as loss of libido, loss of erection, ejaculation disorders, gynecomastia and galactorrhea [5]. Hyperprolactinemia may also affect follicle stimulating hormone (FSH) and inhibin B levels [6]. Inhibin B is produced by the Sertoli cells of the testes and regulates FSH levels through negative feedback on the pituitary and is a marker of fertility [7]. Few studies evaluating these hormonal effects in adult patients using prolactin-elevating AP have been published. These studies report a decrease of testosterone and gonadotropins due to an AP-induced hyperprolactinemic effect in men [6]. The same inverse relation between prolactin and testosterone in males, as well as arrested pubertal development in adolescence, is also seen in prolactinoma-induced hyperprolactinaemia [8]. However, in prolactinomas prolactin levels are two to four times more elevated than in AP-inducedhyperprolactinemia [9]. The influence of AP-induced hyperprolactinemia on reproductive hormones and gonadotropins during puberty has not yet been investigated in pediatric populations. This paper focuses on the effect of long-term AP-induced hyperprolactinemia on testosterone, $\mathrm{LH}, \mathrm{FSH}$, and Inhibin B, and the influence of persistent hyperprolactinemia on pubertal development in adolescents with ASD and DBD treated with and without long-term prolactin-elevating AP medication.

\section{Subjects and Methods}

\subsection{Subjects}

All participants were recruited from the total patient population of the outpatient adolescent clinic of the GGz Central Psychiatric Centre, The Netherlands, from October 2006 to November 2009. Participants were recruited if they were aged between 10 and 19 years, diagnosed with any psychiatric disorder, had an IQ above 85 , and were male. All participants included had a diagnosis of ASD or DBD, i.e. either severe oppositional defiant disorder or conduct disorder. One hundred and four patients ( $66 \%$ of the eligible population) participated. Fifty-six patients of the total study population $(\mathrm{n}=104)$ were treated with AP for more than 1 year and 48 
patients had never been exposed to AP. We were primarily interested in the relationship between hyperprolactinemia and testosterone, $\mathrm{LH}, \mathrm{FSH}$, and Inhibin B levels. Therefore we divided our study population into a group with hyperprolactinemia and one without.

The reason for not participating was fear of venapuncture. None of the participants had a history of diabetes mellitus, thyroid disorders, syndromes or other chronic diseases affecting puberty, endocrine disorders, use of oral corticosteroids or anticonvulsants, or known causes of hyperprolactinemia [10,11]. The first author contacted the parents/ legal guardians and the patients by telephone and letter. The local Medical Ethics Committee approved this study and written informed consent was obtained from the patient and the subject's parents/ legal guardians.

\subsection{Methods}

The clinical diagnosis and IQ was obtained from the patients' chart. Physical examination is the clinical standard to investigate stages of puberty, however The Medical Ethics Committee unfortunately did not approve this method. Therefore, selfassessment, the best alternative, was chosen. The boys selected the different Tanner stage photographs of genitals (G stage) and pubic hair (P stage) that most accurately reflected their appearance [12]. One of the parents/ legal guardians was present during the self-assessment and confirmed the stages pointed out. The pubic hair development self-assessment staging was less reliable than staging of the genital development. We therefore used the genital development as the main measure.

The first author measured height and weight, using a standardized procedure. Height was measured without shoes to the nearest $0.1 \mathrm{~cm}$ using a stadiometer while the participant was standing erect (Seca 206, the Netherlands) and weight was recorded to the nearest $0.1 \mathrm{~kg}$ using an analogue scale (Seca 761, the Netherlands) while the participant was dressed in underwear. Age and gender specific height, weight and BMI z-scores were calculated using normative data for Dutch children [13]. For the Tanner stage data standardized values stratified per age category were compared to published normative data of the general population [13]. The Tanner stage of our study population was compared to the 50th percentile normative data (gender and age matched) of Dutch adolescents: the difference was expressed in years. A non-fasting morning blood sample was obtained around 9.30 a.m. after a light breakfast eaten at around 7.30 a.m. Serum prolactin was measured with an automated chemiluminescence assay system (Immulite 2000, Siemens Healthcare Diagnostics, Los Angeles, CA, USA) calibrated on the 3rd IS 84/500. As macroprolactin, a complex of prolactin and IgG without biological activity, accounts for $10 \%$ of the cases of hyperprolactinemia [14], seven samples with prolactin concentrations higher than $37 \mathrm{ng} / \mathrm{mL}$ were assessed for the presence of macroprolactin. Polyethylene glycol 6000, $200 \mu \mathrm{L},(25 \% \mathrm{w} / \mathrm{w})$ was added to $200 \mu \mathrm{L}$ of serum and, after thorough vortex mixing, the mixture was centrifuged at $2200 \mathrm{~g}$ for $30 \mathrm{~min}$ at $4{ }^{\circ} \mathrm{C}$. Subsequently, prolactin was measured in the supernatant and the untreated 
serum. The recovery of prolactin after precipitation with polyethylene glycol 6000 was $101.4 \pm 9.6 \%$ (mean \pm SD), which excluded the presence of macroprolactin. For prolactin a binary value was defined as either above or below the 97.5 th percentile corrected for age and gender [15]. LH, FSH were measured in serum by a two-site, solid-phase chemiluminescent immunometric assay (Immulite 2000, Siemens Healthcare Diagnostics). Total testosterone was measured by a solid-phase 125I radioimmunoassay in unextracted serum (Coat-a-count, Siemens Healthcare Diagnostics). Inhibin B in serum was measured by a Gen II ELISA assay from Beckman Coulter. Inc. (Webster, USA). Testosterone, LH, FSH, and Inhibin B were compared to literature reference values for age and gender [15-17].

\subsection{Statistical analysis}

Chi-square, independent t-tests, Mann-Whitney, linear regression, or binary logistic regression were used according to the type and distribution of data. Binary logistic regression analysis was conducted to investigate the effect of hyperprolactinemia on testosterone, LH, FSH, and Inhibin B in the study population. All regression models were corrected for age. Dose equivalence was assumed between pimozide $(\mathrm{N}=3)$ and risperidone $(\mathrm{N}=53)[18,19]$. Binary logistic regression analysis was used to investigate the difference between our study population and healthy age and gender matched normative data described in the literature. These data [13] were used to create a new variable showing the difference in years in attaining the 50th percentile of $\mathrm{P}$ and $\mathrm{G}$ stages of puberty. For the difference between our total study group and the normative data we have calculated a weighted average in number of years late attaining 50th percentile Tanner stage of puberty. We have also calculated a weighted average for the height-, weight-, and BMI z-scores. We have applied binary logistic regression analysis to investigate whether ASD or DBD were part of the explanation for being years late in attaining stages of puberty.

\section{Results}

Baseline characteristics of the patients included are presented in Table 1. There were no statistical differences between the two groups in mean age, weight, height, BMI z-scores, and diagnosis. All patients with hyperprolactinemia $(\mathrm{N}=28)$ used AP except one. The dose of the AP medication used was significantly higher in the group with hyperprolactinemia and AP use $(\mathrm{N}=27)$ compared to the group without hyperprolactinemia with AP use (29 patients out of 76 used AP) ( $\mathrm{p}=0.04$, Table 1). The duration of AP use ( $\mathrm{N}=27$ in the hyperprolactinemia group and $\mathrm{N}=29$ in the group without hyperprolactinemia) was the same for both groups with a mean of more than four years. The patients with hyperprolactinemia had significantly lower testosterone levels compared to the group without hyperprolactinemia, after ad- 
justment for age $(9.85 \mathrm{nmol} / \mathrm{l}$ compared to $12.41 \mathrm{nmol} / \mathrm{l}, \mathrm{p}=0.035$, Table 2). The group without hyperprolactinemia and use of AP medication $(\mathrm{N}=29)$ had mean testosterone levels of $11.31 \mathrm{nmol} / \mathrm{L}(\mathrm{p}=0.14$, when compared with AP treated patients with hyperprolactinemia, Table 2). The group without hyperprolactinemia and without AP treatment had mean testosterone levels of $13.12 \mathrm{nmol} / \mathrm{L}$ (Table 2). There was a significant negative relationship between testosterone and prolactin $(\beta=-0.32, p=0.008)$. In the AP treated group a trend was observed $(\beta=-0.28, p=0.07)$. Testosterone was positively associated with $\mathrm{LH}(\beta=0.43, \mathrm{p}<0.0001)$.

Compared to the normative data for age and gender testosterone levels were in the normal range [17]. Results obtained with the Count-a-count (Siemens) assay used in this study are comparable with the LC-MS/MS method using Perkin Elmer MSMS Steroids kit, which is an in vitro diagnostic HPLC-MS/MS reagent kit. The $95 \%$ limits of agreement of these two methods were -0.87 to $1.13 \mathrm{nmol} / \mathrm{L}$. The results did not change after adjustment for ASD or DBD.

LH, FSH, and Inhibin B levels did not differ between the group with and the group without hyperprolactinemia. LH, FSH, and Inhibin B were also in the normal range when compared to age and gender matched normative data values. The age of attainment of Tanner stages was the same for patients with and without hyperprolactinemia. Compared to normative data, our total study population was 1.6 years late in attaining the same Tanner stage. Our study population had normal mean z-scores for height (0.40), weight (0.48), and BMI (0.44). When correcting for autism ( $\mathrm{N}=92)$ versus DBD ( $\mathrm{N}=12)$, autism showed a trend towards significance $(p=0.067)$ in being later in attaining the same stage of puberty than healthy controls. 


\section{SEX HORMONES}

Table 1. Characteristics of adolescents with and without hyperprolactinemia in the cross-sectional study

\begin{tabular}{|c|c|c|c|c|c|}
\hline & \multicolumn{2}{|c|}{$\begin{array}{l}\text { Patients with hyperprolactinemia } \\
(\mathrm{N}=28)\end{array}$} & \multicolumn{2}{|c|}{$\begin{array}{l}\text { Patients without hyperprolactinemia } \\
(\mathrm{N}=76)\end{array}$} & \multirow[t]{2}{*}{ P value } \\
\hline & $\mathrm{N}(\%)$ & Mean (SD, range) & $\mathrm{N}(\%)$ & Mean (SD, range) & \\
\hline Age, years & & $15.1(2.7,10.3-19.2)$ & & $14.9(1.7,11.9-18.8)$ & $0.77^{\mathrm{a}}$ \\
\hline Height (m) & & $1.73(0.1,1.4-2.0)$ & & $1.75(0.1,1.4-2.0)$ & $0.66^{\mathrm{a}}$ \\
\hline Height z-score ${ }^{\$}$ & & $0.52(1.1,-1.4-2.1)$ & & $0.35(1.0,-2.4-2.9)$ & $0.47^{a}$ \\
\hline Weight (kg) & & $65.2(23.2,31.5-138)$ & & $63.0(14.9,33.3-116.0)$ & $0.64^{\mathrm{a}}$ \\
\hline Weight z-score ${ }^{\$}$ & & $0.70(1.3,-1.6-4.5)$ & & $0.40(1.2,-2.5-3.9)$ & $0.28^{a}$ \\
\hline BMI* & & $21.0(5.3,14.6-41.6)$ & & $20.2(3.7,15.2-32.0)$ & $0.62^{\mathrm{a}}$ \\
\hline BMI z-score $\$$ & & $0.23(1.0,-1.8-2.8)$ & & $0.52(1.1,-3.3-2.3)$ & $0.46^{\mathrm{a}}$ \\
\hline $\begin{array}{l}\text { Tanner stage } \\
\text { I/II/III/IV/V }\end{array}$ & & $\begin{array}{l}3.54(1.1,2-5) \\
0 / 6 / 7 / 9 / 6\end{array}$ & & $\begin{array}{l}3.55(0.9,2-5) \\
0 / 11 / 22 / 33 / 10\end{array}$ & $0.94^{\mathrm{a}}$ \\
\hline Caucasian ethnicity & $27(96)$ & & $73(96)$ & & $0.26^{\mathrm{b}}$ \\
\hline \multicolumn{6}{|l|}{ Primary diagnosis } \\
\hline $\mathrm{ASD}^{*}$ & $26(93)$ & & $66(87)$ & & $0.83^{\mathrm{b}}$ \\
\hline DBD* & $2(7)$ & & $10(13)$ & & $0.39^{b}$ \\
\hline \multicolumn{6}{|l|}{ Antipsychotics $^{\wedge}$} \\
\hline Dose (mg/day) \# & $1.89(1.0,0.5-4.0)$ & & $1.28(0.8,0.3-4.0)$ & & $0.04^{\mathrm{d}}$ \\
\hline $\begin{array}{l}\text { Mean dose \# } \\
\text { (mg/day) }\end{array}$ & $1.75(0.7,1-4)$ & & $1.45(0.8,0.5-3.5)$ & & $0.03^{\mathrm{d}}$ \\
\hline $\begin{array}{l}\text { Duration of use \#, } \\
\text { (months) }\end{array}$ & $\begin{array}{l}49.4(26.3,16-118) \\
1(4)\end{array}$ & & $53.2(30.0,19-126)$ & & $0.58^{\mathrm{d}}$ \\
\hline None & & & $47(62)$ & & $<0.0001^{\mathrm{c}}$ \\
\hline \multicolumn{6}{|l|}{$\begin{array}{l}\text { Concomitant } \\
\text { medication }\end{array}$} \\
\hline Melatonin & $2(7)$ & & $5(7)$ & & $1.00^{\mathrm{c}}$ \\
\hline SSRI & $2(7)$ & & 0 & & - \\
\hline Psychostimulants & $4(14)$ & & $19(25)$ & & $0.30^{\mathrm{c}}$ \\
\hline Atomoxetine & 0 & & $2(3)$ & & - \\
\hline Total & $8(29)$ & & $24(32)$ & & - \\
\hline
\end{tabular}

${ }^{a}=$ Student's t-test; ${ }^{b}=$ Chi-square; ${ }^{c}=$ Fisher's exact test; ${ }^{d}=$ Mann-Whitney; ${ }^{\wedge}=$ dose-equivalence was assumed for risperidone ( $\mathrm{N}=53$ and pimozide $\mathrm{N}=3$ ); * $\mathrm{BMI}=$ body mass index; \# only patients with use of $\mathrm{AP}$ medication; $\mathrm{ASD}=$ autism spectrum disorders; $\mathrm{DBD}=$ disruptive behavior disorder; - Not-applicable because of empty cells; $\$$ Normative data Fredriks et al., 2001 were used to calculate z-scores for height, weight and BMI 
Table 2. Prolactin, gonadotropin, and sex steroid levels of boys with $(\mathrm{N}=28)$ and without $(\mathrm{N}=76)$ hyperprolactinemia

\begin{tabular}{|c|c|c|c|c|c|c|}
\hline & \multirow{3}{*}{$\begin{array}{l}\text { Patients with } \\
\text { hyperprolactinemia } \\
\mathrm{N}=28\end{array}$} & \multicolumn{5}{|c|}{ Patients without hyperprolactinemia } \\
\hline & & \multicolumn{5}{|l|}{$\mathrm{N}=76$} \\
\hline & & $\begin{array}{l}\text { Total } \\
\mathrm{N}=76\end{array}$ & $\begin{array}{l}\text { With AP } \\
\text { treatment } N=29\end{array}$ & $\begin{array}{l}\text { Without AP } \\
\text { treatment } \mathrm{N}=47\end{array}$ & P value* & P value** \\
\hline & Mean (SD, range) & Mean (SD, range) & Mean (SD, range) & Mean (SD, range) & & \\
\hline Prolactin ng/ml & $27.83(18,15.1-92.5)$ & $8.96(0.07,2.4-17.0)$ & $10.50(4.0,2.4-17.0)$ & $7.83(2.6,3.8-15.1)$ & $<0.0001^{a}$ & $<0.0001^{a}$ \\
\hline $\begin{array}{l}\text { Testosterone } \\
\mathrm{nmol} / \mathrm{L}\end{array}$ & $9.85(6.1,0.2-22.4)$ & $12.41(6.6,0.3-29.4)$ & $11.31(6.4,0.3-26.4)$ & $13.12(6.6,0.3-29.4)$ & $0.035^{b}$ & $0.14^{b}$ \\
\hline $\mathrm{LH} \mathrm{IU} / \mathrm{L}^{\#}$ & $3.25(2.0,0.4-8.3)$ & $3.48(2.0,0.5-10.2)$ & $3.30(1.8,0.5-6.9)$ & $4.00(2.1,0.8-10.2)$ & $0.44^{\mathrm{b}}$ & $0.47 \mathrm{~b}$ \\
\hline FSH IU/L $\#$ & $4.30(2.1,1.9-10.4)$ & $5.50(4.3,1.0-27.5)$ & $4.81(2.6,1-11.6)$ & $5.95(5.0,1.1-27.5)$ & $0.15^{b}$ & $0.25 \mathrm{~b}$ \\
\hline Inhibin B ng/L & $246(80,110-401)$ & $241(69,67-383)$ & $245(82,110-401)$ & $234(73,67-383)$ & $0.79 \mathrm{~b}$ & $0.69 \mathrm{~b}$ \\
\hline
\end{tabular}

"LH= luteinising hormone; ${ }^{\mathrm{FSSH}}=$ follicle stimulating hormone; * patients with hyperprolactinemia $(\mathrm{N}=28)$ compared to the total patients without hyperprolactinemia $(\mathrm{N}=76)$; ${ }^{* *}$ patients with hyperprolactinemia $(\mathrm{N}=28)$ compared to AP treated patients without hyperprolactinemia $(\mathrm{N}=29)$; ${ }^{\mathrm{a}}=\mathrm{Mann}$ Whitney; ${ }^{b}=$ logistic regression corrected for age

\section{Discussion}

Boys with (mainly) ASD and AP-induced-hyperprolactinemia had significant lower testosterone levels than male adolescents with ASD and normal prolactin levels.

The testosterone levels were not significantly different in the group of patients with AP treatment with and without hyperprolactinemia. However, the prolactin levels of the AP treated patients without hyperprolactinemia were still higher than of the patients not treated with AP. Nonetheless, testosterone levels stayed within the normal limits suggesting that AP with prolactin elevating properties are save in this aspect. We observed a relationship between an increase in prolactin levels and a decrease in testosterone levels. The LH levels were not significantly lower in the patients with hyperprolactinemia than in the groups without hyperprolactinemia, which may be due to lack of power and the range of Tanner stages of the included patients. Still, we hypothesise that a high prolactin inhibits the release of $\mathrm{LH}$, which results in lower testosterone levels. Hyperprolactinemia in AP use is caused by dopamine 2 blockade in the tuberoinfundibular pathway and is a common side effect in children and adolescents treated with AP medication. The group of patients with AP use and hyperprolactinemia had a higher dose of AP than the boys with AP use without hyperprolactinemia, so a higher dose seems to be a risk factor of hyperprolactinemia. However, pharmacogenetic differences may explain individual variation in whether hyperprolactinemia occurs and leads to clinical consequences. For example, the Taq1 A1 allele of the D2 dopamine receptor gene (DRD2) is associated with a significantly reduced density of D2 receptors [20]. Also the 
metabolization rate of prolactin-inducing antipsychotics may influence prolactin levels [21].

This is the first study to investigate the difference in testosterone levels in hyperprolactinemic pubertal boys with ASD compared to a matched control group with ASD with normal prolactin levels. Two previous small studies in ASD patients without AP use showed conflicting results; one study showed significantly lower testosterone levels in 18 medication naïve autistic adolescents [22] compared to 22 healthy controls whereas another small study [23] showed no difference in testosterone levels between 39 medication naïve autistic children and adolescents compared to 21 healthy controls. In both studies the testosterone levels were within the normal range of the normative data [17], like in the present study. LH, FSH and Inhibin B did not differ between the two groups and were also normal compared to normative data. Because we expected that significantly lower testosterone levels in our hyperprolactinemic group could have had a negative influence on puberty, we evaluated the pubertal stage of the patients. The group with hyperprolactinemia did not differ in pubertal stage from the group without hyperprolactinemia. An earlier one- year follow-up study of mainly male $(80 \%)$ children with DBD $(\mathrm{N}=222$, mean age 11.9 years, SD 1.4) starting prolactin-elevating medication showed no difference in the progression of stages of puberty [24]. When we compared the data of our total study group in attaining the 50th percentile of Tanner stage of puberty with the normative data, the adolescents in the present study were 1.6 years late. Delay in pubertal development may be related to the presence of an autistic spectrum disorder. One study in women with ASD showed a later age of menarche than controls [25]. ASD is a neurodevelopment disorder, which may affect the hypothalamic-pituitary-gonadal axis.

\subsection{Limitations}

This study had some limitations that should be taken into account when interpreting the results and should be addressed in future studies.

A limitation could be that our study attracted in particular patients with particular concerns regarding development of puberty. However, it is unlikely that this biased the results because these concerns could be related to either an early or late development of puberty. Another limitation could have been the determination of pubertal stage by self-assessment with confirmation of one of the parents. However, several studies which have investigated this method concluded that compared to physical examination, self-assessment is a less reliable but nonetheless valid method [12, 26-28]. Self-assessment of puberty has not been investigated before in autistic adolescents, but has proven reliable, in adolescents with other chronic diseases such as Crohn's disease and diabetes mellitus $[29,30]$. The present study was cross-sectional and longitudinal studies are needed for evaluating the progression of puberty. 
In addition, prolactin-elevating concomitant medication was permitted, such as, melatonin and the SSRI's [9, 31, 32], which could have influenced the prolactin levels. However, use of these medications was similar in the two groups of boys and appears not to have confounded our results. The prolactin-elevating effect of this concomitant medication is considered to be minor compared with that of the antipsychotics used [32]. Furthermore we did not include a group of healthy controls. However, we used published normative data of large groups of children and adolescents. Finally, our sample size was relatively small, and its power therefore limited.

\subsection{Conclusions}

AP-induced hyperprolactinemia is related to lower testosterone levels in male adolescents with ASD and DBD, although the testosterone levels were within the normal range for age and gender. LH, FSH, Inhibin B and pubertal stage were not influenced by hyperprolactinemia. Although hyperprolactinemia may cause sexual side effects, gynaecomastia, galactorrhea, and diminished bone mineral density, this is the first study to show that AP-induced-hyperprolactinemia has no clinically significant effect on sex hormones, gonadotropins, or puberty in adolescent males with ASD and DBD. Our data suggest a delay in pubertal development, which may be related to the presence of an autism spectrum disorder. Further longitudinal research into this area is needed to confirm our results and to examine the mechanisms involved.

\section{References}

1. McDougle CJ, Stigler KA, Erickson CA, Posey DJ: Atypical antipsychotics in children and adolescents with autistic and other pervasive developmental disorders. J Clin Psychiatry, 2008; 69:15-20.

2. Aman MG, McDougle CJ, Scahill L, Handen B, Arnold LE, Johnson C, Stigler KA, Bearss K, Butter E, Swiezy NB, Sukhodolsky DD, Ramadan Y, Pozdol SL, Nikolov R, Lecavalier L, Kohn AE, Koenig K, Hollway JA, Korzekwa P, Gavaletz A, Mulick JA, Hall KL, Dziura J, Ritz L, Trollinger S, Yu S, Vitiello B, Wagner A: Medication and Parent Training in Children With Pervasive Developmental Disorders and Serious Behavior Problems: Results From a Randomized Clinical Trial. J Am Acad Child Adolesc Psychiatry, 2009; 48:1143-54.

3. Halbreich U, Kinon BJ, Gilmore JA, Kahn LS: Elevated prolactin levels in patients with schizophrenia: mechanisms and related adverse effects. Psychoneuroendocrinology, 2003; 28, 53-67.

4. Calarge CA , Zimmerman B, Xie D, Kuperman S, Schlechte JA: A cross-sectional evaluation of the effect of risperidone and selective serotonine reuptake inhibitors on bone mineral density in boys. J Clin Psychiatry, 2010; 1(3), 338-347.

5. Roke Y, Van Harten PN, Boot AM, Buitelaar JK: Antipsychotic medication in children and adolescents: A descriptive review of the effects on prolactin level and associated side effects. J Child Adolesc Psychopharmacol, 2009; 19(4), 403-14.

6. Konarzewska B, Wołczyński S, Szulc A, Galińska B, Popławska R, Waszkiewicz N: Effect of risperidone and olanzapine on reproductive hormones, psychopathology and sexual functioning in male patients with schizophrenia.Psychoneuroendocrinology, 2009; 34(1),129-39. 
7. Mędraś M, Trzmiel-Bira A, Jóźków P, Terpiłowski L, Zagocka E, Sicińska-Werner T: Inhibin B and FSH as markers of Sertoli cell function in impaired spermatogenesis. Endokrynol Pol. 2010; NovDec;61(6):695-8.

8. Howlett, TA, Wass JA: Prolactinomas presenting as primary amenorrhoea and delayed or arrested puberty: response to medical therapy. Clin Endocrinol, 1989; 30(2), 131-40.

9. Molitch ME: Medication-induced hyperprolactinemia. Mayo Clin Proc, 2005; 80:1050-1057.

10. Verhelst J, Abs R: Hyperprolactinemia: pathophysiology and management. Treat Endocrinol, 2003; 2:23-32.

11. Melmed S, Casanueva FF, Hoffman AR, Kleinberg DL, Montori VM, Schlechte JA, Wass JA: Diagnosis and treatment of hyperprolactinemia: an Endocrine Society clinical practice guideline. J Clin Endocrinol Metab, 2011; 96:273-88.

12. Duke PM, Litt IF, Gross RT: Adolescents'self-assesment of sexual maturation. Pediatrics, 1980; 66(6), 918-20.

13. Fredriks AM, van Buuren S, Burgmeijer RJ, Meulmeester JF, Beuker RJ, Brugman E, Roede MJ, Verloove-Vanhorick SP, Wit JM: Continuing positive secular growth change in The Netherlands 19551997. Pediatr Res, 2000; 47(3), 316-23.

14. McKenna T: Should macroprolactin be measured in all hyperprolactinaemic sera? Clin Endocrinol, 2009; 71:466-9.

15. Emlinger MW, Kühnel W, Ranke MB: Reference ranges for serum concentrations of Lutotropin (LH), Follitropin (FSH), Estradiol (E2), Prolactin, Progesterone, Sex Hormone Binding Globuline (SHBG), Dehydroepiandrosterone sulfate (DHEAS), Cortisol and Ferritin in neonates, children and young adults. Clin Chem Lab Med, 2002; 40(11), 1151-1160.

16. Andersson AM, Skakkebaek NE: Serum inhibin B levels during male childhood and puberty. Mol Cell Endocrinol, 2001; 30, 103-7.

17. Kushnir MM, Blamires T, Rockwood AL, Roberts WL, Yue B, Erdogan E, Bunker AM, Meikle AW: Liquid chromatography-tandem mass spectrometry assay for androstenedione, dehydroepiandrosterone, and testosterone with pediatric and adult reference intervals. Clin Chem, 2010; 56(7), 113847.

18. Atkins M, Burgess A, Bottomley C, Riccio M: Chlorpromazine equivalents: a consensus of opinion for both clinical and research applications. Psychiatric Bulletin 1997; 21: 224-226.

19. Woods SW: Chlorpromazine equivalent doses for the newer atypical antipsychotics. J Clin Psychiatry, 2003; 64:663-7.

20. Calarge CA, Ellingrod VL, Acion L: Variants of the dopamine D2 receptor gene and risperidoneinduced hyperprolactinemia in children and adolescents. Pharmacogenetics and Genomics, 2009;19:373-382.

21. Troost PW, Lahuis BE, Hermans MH: Prolactin release in children treated with risperidone: Impact and role of CYP2D6 metabolism. Journal of Clinical Psychopharmacology, 2007;27:52-57.

22. Croonenberghs J, Grieken van S, Wauters A, West van D, Brouw L, Maes M, Deboutte D: Serum testosterone concentration in male autistic youngsters. Neuroendocrinol Lett, 2010;.31 (4), 483-88.

23. Tordjman S: Plasma androgens in autism. Journal of Autism and Developmental disorders, $1995 ; 25$ (3), 295-304.

24. Dunbar FV, Kusumakar: Growth and sexual maturation during long-term treatment with risperidone. Am J Psychiatry, 2004; 161(5), 918-20.

25. Knickmeyer RC, Wheelwright S, Hoekstra R, Baron-Cohen S: Age of menarche in females with autism spectrum conditions. Dev Med Child Neurol 2006; 48, 1006-1011.

26. Wacharasindhu S, Pri-Ngam P, Kongchonrak T: Self-assessment of sexual maturation in Thai children by Tanner photograph. J Med Assoc Thai, 2002;85(3):308-19.

27. Leone M, Comtois AS: Validity and reliability of self-assessment of sexual maturity in elite adolescent athletes. J Sports Med Phys Fitness,.2007;47(3):361-5.

28. Chan NP, Sung RY, Kong AP, Goggins WB, So HK, Nelson EA: Reliability of pubertal self-assessment in Hong Kong Chinese children. J Paediatr Child Health. 2008;44(6):353-8.

29. Schall JI, Semeao EJ, Stallings VA, Zemel BS: Self-assessment of sexual maturity status in children with Crohn's disease. J Pediatr, 2002;141(2):223-9 


\section{CHAPTER 4}

30. Stephen MD, Bryant WP, Wilson DP: Self-assessment of sexual maturation in children and adolescents with diabetes mellitus. Endocr Pract. 2008;14(7):840-5.

31. Blaicher W, Imhof MH, Gruber DM, Schneeberger C, Sator MO, Huber JC: Focusing on melatonin's interactions. Gynecol Obstet Invest, 1999; 48:179-82.

32. Coker F, Taylor D: Antidepressant-induced hyperprolactinaemia. CNS Drug, 2010; 24:563-574. 


\section{Chapter 5}

\section{Bone mineral density in male adolescents with autism spectrum disorders and disruptive behavior disorder with or without antipsychotic treatment}

Yvette Roke, Peter N. van Harten, Jan K. Buitelaar, Diederik E. Tenback, Lorentz G.B.A. Quekel, Yolanda B. de Rijke, Annemieke M. Boot

Eur J Endocrinol. 2012 Dec;167(6):855-63.

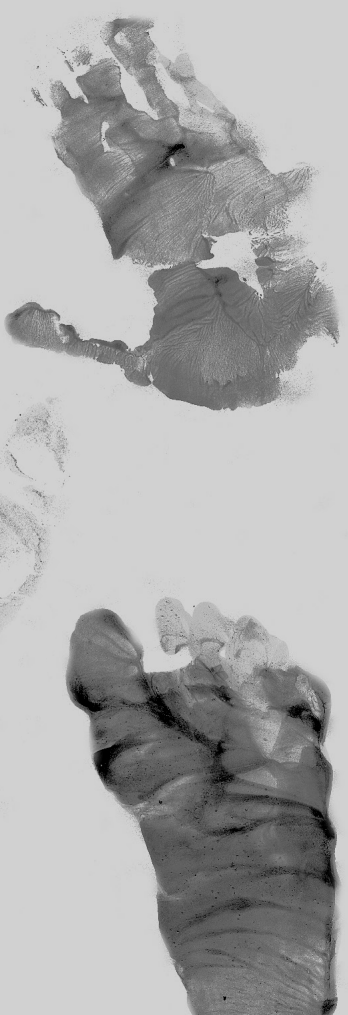




\section{Abstract}

Objective: To investigate the long-term effects of antipsychotic (AP) treatment and AP-induced hyperprolactinemia on bone mineral density (BMD) and body composition in male adolescents with autism spectrum disorders (ASD) and/or disruptive behavior disorder (DBD).

Design: Physically healthy 10-to 20-year-old boys with ASD and/ or DBD, chronically treated ( $\mathrm{N}=56$; mean 52 months, range 16-126 months) or not treated $(\mathrm{N}=47)$ with an AP were recruited to this observational study. Prolactin levels and biochemical bone parameters were measured and BMD of the lumbar spine and total body, and body composition were assessed by dual energy X-ray absorptiometry (DXA), and volumetric BMD of the lumbar spine calculated. Group differences were tested with Student's t-, Chi-square, Fisher exact tests, and logistic regression analysis.

Results: $49 \%$ of the boys treated with an AP had hyperprolactinemia. The mean volumetric lumbar spine BMD z-score was lower ( $\mathrm{p}=0.043)$, the total $\%$ body fat $\mathrm{z}$-score was higher $(\mathrm{p}=0.032)$, and biochemical bone marker carboxyterminal cross-linking telopeptide of bone collagen (CTx) was lower in the AP-treated boys with hyperprolactinemia than in the AP-treated boys without hyperprolactinemia. $7-11 \%$ of the hyperprolactinemic boys had low BMD. The mean lumbar spine and total body BMD z-scores and body composition were similar in the boys who were or were not treated with an AP. The total study population had a lower mean lean tissue mass (mean z-score $-0.37, \mathrm{p}=0.004$ ) and a higher $\%$ total body fat (mean Zscore 1.16, $\mathrm{p}<0.001$ ) than healthy controls (normative data); biochemical bone parameters were within normal limits.

Conclusion: AP-induced hyperprolactinemia in boys with ASD or DBD may have an negative effect on lumbar spine BMD. Longitudinal studies are needed to confirm this finding.

Key words: Hyperprolactinemia, Adolescents, Bone mineral density, Body composition, Antipsychotics 


\section{Introduction}

Children and adolescents with autism spectrum disorders (ASD) are often treated with antipsychotic (AP) medication, mostly second-generation AP because the incidence of extrapyramidal side effects is lower than with first-generation $\mathrm{AP}^{1}$. AP reduce maladaptive behaviors, such as irritability, self-injury, stereotypies, and hyperactivity, in children and adolescents with ASD, and reduce irritability and aggressive behavior in children and adolescents with disruptive behavior disorder $(\mathrm{DBD})^{2}$.

While the Food and Drug Administration (FDA) in the USA has approved risperidone and aripiprazole for the treatment of children and adolescents with irritability associated with $\mathrm{ASD}^{3-5}$, these drugs have not yet been approved for this indication in Europe. AP are also frequently used, off-label, to treat severe aggression in children and adolescents with DBD. Despite their efficacy ${ }^{5}$, there are concerns about metabolic (such as obesity, hyperglycemia, and dyslipidemia) and endocrine (such as hyperprolactinemia) side effects ${ }^{6-8}$. AP such as olanzapine, clozapine, and risperidone can reduce hepatic insulin sensitivity ${ }^{9}$, possibly by reducing serotonin levels in the brain, which causes a reduction in osteocalcin and adiponectin levels and ultimately diminished insulin sensitivity ${ }^{10}$. AP-linked obesity and type 2 diabetes mellitus are more prevalent in children and adolescents than in adults ${ }^{7}$, possibly because of differences in their body composition, e.g. a higher percentage of body fat and less lean body mass. Adolescence is the most important time in terms of attaining peak bone mass ${ }^{11}$, and an increase in lean body mass, mainly muscles, is important for optimal bone mass ${ }^{12}$. Disturbances in this process during puberty may increase the risk of osteoporosis later in life. The AP-induced change in energy metabolism and insulin signaling could lead to a lower bone mineral density $(B M D)^{10}$, which in turn could increase the risk of osteoporosis later in life.

AP-induced hyperprolactinemia could influence bone metabolism in two ways. First, hyperprolactinemia might directly affect bone turnover, by stimulating bone resorption relative to bone formation ${ }^{13,14}$. Secondly, prolonged hyperprolactinemia may cause hypogonadotropic hypogonadism ${ }^{15}$, resulting in suppression of gonadotropin-releasing hormone $(\mathrm{GnRH})$ secretion in the hypothalamus and diminished secretion of luteinizing hormone (LH) and follicle-stimulating hormone (FSH) by the pituitary gland, resulting in a diminished secretion of sex hormones and ultimately in changes in bone metabolism. Patients with psychiatric disorders also have other risk factors for osteopenia, such as smoking, low calcium intake, vitamin D deficiency, and insufficient exercise.

Only one study has investigated the effect of AP-induced hyperprolactinemia on BMD in boys with different diagnoses $(n=83 \text {; mean age } 11.9 \text { years, SD 2.8 })^{16}$. BMD was lower in boys with hyperprolactinemia than in boys without hyperprolactinemia, but comparisons with healthy controls were not made. In adolescents with prolactinomas, in which prolactin levels are at least two to four times higher than in AP-induced hyperprolactinemia, BMD was decreased and was not restored after 2 
years of treatment with dopamine agonists ${ }^{17}$. Several studies of adults have shown AP-induced hypogonadism to be associated with a decreased BMD ${ }^{18-22}$ and two large case-control studies $(44,500$ patients and 16,341 patients) showed AP medication to be associated with a two-fold increased risk of hip or femur fractures ${ }^{23,24}$.

In this study, we investigated the consequences of long-term AP treatment and AP-induced hyperprolactinemia on BMD, biochemical bone parameters, and body composition in boys with ASD and/ or DBD compared with boys with similar disorders never treated with AP.

\section{Subjects and Methods}

\subsection{Subjects}

All participants were recruited from the patient population of the adolescent outpatient clinic of the GGZ Centraal Psychiatric Center, The Netherlands, from October 2006 to November 2009. Eligible participants were aged between 10 and 20 years, diagnosed with a psychiatric disorder, treated with potential prolactin-elevating AP medication continuously for more than 16 months, and had an IQ above 85. All participants ( 56 boys, 6 girls; $80 \%$ of the eligible population) had a diagnosis of ASD or DBD and were treated primarily with risperidone (57 out of 62). Comparison subjects ( 47 boys and 10 girls; $50 \%$ of the eligible population) met the same inclusion criteria except that they had never been treated with AP. The main reason for not participating was fear of venipuncture. None of the participants had a history of chronic diseases affecting puberty, endocrine disorders, thyroid disorders, bone diseases, use of oral corticosteroid or anticonvulsants, or known causes of hyperprolactinemia ${ }^{25}$. The data for the girls (15 in a total study sample of 119) were not analyzed because of the low number of girls. Thus the AP group consisted of 56 boys with ASD or DBD treated with AP and the comparison group consisted of 47 boys with ASD or DBD who had never been treated with AP. Use of other concomitant medication was permitted (Table 1). The first author contacted the parents/ legal guardians and the patients by telephone and letter. The Local Medical Ethics Committee approved the study and written informed consent was obtained from the patient and his parents/ legal guardians after the study procedures had been clearly explained.

\subsection{Methods}

The clinical diagnosis was obtained from the patients' chart. The first author measured the participants' height (without shoes, to the nearest $0.1 \mathrm{~cm}$ using a stadiometer, Seca 206, the Netherlands) and weight (participant wearing underwear, to the nearest $0.1 \mathrm{~kg}$, using an analogue scale, Seca 761, the Netherlands). Age-specific 
height, weight, and body mass index (BMI) z-scores were calculated using normative data for male Dutch children ${ }^{26,27}$. Pubertal stage was established by showing the boys different Tanner stage photographs of the genitals ( $G$ stage) and pubic hair (P stage) and asking them to select the photographs that most accurately reflected their appearance ${ }^{28}$. One of the parents/ legal guardians was present during the selfassessment and confirmed the stages pointed out. The severity of disease was measured using The Clinical Global Impression - Severity scale (CGI-S) ${ }^{29}$. It is a 7point scale that requires the first author to rate the severity of the patient's illness at the time of assessment, relative to the past experience with patients who have the same diagnosis. Considering total clinical experience, a patient is assessed on severity of mental illness at the time of rating 1 , normal, not at all ill; 2 , borderline mentally ill; 3, mildly ill; 4, moderately ill; 5, markedly ill; 6 , severely ill; or 7, extremely ill.

The average calcium intake (mg/day) was determined using the food frequency questionnaire for dairy products ${ }^{30}$. Physical activity was divided into leisure sports, activity at school/work, home activities, and transport (biking or walking) ${ }^{31}$. Each activity was expressed in terms of its ground reaction force (GRF) ${ }^{32,33}$ and then classified into four categories: 0 : GRF $<1$ x body weight e.g., swimming, cycling, 1: GRF between 1 and $2 \mathrm{x}$ body weight, e.g., rowing, dancing, 2: GRF between 2 and $4 \mathrm{x}$ body weight, e.g., running, hockey, soccer, 3: GRF > 4 x body weight, e.g., basketball, volleyball. The GRF score reported is the sum of the GRF scores.

A non-fasting morning blood sample was collected at about 9.30 a.m.; a light breakfast had been eaten at about 7.30. Serum prolactin was measured with an automated chemiluminescence assay system (Immulite 2000, Siemens Healthcare Diagnostics) calibrated on the 3rd IS 84/500. As macroprolactin, a complex of prolactin and IgG without biological activity, is responsible for $10 \%$ of cases of hyperprolactinemia ${ }^{34}$, seven samples with prolactin concentrations higher than 37 $\mathrm{ng} / \mathrm{mL}$ were assessed for the presence of macroprolactin. Polyethylene glycol 6000, $200 \mu \mathrm{L},(25 \% \mathrm{w} / \mathrm{w})$ was added to $200 \mu \mathrm{L}$ of serum and, after thorough vortex mixing, the mixture was centrifuged at $2200 \mathrm{~g}$ for $30 \mathrm{~min}$ at $4{ }^{\circ} \mathrm{C}$. Subsequently, prolactin was measured in the supernatant and the untreated serum. The recovery of prolactin after precipitation with polyethylene glycol 6000 was $101.4 \pm 9.6 \%$ (SD), which excluded the presence of macroprolactin. TSH was measured by means of a Vitros Eci system (Ortho Diagnostics) to exclude children or adolescents with hyperprolactinemia due to thyroid disorders. Hyperprolactinemia was defined as a prolactin level above the 97.5th percentile based on normative data for age and $\operatorname{sex}^{35}$.

Various biochemical bone parameters were measured. Type 1 amino-terminal propeptide of procollagen (P1NP) and bone-specific alkaline phosphatase (BAP) were measured as markers of bone formation and carboxyterminal cross-linking telopeptide of bone collagen (CTx) as marker of bone resorption. Calcium was measured with the Modular E170 (Roche Diagnostics, Mannheim, Germany) and BAP was measured by an immunoenzymetric assay using the Ostase BAP kit (IDS, 
Frankfurt am Main, Germany) with an inter-assay coefficient of variation (CV) of $<7.5 \%$. 25-Hydroxyvitamin $\mathrm{D}_{3}$ was assessed by radioimmunoassay (DiaSorin Inc, USA) with intra-assay and inter-assay CVs of $<7 \%$ and $<12 \%$, respectively. P1NP was also measured by radioimmunoassay (Orion Diagnostica Oy, Espoo, Finland) with intra-assay and inter-assay CVs of $13.7 \%$ and $<6.4 \%$, respectively. CTx was measured in serum by sandwich electrochemiluminescence immunoassay (Roche Diagnostics, Mannheim,Germany); the inter-assay CV was 1\%. P1NP, BAP and CTx, were compared to literature reference values for age and $\operatorname{sex}^{37,37}$. 25hydroxyvitamin $\mathrm{D}_{3}$ levels below $30 \mathrm{nmol} / \mathrm{L}$ were considered deficient and below 50 nmol/L as insufficient ${ }^{38}$.

Bone mineral density (BMD, g/cm2) of the lumbar spine and total body was measured by dual energy X-ray absorptiometry (DXA, Lunar Prodigy). The reported $\mathrm{CV}$ is $1.0 \%$ for lumbar spine BMD and $0.73 \%$ for total body BMD ${ }^{39}$. Quality assurance was performed daily. Ancillary DXA-derived data were used to calculate lumbar spine volumetric BMD, to adjust for bone size, bone mineral apparent density (BMAD), with the model BMAD=BMD $x\left(4 /(\pi \times \text { width })^{36,40,41}\right.$.

Body composition was measured as bone mineral content (BMC), lean tissue mass (lean, in grams), and fat mass (DXA, Lunar Prodigy), and total \% body fat was determined. The coefficient of variation for these measurements is reported as 1.29 $\%$ for lean tissue mass, $2.59 \%$ for fat mass, and $0.74 \%$ for $\mathrm{BMC}^{39}$. In the analysis, lean body mass and total \% body fat were used. The results were compared to ageand sex-matched Dutch reference values ${ }^{36,41}$ and expressed as z-scores.

Plasma levels of risperidone, 9-hydroxyrisperidone, and pimozide were measured to evaluate compliance.

\subsection{Data analysis}

One sample t-tests were used to compare the mean z-scores of the boys with age matched normative data. To test for differences between the two study groups, Student's t-test, Chi-square, Mann-Whitney tests, or Fisher exact test was applied according to the type and distribution of the data. Dose equivalence was assumed between pimozide $(\mathrm{N}=3)$ and risperidone $(\mathrm{N}=53)^{42,43}$.

Multiple linear regression was used to investigate whether BMD, body composition, and biochemical bone parameters were different between the two groups, with adjustment for BMI z-score, average daily calcium intake, and serum 25hydroxyvitamin $\mathrm{D}_{3}$ level. Low BMD was defined as a $\mathrm{z}$-score $\leq-2^{44}$. Pearson's correlation coefficient was calculated to investigate the relationship between prolactin levels and the biochemical bone markers. Hyperprolactinemia and inactivity are both associated with weight gain, and therefore we also investigated the relationship between prolactin and GRF score and the total \% body fat z-score. 


\section{Results}

The baseline characteristics of the participants are presented in Table 1. There was no significant difference in mean age, Tanner stage, height z-score, BMI z-score, GRF-score, or diagnosis between the boys who were or were not treated with AP. The AP treated boys had a higher disease severity score in comparison to the boys without AP treatment (respectively 4.7 for the AP treated boys versus 4.0 for the boys without AP treatment; $\mathrm{p}=0.003$ ). Of the boys treated with AP, 53 were treated with risperidone at a mean dose of $1.6 \mathrm{mg} /$ day (SD 0.8, range 0.5-4) with mean treatment duration of 51.4 months (SD 28, range 16-126), and 3 were treated with pimozide at a mean dose of $1.7 \mathrm{mg} /$ day. Two-thirds of the AP-treated boys (37 out of 56) had used their AP medication for more than 3 years. The mean prolactin level in AP-treated boys was $18.9 \mathrm{ng} / \mathrm{mL}$ (SD 16, range 2.4-92.5): it was $28.08 \mathrm{ng} / \mathrm{mL}$ (SD 19.1 , range $14.6,92.5$ ) in the 27 boys with hyperprolactinemia and $10.38 \mathrm{ng} / \mathrm{mL}$ (SD 4.0, 2.4, 17) in the 29 boys without hyperprolactinemia. Four out of the 27 (15\%) hyperprolactinemic boys had possible prolactin related sexual functioning disorders. The mean serum prolactin level was $8.0 \mathrm{ng} / \mathrm{mL}$ (SD 2.8, range 3.8-15.1) in the boys not treated with AP. The calcium intake was significantly lower in the AP-non-treated boys than in the AP-treated boys, but the later had a significantly lower 25-hydroxyvitamin $\mathrm{D}_{3}$ level $(\mathrm{p}=0.017)$. 25-Hydroxyvitamin $\mathrm{D}_{3}$ levels were deficient in 8 (14\%) of the AP treated boys and insufficient in 17 (30\%). Of the 47 boys not treated with AP, 5 (11\%) and $6(13 \%)$ had deficient and insufficient 25hydroxyvitamin $\mathrm{D}_{3}$ levels, respectively. Ten AP-treated boys $(18 \%)$ reported a history of a fracture compared with 12 boys not treated with AP (26\%). 
Table 1. Characteristics of adolescents with autism spectrum disorders who were (cases, N=56) or who were not (comparison subjects, $\mathrm{N}=47$ ) treated with antipsychotics

\begin{tabular}{|c|c|c|c|}
\hline & $\begin{array}{l}\text { Cases } \\
(\mathrm{N}=56)\end{array}$ & $\begin{array}{l}\text { Comparison subjects } \\
(\mathrm{N}=47)\end{array}$ & $P$ value \\
\hline & Mean (SD; range) & Mean (SD; range) & \\
\hline Age, years & $14.8(2.2 ; 10,19)$ & $15.0(1.6 ; 12,18)$ & $0.50^{\#}$ \\
\hline Height z-score $(\mathrm{cm})$ & $0.43(1.1 ;-2.4,2.12)$ & $0.36(0.94 ;-1.5,2.9)$ & $0.37 \#$ \\
\hline BMI z-score & $0.25(1 ;-1.8,2.8)$ & $-0.08(1.2 ;-3.3,2.3)$ & $0.15^{\#}$ \\
\hline Tanner stage, N I/II/III/IV/V & $0 / 8 / 16 / 22 / 10$ & $0 / 9 / 13 / 19 / 6$ & \\
\hline Caucasian ethnicity, N (\%) & $55(98)$ & $46(96)$ & $0.54^{\wedge}$ \\
\hline \multicolumn{4}{|l|}{ Primary diagnosis, $N(\%)$ : } \\
\hline $\mathrm{ASD}^{*}$ & $52(93)$ & $40(85)$ & $0.17^{\wedge}$ \\
\hline DBD* & $4(7)$ & 7 (15) & \\
\hline CGI-S & $4.7(1 ; 1-7)$ & $4.0(0.6 ; 3-6)$ & $0.003^{\#}$ \\
\hline Antipsychotic dose (mg/day) & $1.6(0.8 ; 0.5,4$ & & \\
\hline Duration of use (months) & $51.4(28 ; 16-126)$ & & \\
\hline \multicolumn{4}{|l|}{ Concomitant medication, $N(\%)$ : } \\
\hline Melatonin & $5(9)$ & $4(9)$ & \\
\hline SSRI & $2(4)$ & 0 & \\
\hline Psychostimulants & $10(18)$ & $13(28)$ & \\
\hline Atomoxetine & $2(4)$ & 0 & \\
\hline Calcium intake (mg/day) & $1314(725 ; 268,4164)$ & $992(564 ; 5-2958)$ & 0.008@ \\
\hline $\mathrm{GRF}^{*}$ & $18(7 ; 3,40)$ & $19(6 ; 10,34)$ & $0.25^{@}$ \\
\hline History of fracture(s), N (\%)* & $10(18)$ & $12(26)$ & $0.34^{\wedge}$ \\
\hline 25-hydroxyvitamin D (nmol/L) & $55.3(22 ; 14,107)$ & $66.4(23 ; 14,120)$ & $0.017 \#$ \\
\hline Deficient, N (\%) & $8(14)$ & $5(11)$ & 0.77 \\
\hline Insufficient, N (\%) & $24(43)$ & $13(28)$ & 0.15 \\
\hline
\end{tabular}

*ASD = autism spectrum disorders; $\mathrm{DBD}=$ disruptive behavior disorder; GRF=ground reaction force; SSRI=selective serotonin re-uptake inhibitor; CGI-S=The Clinical Global Impression - Severity scale (CGI$\mathrm{S})$; History of fracture $(\mathrm{s})=$ number of patients that ever had one or more fractures from birth until now; \# Independent sample Student's t-test; ^ Chi square; @ Mann-Whitney 
Table 2. Bone mineral density, body composition, and biochemical parameters of adolescent boys with autism spectrum disorders who were treated $(\mathrm{N}=56)$ or not treated $(\mathrm{N}=47)$ with antipsychotics

\begin{tabular}{|c|c|c|c|c|c|}
\hline & \multicolumn{2}{|c|}{$\begin{array}{l}\text { Treated with antipsychotics } \\
(\mathrm{N}=56)\end{array}$} & \multicolumn{3}{|c|}{$\begin{array}{l}\text { Not treated with antipsychotics } \\
(\mathrm{N}=47)\end{array}$} \\
\hline & $\begin{array}{l}\text { With } \\
\text { Hyperprolactinemia } \\
\mathrm{N}=27\end{array}$ & $\begin{array}{l}\text { Without } \\
\text { hyperprolactinemia } \\
\mathrm{N}=29\end{array}$ & & & \\
\hline & Mean (SD, range) & Mean (SD, range) & $\mathrm{P}$ value $^{1}$ & Mean (SD, range) & Pvalue $^{2}$ \\
\hline Lean tissue mass z-score & $-0.29(1.3 ;-2.24,2.31)$ & $-0.13(1.1 ;-1.92,2.75)$ & $0.69^{\$}$ & $-0.57(1.4 ;-0.87,0.15)$ & $0.67^{\$}$ \\
\hline$\%$ body fat z-score & $1.40(0.71 ;-0.26,2.95)$ & $1.10(0.83 ;-0.53,2.57)$ & $0.032^{\$}$ & $1.06(0.90 ;-0.73,2.74)$ & $0.81^{\$}$ \\
\hline Lumbar spine BMD z-score & $-0.18(1.0 ;-2.36,1.69)$ & $0.15(0.78 ;-1.46,1.51)$ & $0.15^{\$}$ & $-0.026(1.17 ;-0.46,0.35)$ & $0.74^{\$}$ \\
\hline Total body BMD z-score & $0.038(1.16 ;-2.1,2.84)$ & $0.083(0.81 ;-1.24,2.24)$ & $0.79 \$$ & $-0.20(1.11 ;-0.67,0.14)$ & $0.80^{\$}$ \\
\hline $\begin{array}{l}\text { Lumbar spine BMAD z- } \\
\text { score }\end{array}$ & $-0.32(0.80 ;-2.49,0.75)$ & $0.12(0.77 ;-1.4,1.35)$ & $0.043^{\$}$ & $-0.12(0.04 ;-0.36,0.30)$ & $0.33^{\$}$ \\
\hline $\mathrm{P} 1 \mathrm{NP} \mu \mathrm{g} / \mathrm{L}$ & $462(286 ; 67,1033)$ & $589(313 ; 143,1111)$ & $0.060^{\$}$ & $546.19(338.9 ; 61,1586)$ & $0.48^{\$}$ \\
\hline $\mathrm{BAP} \mu \mathrm{g} / \mathrm{L}$ & $82.5(52.1 ; 10.7,173)$ & $98.4(60.3 ; 16,257)$ & $0.16^{\$}$ & $78.40(51.4 ; 14.3,241)$ & $0.062^{\$}$ \\
\hline CTx $\mu \mathrm{g} / \mathrm{L}$ & $0.80(0.40 ; 0.23,1.51)$ & $0.99(0.39 ; 0.31,1.95)$ & $0.042^{\$}$ & $1.11(0.52 ; 0.32,3.22)$ & $0.19^{\$}$ \\
\hline
\end{tabular}

* Students T-test; $\mathrm{BMD}=$ bone mineral density; $\mathrm{BMAD}=$ bone mineral apparent density; $\mathrm{P} 1 \mathrm{NP}=$ type 1 amino-terminal propeptide of procollagen; $\mathrm{CTX}=$ carboxyterminal cross-linking telopeptide of bone collagen; $\mathrm{BAP}=$ bone-specific alkaline phosphatase; \$ Linear regression analysis corrected for BMI Zscore, 25-hydroxyvitamin $\mathrm{D}$, and average calcium daily intake; $\mathrm{P}$ value ${ }^{1}$ Compares boys treated with antipsychotics with and without hyperprolactinemia; $\mathrm{P}$ value ${ }^{2}$ Compares boys treated with antipsychotics with boys not treated with antipsychotics

\section{Bone mass and body composition}

The mean z-scores of the lumbar spine, total body BMD, and the lumbar spine BMAD, (volumetric BMD), for all boys $(\mathrm{N}=103)$ were not significantly different from zero. The mean height $\mathrm{z}$-score $(0.39, \mathrm{p}<0.001)$ and total $\%$ body fat $\mathrm{z}$-score $(1.16$, $\mathrm{p}<0.001)$ were significantly higher than normal and the mean lean tissue mass $\mathrm{z}-$ score $(-0.37, \mathrm{p}<0.004)$ was significantly lower than normal.

Table 2 shows the differences between AP-treated boys with $(\mathrm{N}=27)$ and without $(\mathrm{N}=29)$ hyperprolactinemia and the differences between the boys who were or were not treated with AP. There were no significant differences in z-scores of the lumbar spine and total body BMD, lumbar spine BMAD, lean tissue mass, and total $\%$ body fat between the boys who were or were not treated with AP. Within the group AP-treated boys, the boys with AP-induced hyperprolactinemia had a lower BMAD z-score $(\mathrm{p}=0.043)$ and a higher total $\%$ body fat $\mathrm{z}$-score $(\mathrm{p}=0.032)$ than did the AP-treated boys without hyperprolactinemia; there were no significant differences in mean z-scores of lumbar spine and total body BMD and lean tissue mass between the two groups of AP-treated boys. The BMD and body composition of the hyperprolactinemic boys with prolactin related side effects (4 out of 27) was not significantly different from the hyperprolactinemic boys without clinical prolactin related signs. 
Low lumbar spine BMAD (defined as a z-score of $\leq-2$ ) was present in 2 out of the 27 (7.4\%) hyperprolactinemic AP treated boys and in none of the boys with AP treatment without hyperprolactinemia and in none without AP treatment. The two boys with hyperprolactinemia and low BMD had no prolactin-related side effects, such as erectile dysfuction, gynecomastia, or loss of libido. Low lumbar spine BMD was present in 3 out of 27 (11.1\%) hyperprolactinemic AP treated boys, of which one of these boys had a possible prolactin related side effect; he reported a loss of libido and problems in the ability to have an orgasm, and low lumbar spine BMD was present in 1 out of 47 (2.1\%) boys without AP treatment and in none of the boys with AP treatment without hyperprolactinemia.

Prolactin levels were positively associated with the mean total \% body fat zscore $(\mathrm{r}=0.188, \mathrm{p}=0.06)$, and the mean total \% body fat $\mathrm{z}$-score was negatively associated with the GRF score ( $r=-0.312, \mathrm{p}=0.001)$.

\section{Biochemical bone parameters}

Table 3 shows that the levels of markers of bone resorption (CTx) and formation (BAP, P1NP) were not significantly different between the boys who were or were not treated with AP and were also normal compared to normative data ${ }^{36,37}$. The APtreated boys with hyperprolactinemia had significantly lower CTx levels $(p=0.042)$ than the AP-treated boys without hyperprolactinemia. P1NP levels showed a trend towards being lower in the AP-treated boys compared to those without AP treatment $(p=0.06)$. BAP levels were not different between the two groups $(p=0.16)$. Prolactin levels were negatively correlated with CTx $(r=-0.20, p=0.048)$ and showed a trend towards negative correlation with P1NP levels $(r=-0.17, p=0.095)$. BAP was not associated with prolactin levels $(r=-0.05, p=0.60)$.

\section{Discussion}

\subsection{Bone strength and autism spectrum disorders}

There are two previous studies investigating the effect of ASD or infantile autism on bone strength. These studies investigated the strength in two different ways; one study looked at the outcome measurement of bone strength expressed as fracture prevalence, and the other study investigated the bone cortical thickness. The fracture prevalence rate appeared to be lower for the autistic group, $12 \%$ for the patients with infantile autism versus $25 \%$ for the comparison group, (follow up for 30 years, $\mathrm{N}=118$ ) (Mouridsen 2012). Our study showed a fracture prevalence rate of about 20\% (19\% for the ASD boys with hyperprolactinemia versus $21 \%$ for the ASD boys without hyperprolactinemia), which was also low, compared to the normative data fracture rate of $36 \%$ (Boot 2010). One explanation could be that boys 
with ASD have less organized outdoor sports activities, and their preferred leisure activities often involve an indoor setting, which would protect them from sustaining fractures ${ }^{49}$.

However, when investigating the bone cortical thickness the children with ASD (mean age 7 years, $\mathrm{N}=75$ ) had reduced bone cortical thickness when compared with normative data. Our study showed no difference in areal and volumetric BMD for the ASD or DBD boys compared to normative data.

We found, as expected, lean tissue mass to be lower and the percentage of mean total body fat to be higher in our total study population than in healthy controls, which may be due to disease-specific differences in lifestyle. As mentioned above, children or adolescents with ASD do not commonly participate in organized outdoor sports, preferring indoor leisure activities ${ }^{49}$. The GRF score, a parameter of physical activity, was negatively associated with fat percentage. Lean tissue mass, which is mainly muscle mass, is highly related to bone mass in children and is important for the attainment of peak bone mass ${ }^{49}$. It is reassuring from a clinical perspective that the psychiatric condition of ASD or infantile autism does not seem to lead to a higher fracture prevalence rate and that at older age the boys did not have a lower BMD compared to normative data.

\subsection{Hyperprolactinemia and biochemical bone markers}

Our study is the first to investigate bone markers in boys with hyperprolactinemia. The levels of bone resorption marker CTx were significantly lower and levels of bone formation marker P1NP tended to be lower in AP-treated boys with hyperprolactinemia than in AP-treated boys without hyperprolactinemia. This suggests that hyperprolactinemia may inhibit bone turnover, possibly by a direct negative effect on osteoblasts, or by a secondary effect through hyperprolactinemia-induced hypogonadotropic hypogonadism. We have reported before that the boys with hyperprolactinemia had significantly lower testosterone levels ${ }^{47}$, which may have resulted in a decrease in bone turnover.

Further research in this area is needed since bone turnover markers reflect the dynamic aspect of bone metabolism, and longitudinal data are needed to investigate the changes over time.

\subsection{Hyperprolactinemia and body composition}

The AP-treated boys with hyperprolactinemia had higher total \% body fat z-scores than did the AP-treated boys without hyperprolactinemia, which may be a risk factor for future fractures in children and adolescents (Goulding 2005). Prolactin levels were positively associated with the total \% body fat z-scores. As the APtreated boys were earlier found to have low, but still within the normal range, testosterone levels (Roke et al 2012), the lower testosterone levels could explain in part the higher percentage of body fat in relation to the lean tissue mass in these 
boys because testosterone is an important mediator of gain in muscle mass in adolescence ${ }^{50}$. Relatively less physical exercise could also be an explanation for the higher body fat content of the AP-treated boys.

\subsection{5-hydroxyvitamin $\mathrm{D}_{3}$}

25-hydroxyvitamin $\mathrm{D}_{3}$ is a determinant of peak bone BMD in children and adolescents. Thirteen of the 113 boys $(13 \%)$ had deficient levels of 25 -hydroxyvitamin $\mathrm{D}_{3}$ and 37 (36\%) insufficient levels, these are higher proportions than reported for Dutch young adult males without psychiatric disorders (4\% and 22\%, respectively) ${ }^{51}$. This difference in 25-hydroxyvitamin $\mathrm{D}_{3}$ levels could be due to the disease-specific dietary restrictions and/ or food selectivity52, a lack of exposure to sunlight, given the preferred indoors activities of our ASD population, or seasonal variance $^{49}$.

\subsection{Hyperprolactinemia and bone mineral density}

In adults with AP-induced hyperprolactinemia the effect on bone mineral density and prevalence of fractures has been studied. Patients treated with these AP have a two-fold risk in gaining an upper leg or hip fracture (Howard 2007, Hugentholtz 2007). The patients with schizophrenia treated with AP-inducing hyperprolactinemia have significant diminished areal BMD compared to patients without hyperprolactinemia (Kishimoto 2008, Misra 2004). However, there are conflicting results showing that the negative symptoms and lifestyle differences in schizophrenia may be the cause of the diminished BMD in addition to lifestyle differences instead of the hyperprolactinemia (e.g. less exercise, nutritional alterations, smoking) (Sugawara 2011). In male children and adolescents with various psychiatric conditions the effect of AP-induced hyperprolacinemia was investigated in one previous study. This study ( $\mathrm{N}=83$, mean age 12 years) reported a reduced BMD in the hyperprolactinemic boys, with boys with and without hyperprolactinemia having the same 25hydroxyvitamin $\mathrm{D}_{3}$ levels and daily calcium intake; comparisons with healthy controls were not made (Calarge 2010). Our study replicated this finding showing a diminished volumetric BMD of the lumbar spine for the group of boys with hyperprolactinemia compared to the boys with AP treatment and without hyperprolactinemia. The volumetric BMD of the lumbar spine is a good predictor of future fractures (especially wrist and forearm fractures) ${ }^{45,46}$, and therefore our findings suggest that AP-induced hyperprolactinemia may have a negative influence on BMD, especially of trabecular bone, such as of the lumbar vertebrae. Low BMD was present in respectively 7\% (volumetric lumbar spine BMD) and 11\% (areal lumbar spine BMD) of the AP treated hyperprolactinemic boys. Just one of these boys had possible clinical prolactin related signs of hypogonadism; thus clinicians should be aware that hyperprolactinemia may be associated with low BMD without alarming signs. However, both our study as the Calarge study had a cross-sectional design; 
therefore it is not possible to draw any final conclusions about these results. Welldesigned prospective studies are needed to assess the relative contributions of hyperprolactinemia, hypogonadotropic hypogonadism, the psychiatric condition, nutritional alterations and other lifestyle changes on BMD and it's clinical consequences.

\subsection{Limitations}

This study had some limitations that should be taken into account when interpreting the results and which should be addressed in future studies. Since the study was observational and cross-sectional, we cannot establish causality and the power of the study was limited because of the relatively small sample size. Peak bone mass is usually attained between 18 and 23 years ${ }^{49}$, and as our study participants were about 15 years old, bone growth, modeling, and remodeling were all active, which makes it difficult to evaluate bone metabolism at one time point. Another potential limitation was the choice to measure BMD using DXA, instead of the more sensitive peripheral quantitative computed tomography (pQCT). Although DXA is the clinical standard, trabecular bone, which is more vulnerable than cortical bone to hormonal abnormalities, such as hyperprolactinemia ${ }^{53}$, cannot be distinguished from cortical bone by DXA, and thus early effects of hyperprolactinemia on BMD might have been missed $^{54}$. Even so, we did find significant differences in the lumbar spine BMAD, measured by DXA, between the AP-treated boys with or without hyperprolactinemia.

We further measured bone turnover markers, which reflect the dynamic aspect of bone metabolism, however, bone markers of bone turnover are difficult to interpret, especially in children and adolescents since they reflect both growth and bone modeling and remodeling. Longitudinal data are needed to investigate the changes over time and to establish a clinical important difference in these markers due to AP-induced hyperprolactinemia.

The boys with AP were more severely ill than the boys without AP, and we cannot exclude that severity of the illness had a negative effect on BMD. We could hypothesize that more severely ill patients had specific dietary restrictions and/ or food selectivity and less physical exercise and this could have had a negative influence on their BMD. Another potential limitation is that the boys were allowed to use concomitant prolactin-elevating medication, such as melatonin and selective serotonin re-uptake inhibitors, which could have influenced the prolactin levels and BMD16. However, use of these medications was similar in both groups and probably did not confound our results. Moreover, the prolactin-elevating effect of this concomitant medication is considered to be relatively minor compared with that of the AP used 55 . 


\subsection{Conclusion}

This study suggest that AP-induced hyperprolactinemia in boys with ASD may have a negative influence on BMD. Further research including longitudinal studies is needed to disentangle the effects of psychiatric conditions (ASD or DBD) and the effects of AP treatment and hyperprolactinemia. The physician should evaluate the history of fractures, calcium intake, sun exposure and exercise in boys with hyperprolactinemia due to AP treatment. Assessment of serum 25-hydroxyvitamin $\mathrm{D}_{3}$ and BMD measurement should be considered. If AP-induced hyperprolactinemia occurs, the AP should be reduced if this is clinically feasible. Prolactin levels should normalize within days dependent on the half-life (T1/2) of the drug56. If this is not effective a switch to an AP without prolactin-elevating qualities may be useful 57,58 .

\section{References}

1. McDougle C, Stigler K, Erickson C \& Posey D. Atypical antipsychotics in children and adolescents with autistic and other pervasive developmental disorders. J Clin Psychiatry 2008 69 15-20.

2. Aman M, McDougle C, Scahill L, Handen B, Arnold L, Johnson C, Stigler K, Bearss K, Butter E, Swiezy N, Sukhodolsky D, Ramadan Y, Pozdol S, Nikolov R, Lecavalier L, Kohn A, Koenig K, Hollway J, Korzekwa P, Gavaletz A, Mulick J, Hall K, Dziura J, Ritz L, Trollinger S, Yu S, Vitiello B \&Wagner A. Medication and Parent Training in Children With Pervasive Developmental Disorders and Serious Behavior Problems: Results From a Randomized Clinical Trial. J Am Acad Child Adolesc Psychiatry 2009 48 1143-54.

3. Research Units on Pediatric Psychopharmacology Autism Network. Risperidone in children with autism and serious behavioral problems. New Eng. J Med 2002347 314-321.

4. Blankenship K, Erickson C, Stigler K, Posey DJ \& McDougle CJ. Aripiprazole for irritability associated with autistic disorder in children and adolescents aged 6-17 years. Ped Health 20104 375-381.

5. Wink L, Erickson C \& McDougle C. Pharmacologic treatment of behavioral symptoms associated with autism and other pervasive developmental disorders. Curr Treat Opt Neurol 201012 529-38.

6. Newcomer J. Second-generation (atypical) antipsychotics and metabolic effects: a comprehensive literature review. CNS Drug 2005 19:1-93.

7. Correll C, Manu P, Olshanskiy V, Napolitano B, Kane J \& Malhotra A. Cardiometabolic risk of secondgeneration antipsychotic medications during first-time use in children and adolescents. JAMA 2009 $212302-22$.

8. Roke Y, Van Harten P, Boot A \& Buitelaar J. Antipsychotic medication in children and adolescents: A descriptive review of the effects on prolactin level and associated side effects.J Child Adolesc Psychopharmacol 200919 403-14.

9. Houseknecht K, Robertson A, Zavadoski W, Gibbs E, Johnson D \& Rollema H. Acute effects of atypical antipsychotics on whole-body insulin resistance in rats: implications for adverse metabolic effects. Neuropsychopharmacology 200732 289-97.

10. Schwetz V, Pieber T \& Obermayer-Pietsch B. Mechanisms in endocrinology: The endocrine role of the skeleton: background and clinical evidence. Eur J Endocrinol 2012166 959-967

11. Davies J, Evans B \& Gregory J. Bone mass acquisition in healthy children. Arch Dis Child 200590 373-8.

12. Taes Y, Lapauw B, Vanbillemont G, Bogaert V, De Bacquer D, Zmierczak H \& Goemaere S. Fat Mass Is Negatively Associated with Cortical Bone Size in Young Healthy Male Siblings. J Clin Endocrinol Metab 200994 2325-31. 
13. Seriwatanachai D, Thongchote K, Charoenphandhu N, Pandaranandaka J, Tudpor K, Teerapornpuntakit J, Suthiphongchai T\& Krishnamra N. Prolactin directly enhances bone turnover by raising osteoblast-expressed receptor activator of nuclear factor kappaB ligand/osteoprotegerin ratio. Bone 200842 535-46.

14. Motyl K, Dick-de-Paula I, Maloney A, Lotinun S, Bornstein S, de Paula F, Baron R, Houseknecht K \& Rosen C. Trabecular bone loss after administration of the second-generation antipsychotic risperidone is independent of weight gain. Bone 201250 490-8.

15. Graham S, Howgate D, Anderson W, Howes C, Heliotis M, Mantalaris A, Tsiridis E \& Tsapakis E. Risk of osteoporosis and fracture incidence in patients on antipsychotic medication. Expert Opin Drug Saf $201110575-602$.

16. Calarge C, Zimmerman B, Xie D, Kuperman S \& Schlechte J. A cross-sectional evaluation of the effect of risperidone and selective serotonine reuptake inhibitors on bone mineral density in boys. J Clin Psychiatry $20101338-347$.

17. Colao A, Di Somma C, Loche S, Di Sarno A, Klain M \& Pivonello R. Prolactinomas in adolescents: persistent bone loss after 2 years of prolactin normalization. Clin Endocrinol 200052 319-27.

18. Abraham G, Halbreich U, Friedman R \& Josiassen R. Bone mineral density and prolactin associations in patients with chronic schizophrenia. Schizophr Res 2003 59 17-8.

19. Abraham G, Paing W, Kaminski J, Joseph A, Kohegyi E \& Josiassen R. Effects of elevated serum prolactin on bone mineral density and bone metabolism in female patients with schizophrenia: a prospective study. Am J Psychiatry 2003160 1618-20.

20. Meaney A, Smith S, Howes O, O'Brien M, Murray R, O'Keane V. Effects of long-term prolactin-raising antipsychotic medication on bone mineral density in patients with schizophrenia. Br J Psychiatry 2004184 503-8.

21. O'Keane V \& Meaney A. Antipsychotic drugs: a new risk factor for osteoporosis in young women with schizophrenia? J Clin Psychopharmacol 200525 26-31.

22. Becker A \& Epperson C. Female puberty: clinical implications for the use of prolactin-modulating psychotropics. Child Adolesc Psychiatr Clin N Am 2008 15: 207-20.

23 Hugenholtz G. Antipsychotic in daily clinical practice: patterns, choices and consequences. Universiteit Utrecht. Utrecht, Utrecht 2005.

24. Howard L, Kirkwood G \& Leese M. Risk of hip fracture in patients with a history of schizophrenia. Br J Psychiatry 2007190 129-34.

25. Verhelst J \& Abs R. Hyperprolactinemia: pathophysiology and management. Treat Endocrinol 20032 23-32.

26. Fredriks A1, van Buuren S, Burgmeijer R, Meulmeester J, Beuker R, Brugman E, Roede M, VerlooveVanhorick S \& Wit J. Continuing positive secular growth change in The Netherlands 1955-1997. Pediatr. Res 200047 316-23.

27. Fredriks A2, van Buuren S, Wit J \& Verloove-Vanhorick S. Body index measurements in 1996-7 compared with 1980. Arch Dis Child 200082 107-12.

28. Duke P, Litt I \& Gross R. Adolescents'self-assesment of sexual maturation. Pediatrics 198066918 20.

29. Guy W. ECDEU Assessment Manual for Psychopharmacology. Rockville, MD: U.S. Department of Health, Education, and Welfare; 1976.

30. Angus R, Sambrook P \& Pocock N. A simple method for assessing calcium intake in Caucasian women. J Am Diet Assoc 198989 209-214.

31. Greendale G, Huang M, Wang Y, Finkelstein J, Danielson M \& Sternfeld B. Sport and home physical activity are independently associated with bone density. Med Sci Sports Exerc 200335 506-512, 2003.

32. Kemper H, Twisk J \& van Mechelen W. A fifteen-year longitudinal study in young adults on the relation of physical activity and fitness with the development of the bone mass: The Amsterdam Growth And Health Longitudinal Study. Bone 200027 847-853.

33. Bakker I, Twisk J, van Mechelen W, Roos J \& Kemper H. Ten-year longitudinal relationship between physical activity and lumbar bone mass in (young) adults. J Bone Miner Res 200318 325-332. 
34. Amadori P, Dilberis C, \& Marcolla A. All the studies on hyperprolactinemia should not forget to consider the possible presence of macroprolactinemia. Eur J Endocrinol 2004150 93-94.

35. Emlinger M, Kühnel W \& Ranke M. Reference ranges for serum concentrations of Lutotropin (LH), Follitropin (FSH), Estradiol (E2), Prolactin, Progesterone, Sex Hormone Binding Globuline (SHBG), Dehydroepiandrosterone sulfate (DHEAS), Cortisol and Ferritin in neonates, children and young adults. Clin Chem Lab Med 200240 1151-1160.

36. Van der Sluis I, de Ridder M, Boot A, Krenning E \& de Muinck Keizer-Schrama S. Reference data for bone density and body composition measured with dual energy x ray absorptiometry in white children and young adults. Arch Dis Child 200287 341-7.

37. Rauchenzauner M, Schmid A, Heinz-Erian P, Kapelari K, Falkensammer G, Griesmacher A, Finkenstedt G \& Högler W. Sex- and age-specific reference curves for serum markers of bone turnover in healthy children from 2 months to 18 years. J Clin Endocrinol Metab 200792 443-9.

38. Allgrove J \& Shaw N. Calcium and Bone Disorders in Children and Adolescents. Karger Basel 2009.

39. Margulies L, Horlick M, Thornton J, Wang J, Ioannidou E \& Heymsfield S. Reproducibility of pediatric whole body bone and body composition measures by dual-energy X-ray absorptiometry using the GE Lunar Prodigy. J Clin Densitom 20058 298-304.

40. Kröger H, Kotaniemi A, Vainio P, Alhava E. Bone densitometry of the spine and femur in children by dual-energy x-ray absorptiometry. Bone Miner 199217 75-85.

40. Boot A, Bouquet J, de Ridder M, Krenning E \& de Muinck Keizer-Schrama S. Determinants of body composition measured by dual-energy X-ray absorptiometry in Dutch children and adolescents. Am J Clin Nutr 199766 232-8.

42. Atkins M, Burgess A, Bottomley C \& Riccio M. Chlorpromazine equivalents: a consensus of opinion for both clinical and research applications. Psychiatric Bulletin 199721 224-226.

43. Woods S. Chlorpromazine equivalent doses for the newer atypical antipsychotics. J Clin Psychiatry 200364 663-7.

44. Lewiecki EM, Gordon CM, Baim S, Leonard MB, Bishop NJ, Bianchi M, Kalkwarf HJ, Langman CB, Plotkin H, Rauch F, Zemel BS, Binkley N, Bilezikian JP, Kendler DL, Hans DB \& Silverman S.International Society for Clinical Densitometry 2007 Adult and Pediatric Official Positions. Bone $2008431115-1121$.

45. Boot A, de Ridder M, van der Sluis I, van Slobbe I, Krenning E \& Keizer-Schrama S. Peak bone mineral density, lean body mass and fractures. Bone 201046 336-41.

46. Jones G, Ma D \& Cameron F. Bone density interpretation and relevance in Caucasian children aged 917 years of age: insights from a population-based fracture study. J Clin Densitom 2006 9 202-9.

47. Roke Y, van Harten P, Buitelaar J, Tenback D, de Rijke Y, \& Boot A. Antipsychotic-induced hyperprolactinemia and testosterone levels in boys. Horm Res Paediatr 201277 235-40.

48. Hediger ML, England LJ, Molloy CA, Yu KF, Manning-Courtney P\& Mills JL. Reduced cortical bone thickness in boys with autism or autism spectrum disorders. J Autism Dev Disord 2008 38 848-56.

49. Macdonald M, Esposito P \& Ulrich D. The physical activity patterns of children with autism. BMC Res Notes 201118 4-422.

50. Herbst K, Anawalt B, Amory J, Matsumoto A \& Bremner W. The male contraceptive regimen of testosterone and levonorgestrel significantly increases lean mass in healthy young men in 4 weeks, but attenuates a decrease in fat mass induced by testosterone alone. J Clin Endocrinol Metab 200888 1167-73.

51. Boot A, Krenning E \& de Muinck Keizer-Schrama S. The relation between 25-hydroxyvitamin D with peak bone mineral density and body composition in healthy young adults. J Pediatr Endocrinol Metab 201124 355-60.

52. Kodak T \& Piazza C. Assessment and behavioral treatment of feeding and sleeping disorders in children with autism spectrum disorders. Child Adolesc Psychiatr Clin N Am 2008 17 887-905.

53. Schlechte J, Walkner L \& Kathol M. A longitudinal analysis of premenopausal bone loss in healthy women and women with hyperprolactinemia. J Clin Endocrinol Metab 199275 698-703.

54. Pitukcheewanont P \& Chen P. Bone density measurements in children and adolescents. Quantitative computed tomography versus dual-energy X-ray absorptiometry. The Endocrinologist $200515232-$ 239. 
55. Coker F \& Taylor D. Antidepressant-induced hyperprolactinaemia. CNS Drug 201024 563-574.

56. Turrone P, Kapur S, Seeman M \& Flint A. Elevation of prolactin levels by atypical antipsychotics. Am J Psychiatry 2002159 133-135.

57. Stevens J, Kymissis P \& Baker A. Elevated prolactin levels in male youths treated with risperidone and quetiapine. J Child Adolesc Psychopharmacol 200515 893-900.

58. Greenaway M \& Elbe D. Focus on aripiprazole: a review of its use in child and adolescent psychiatry. J Can Acad Child Psychiatry 200918 250-60. 

PART 2b

Genetic risk factors

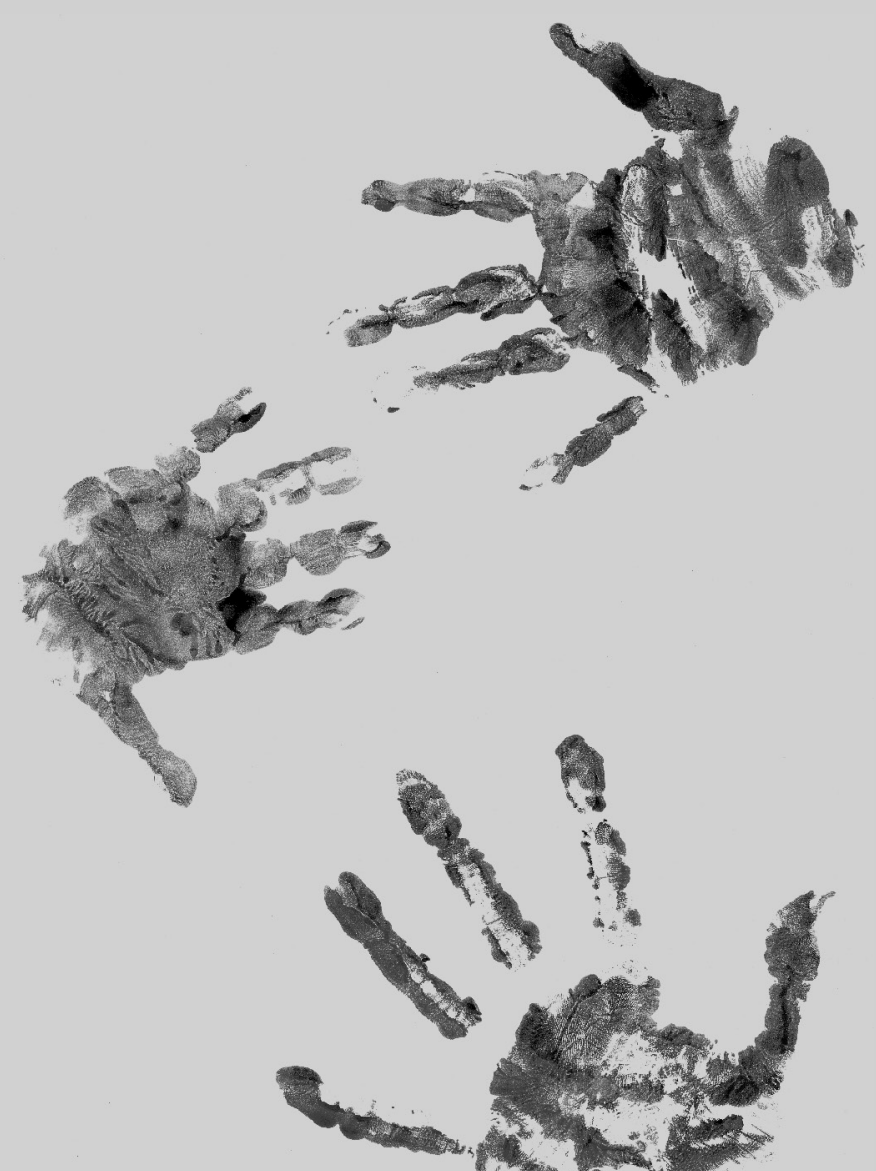





\section{Chapter 6}

\section{The effect of the Taq1A variant in the dopamine $D 2$ receptor gene and common CYP2D6 alleles on prolactin levels in risperidone treated boys.}

Yvette Roke, Peter N. van Harten, Barbara Franke, Tessel E. Galesloot, Annemieke M. Boot, Jan K. Buitelaar

Accepted for publication in Pharmacogenetics and Genomics

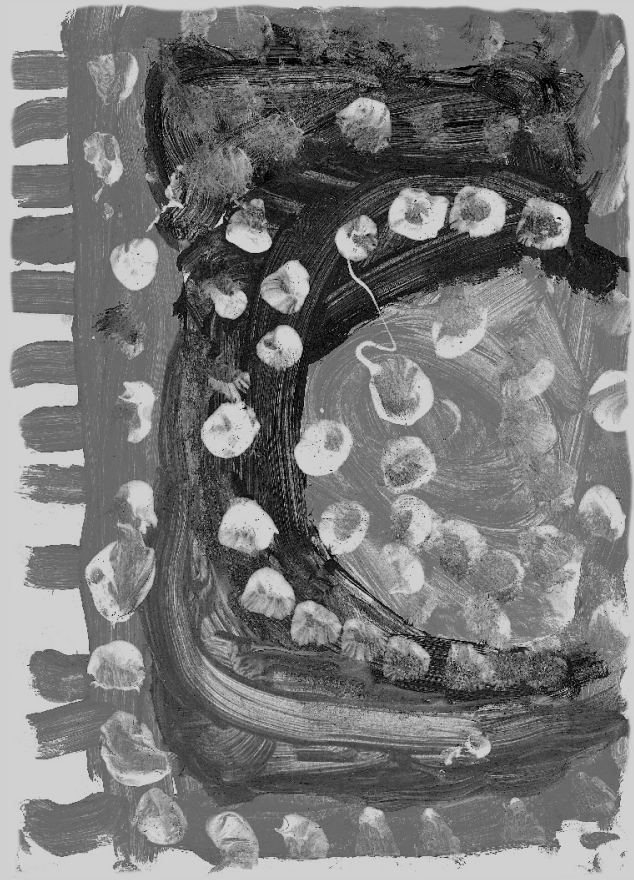




\begin{abstract}
Objective: To investigate the effect of the Taq1A variant in the Dopamine D2 receptor gene (DRD2) and common functional genetic variants in the cytochrome P450 2D6 gene (CYP2D6) on prolactin levels in risperidone treated boys with autism spectrum disorders (ASD) and disruptive behavior disorders (DBD).

Methods: 47 physically healthy 10- to 19-year-old boys with ASD and/ or DBD, chronically treated (mean 52 months, range 16-126 months) with an antipsychotic were recruited to this observational study. Prolactin levels, hyperprolactinemia, risperidone levels and 9-hydroxy-risperidone levels were assessed and the participants were genotyped for common CYP2D6 polymorphisms and the Taq1A allele of the dopamine D2 receptor gene. Group differences were tested with Student's ttest, Chi-square, and logistic regression analysis.

Results: Prolactin levels were positively and significantly associated with risperidone levels $(p=0.05)$, 9-hydroxy risperidone levels $(p=<0.0001)$ and with oral risperidone dose in milligram per kilogram $(\mathrm{p}=<0.0001)$. Furthermore, multiple regression analysis revealed no correlations between prolactin level and the presence of a least one Taq1A A1 allele of the DRD2 gene $(p=0.12)$.

Conclusion: While CYP2D6 might have an effect, the presence of a least one Taq1A A1 allele of the D2DR gene did not contribute to one's susceptibility to risperidone-induced hyperprolactinemia, and as a result to developing prolactin related adverse events such as amenorrhea, galactorrhea, and sexual dysfunctioning.
\end{abstract}

Keywords: risperidone, prolactin, genetics, adolescents 


\section{Introduction}

Second-generation antipsychotics are increasingly prescribed to children and adolescents with psychiatric disorders and have been used successfully to reduce maladaptive behaviours, such as irritability, self-injury, stereotypies and hyperactivity in children and adolescents with autism spectrum disorders (ASD) and irritability and aggressive behaviour in children and adolescents with disruptive behavior disorder (DBD) [1].

While risperidone and aripiprazole have been approved by the United States Food and Drug Administration (FDA) for the treatment of children and adolescents with irritability associated with ASD [2-4], these drugs have not yet been approved for this indication in Europe. Their clinical effectiveness is well established and there is a lower risk of neurological adverse effects compared to the first generation antipsychotics [4]. However, some concerns exist about the treatment with risperidone, as it may induce side effects like weight gain, glucose dysregulation and dyslipidemia, and hyperprolactinemia [5-8].

Hyperprolactinemia may cause amenorrhea, galactorrhea, impotence, libido loss, hypospermatogenesis, hypogonadotropic hypogonadism, and further a longterm risk of osteoporosis $[9,10]$. Fifty percent of the children and adolescents that have been long-term treated with antipsychotics still have hyperprolactinemia [11,12]. Antipsychotics increase plasma prolactin concentration through antidopamine activity by the blockade of dopamine D2 receptors in the anterior pituitary [13]. Pharmacogenetic differences may explain individual variation in prolactin elevation in response to antipsychotic medication leading to clinical consequences. As dopamine 2 antagonism plays an important role in the prolactin elevation, the dopamine D2 receptor gene (DRD2) is an attractive candidate gene. Studies on human post mortem brains [14] revealed a lower dopamine D2 receptor density in the striatum and related structures in A1 allele carriers of the DRD2 Taq1A polymorphism (rs1800497). Similar results were found in vivo [15]. Studies showed an association between the presence of the A1 allele of the Taq1A polymorphism and a higher prolactin elevation to antipsychotics in adult females [16] and in the general population $[17,18]$. However, another study showed no correlation between prolactin concentration and dopamine-related polymorphisms in male and female patients with schizophrenia [19]. In addition one study with longterm risperidone treated children and adolescents showed four times more prolactin-related side effects in Taq1A A1 allele carriers [20]. Since prolactin elevation is (partly) related to antipsychotic blood levels, the gene coding for the cytochrome P450 2D6 enzyme (CYP2D6) is another interesting candidate gene for explaining variation in prolactin levels after treatment with antipsychotic medication. This enzyme metabolizes many antipsychotics including risperidone. The CYP2D6 gene is highly polymorphic resulting in different phenotypic metabolism rates of the encoded enzyme. Normal metabolizers are homozygous for functional CYP2D6 alleles or heterozygous with 1 functional CYP2D6 allele; poor metabolizers have no 
functional CYP2D6 alleles (7\% of the Caucasian, 1\% of the Asian and 3\% of the African individuals). Ultrarapid metabolizers have a duplication (rapid) or multiplications (ultrarapid) of the intact CYP2D6 gene (found in 2\% of the Caucasian population and up to $25 \%$ of several Ethiopian subpopulations) [20, 21].

The half-life for risperidone depends on its metabolization rate, and ranges between 2-4 hours in normal metabolizers and 22 hours in poor metabolizers. Risperidone is converted into its major active metabolite 9-hydroxy risperidone by the enzyme CYP2D6. The half-life of 9-hydroxy risperidone is 21 hours partly dependent of the CYP2D6 metabolism [22, 23]. Usually the ratio of risperidone to 9hydroxy risperidone is about $1: 3$, but this ratio is typically inverted in poor metabolizers $[23,26]$. A previous study showed the number of functional CYP2D6 alleles to be associated with prolactin levels [27]. Prolactin levels were also positively correlated with the oral dose of risperidone and serum 9-hydroxy risperidone levels [27]. On the other hand, other studies reported a higher risk of clinically important side effects among risperidone-treated patients with impaired CYP2D6 enzyme activity $[22,28]$.

The primary aim of this study was to determine the association between the prevalence of hyperprolactinemia in children and adolescents long-term treated with risperidone on the one hand, and the DRD2 Taq1A polymorphism and functional genetic variants of CYP2D6 on the other.

Additional aims included the exploration of the effects of clinical and pharmacogenetic factors on prolactin levels in this sample.

\section{Methods}

\subsection{Subjects}

All participants were recruited from the total patient population of the outpatient adolescent clinic of the GGz Central Psychiatric Centre, The Netherlands, from October 2006 to November 2009 [12, 29]. All participants had a diagnosis of ASD or DBD. The GGz Central Psychiatric Centre hardly ever sees children and adolescents with psychotic or bipolar disorders, because these individuals tend to be referred to the nearby university hospital.

Inclusion criteria were: (i) an age between 10- and 20 years old, (ii) diagnoses of any psychiatric disorder, (iii) an IQ above 85, and (iv) treatment with any potential prolactin-elevating antipsychotic medication continuously for more than 16 months. Participants were excluded if they had a history of thyroid disorders, syndromes or other chronic diseases affecting puberty, endocrine disorders, if they used oral corticosteroids or anticonvulsants, or if they had a known cause of hyperprolactinemia $[30,31]$. 
The first author contacted all children and adolescents that met the inclusion criteria by telephone and letter. Seventy-seven children and adolescents were contacted. From this group 56 boys and 6 girls ( $80 \%$ of the contacted patients) participated in the study. The main reason for not participating was fear of venipuncture.

For the homogeneity of the group data of six female participants, two boys using concomitant SSRI medication and three boys treated with pimozide instead of risperidone were not analysed. The data of another four boys were not analyzed since they were not compliant to antipsychotic treatment (defined as having a 9hydroxy risperidone serum level of $0 \mu \mathrm{g} / \mathrm{l}$ ). Thus the risperidone group consisted of 47 boys with ASD or DBD treated long-term with risperidone and being compliant to this treatment. Use of other concomitant medication, such as, psychostimulants, melatonin, and atomoxetine was permitted (Table 1). The Local Medical Ethics Committee approved this study and written informed consent was obtained from the patient and the subject's parents/legal guardians after a clear explanation of the study procedures.

\subsection{Procedures}

The clinical diagnosis was obtained from the patients' chart. The first author measured the participants' height (without shoes to the nearest $0.1 \mathrm{~cm}$ using a stadiometer, Seca 206, The Netherlands) and weight (participant wearing underwear, to the nearest $0.1 \mathrm{~kg}$ using an analogue scale, Seca 761, The Netherlands). Age- and gender-specific height, weight and body mass index (BMI) z-scores were calculated using normative data for Dutch children [32,33].

A non-fasting morning blood sample was obtained around 9.30 a.m. after a light breakfast was eaten at around 7.30 a.m. Serum prolactin was measured with an automated chemiluminescence assay system (Immulite 2000, Siemens Healthcare Diagnostics) calibrated on the 3rd IS 84/500. As macroprolactin, a complex of prolactin and IgG without biological activity, is responsible for $10 \%$ of cases of hyperprolactinemia [34], seven samples with prolactin concentrations higher than 37 $\mathrm{ng} / \mathrm{ml}$ were assessed for the presence of macroprolactin. Polyethylene glycol 6000, $200 \mu \mathrm{l},(25 \% \mathrm{w} / \mathrm{w})$ was added to $200 \mu \mathrm{l}$ of serum and, after thorough vortex mixing, the mixture was centrifuged at $2200 \mathrm{~g}$ for $30 \mathrm{~min}$ at $4{ }^{\circ} \mathrm{C}$. Subsequently, prolactin was measured in the supernatant and the untreated serum. The recovery of prolactin after precipitation with polyethylene glycol 6000 was $101.4 \pm 9.6$ (mean \pm SD), which excluded the presence of macroprolactin. TSH was measured to exclude boys with hyperprolactinemia due to thyroid disorders. Plasma levels of risperidone and 9-hydroxyrisperidone were measured by HPLC (reverse phase, CN column, Thermo Fisher Scientific, Dreieich, Germany) to evaluate compliance. Genetic analyses were performed in a CCKL (Central Commission for the promotion of quality of Laboratory research)-accredited laboratory at the Department of Human Genetics, Radboud University Nijmegen Medical Centre, the Netherlands. Blood samples were obtained by venipuncture, and DNA was isolated using standard protocols. The 
DRD2 Taq1A (rs1800497) polymorphism and the CYP2D6 single nucleotide polymorphisms (SNPs) CYP2D6*3 del A (rs35742686), CYP2D6*4 G>A (rs3892097), CYP2D6*6 del T (rs5030655) as well as the CYP2D6 gene deletion (CYP2D6*5) and the gene duplication (CYP2D6xn) were genotyped using TaqMan-based analysis. Genotyping was performed in a volume of $10 \mu \mathrm{l}$ containing $10 \mathrm{ng}$ of genomic DNA. For DRD2, $5 \mu$ l of TaqMan Mastermix (2x; Life Technologies, Nieuwerkerk a/d Ijssel, The Netherlands) and $0.125 \mu \mathrm{l}$ of TaqMan assay (Assay ID: C_7486676_10, reporter 1, VIC-A-allele, reverse assay; Life Technologies) were added to $3.875 \mu \mathrm{l}$ of H2O. For the CYP2D6 variants CYP2D6*4 G>A, CYP2D6*3 del A and CYP2D6*6 del T, $0.25 \mu \mathrm{l}$ of TaqMan assay (Assay IDs: C_27102431_B0, reporter 1, VIC-C-allele, reverse assay, C_32407232_50 reporter 1, VIC-T-allele, forward assay, C_32407243_20, reporter 1, VIC-A-allele, forward assay; Life Technologies) were added to the Mastermix and $3.75 \mu \mathrm{l}$ of H2O. The gene deletion/duplication copy number polymorphism was genotyped using $0.25 \mu \mathrm{l}$ of TaqMan assay (Assay ID: Hs00010001_cn, Fam label; Life Technologies) and $0.25 \mu \mathrm{l}$ of assay for the reference gene RNASE P (Assay ID: 4316844, Vic label; Life Technologies) in combination with $5 \mu \mathrm{l}$ Mastermix and $4.50 \mu \mathrm{l}$ of H2O. Amplification was performed using the 7500 Fast Real-Time PCR (Life Technologies). The PCR program for SNP genotyping started with 15 minutes at $95^{\circ} \mathrm{C}$, followed by 50 cycles of 15 seconds at $95^{\circ} \mathrm{C}$ and 1 minute at $60^{\circ} \mathrm{C}$. Genotypes were scored using the algorithm and software supplied by the manufacturer. The PCR program for the copy number analysis started with 2 minutes at $50^{\circ} \mathrm{C}$ and 10 minutes at $95^{\circ} \mathrm{C}$, followed by 40 cycles of 15 seconds at $95^{\circ} \mathrm{C}$ and 1 minute at $60^{\circ} \mathrm{C}$. Copy number analysis used Copy caller software (Life Technologies). To investigate random genotyping error rate in the four SNP genotyping assays, the laboratory included 5\% duplicate DNA samples, which showed $100 \%$ consistency in genotype. In addition, $4 \%$ blanks were included, which were all negative. For the analysis of the copy number assay, we included 4 positive controls, 2 for the duplication and deletion each.

\subsection{Data analysis}

Spearman correlation analysis was used to investigate whether prolactin levels were associated with the risperidone levels, 9-hydroxy risperidone levels, with the total active molecule (risperidone levels and 9-hydroxyrisperidone levels together) [35], oral dose of risperidone in milligram per kilogram, the ratio risperidone/9hydroxy risperidone and with age.

Multiple logistic regression analysis was conducted to investigate whether the Taq1A A1 allele of the DRD2 gene was associated with prolactin level. We grouped the individuals with either one or two Taq1A A1 alleles into one group (there was only one boy carrying two Taq1A A1 alleles) and compared them to those individuals not carrying any Taq1A A1 alleles. We adjusted for age in the analysis for two reasons: firstly, the dopamine $\mathrm{D} 2$ receptor density falls with age, and secondly, the prolactin levels are age dependent $[36,37]$. We also adjusted for the 9-hydroxy 
risperidone level to correct for the dose of the treatment used [38] and we adjusted for concomitant methylphenidate medication that theoretically could have decreased prolactin levels given the dopaminergic activity of methylphenidate [39]. To investigate the risk on hyperprolactinemia as a dichotomous outcome when carrying at least one Taq1A A1 allele (A1A1+A1A2) of DRD2 we calculated the odds ratio (OR). Hyperprolactinemia was defined as a prolactin level above the 97.5th percentile based on normative data for age and gender [40]. Because our data (prolactin level and 9-OH risperidone level) was skewed we used a log transformation to make our data more normal.

The number of functional alleles of the CYP2D6 gene determines the activity of the enzyme complex, therefore we grouped the activity of the different nonfunctional alleles $* 3, * 4, * 5, * 6$ and the gene duplication into categories of activity as follows: poor metabolizers (two non-functional alleles), intermediate metabolizers (one non-functional allele), normal metabolizers (two functional alleles) and ultra rapid metabolizers (three or more functional alleles). The CYP2D6 data of one patient in this group was missing, reducing the number of patients from 47 to 46 . We described the levels of prolactin, 9-hydroxy risperidone and the presence of hyperprolactinemia over the categories of CYP2D6 activity and we compared the prolactin level means for the normal and reduced activity group with an independent sample t-test.

\subsection{Results}

Baseline characteristics of the included patients are presented in Table 1 . The 47 boys had a mean age of 14.7 years (standard deviation (SD) of 2.1 years), the mean treatment dose of risperidone was $1.6 \mathrm{mg}$ per day or $0.026 \mathrm{mg}$ per $\mathrm{kg}$ (SD $0.95 \mathrm{mg}$ per day, and SD $0.016 \mathrm{mg}$ respectively), with a mean duration of treatment of 4.4 years (SD 2.4 years, 74\% of the boys were treated for 3 years or more), the mean prolactin level was $19.9 \mathrm{ng} / \mathrm{ml}$ (SD $17.0 \mathrm{ng} / \mathrm{ml}$ ), and 23 out of 47 (49\%) boys had hyperprolactinemia. None of these cases were due to macroprolactinemia. Table 2 and 3, respectively show the characteristics of the boys with the three different DRD2 and the four different CYP2D6 genotypes. Multiple logistic regression analysis revealed that the presence of at least one Taq1A A1 allele of the DRD2 gene was not associated with the prolactin level $(\beta=0.27$, SE $0.17, p=0.12)$. The OR for having hyperprolactinemia when carrying at least one Taq1A A1 allele was 1.56 (95\% CI 0.46-5.26).

Prolactin levels were positively and significantly associated with risperidone levels $(r=0.29, p=0.05)$, 9-hydroxy risperidone levels $(r=0.60, p=<0.0001)$, the total active molecule $(\mathrm{r}=0.6, \mathrm{p}=<0.0001)$ and with oral risperidone dose in milligram per kilogram $(\mathrm{r}=0.51, \mathrm{p}=<0.0001)$. A positive, although not significant association was observed for prolactin level with age $(r=0.25, \mathrm{p}=0.09)$ and with the ratio risperidone/9-hydroxy risperidone $(r=0.007, \mathrm{p}=0.96)$. 
Table 3 shows that the prolactin level was higher in normal versus reduced or no activity of CYP2D6. Mean prolactin level was $48.6 \mathrm{ng} / \mathrm{ml}$ for no CYP2D6 activity, $18.4 \mathrm{ng} / \mathrm{ml}$ for reduced CYP2D6 activity, $19.8 \mathrm{ng} / \mathrm{ml}$ for normal activity and 6.8 $\mathrm{ng} / \mathrm{ml}$ for ultrarapid CYP2D6 activity. When comparing the prolactin levels with an independent sample t-test there was no difference for the reduced activity and the normal activity group ( $\mathrm{p}=0.8)$. We did not further analyse but only describe this data for both the poor metabolizers $(\mathrm{N}=2)$ and ultra rapid metabolizers $(\mathrm{N}=2)$ because of lack of power.

Table 1. Characteristics of boys with autism spectrum disorders (ASD) or disruptive behavior disorders (DBD) with long-term risperidone-treatment included in the current study $(\mathrm{N}=47)$.

\begin{tabular}{|c|c|c|}
\hline & N (\%) & Mean (SD; range) \\
\hline Age, years & & $14.7(2.1 ; 10 ; 19)$ \\
\hline Caucasian ethnicity & $46(98)$ & \\
\hline Height (cm) & & $175(11 ; 143 ; 196)$ \\
\hline Height z-score & & $0.5(1.1 ;-2.4 ; 2.1)$ \\
\hline Weight (kg) & & $65.1(19 ; 35 ; 138)$ \\
\hline Weight z-score & & $0.6(1.1 ;-2.5 ; 3.2)$ \\
\hline BMI & & $21(4.5 ; 16 ; 42)$ \\
\hline BMI z-score & & $0.3(0.8 ;-1.5 ; 1.8)$ \\
\hline \multicolumn{3}{|l|}{ Primary diagnosis } \\
\hline ASD* $^{*}$ & $45(96)$ & \\
\hline $\mathrm{DBD}^{* *}$ & $2(4)$ & \\
\hline Risperidone (mg/day) & & $1.6(1.0 ; 0.3 ; 4)$ \\
\hline Duration of use (months) & & $53.3(28.7 ; 16 ; 126)$ \\
\hline $\mathrm{RIS}^{* * *} \mu \mathrm{g} / \mathrm{l}$ & & $3.0(5.2 ; 0 ; 28)$ \\
\hline 9-OH RIS**** $\mu \mathrm{g} / \mathrm{l}$ & & $9.2(7.4 ; 3 ; 36)$ \\
\hline \multicolumn{3}{|l|}{ Concomitant medication: } \\
\hline Melatonin & $2(4)$ & \\
\hline Psychostimulants & $9(19)$ & \\
\hline Atomoxetine & $2(4)$ & \\
\hline Prolactin ng/ml & & $19.8(17.2 ; 2.4 ; 92.5)$ \\
\hline Hyperprolactinemia ${ }^{\$}$ & $23(49)$ & \\
\hline
\end{tabular}


Table 2. Characteristics of male children and adolescents with autism spectrum disorders or disruptive behavior disorders $(\mathrm{N}=47)$ with long-term risperidone treatment carrying the Taq1A A2/A2 allele $(\mathrm{N}=31)$ compared to the Taq1A A1/A1 $(\mathrm{N}=1)$ and the Taq1A A1/A2 allele $(\mathrm{N}=15)$ carriers

\begin{tabular}{|c|c|c|c|c|c|c|}
\hline & $\begin{array}{l}\text { A2/A2 } \\
(\mathrm{N}=31)\end{array}$ & & $\begin{array}{l}\mathrm{A} 1 / \mathrm{A} 2 \\
(\mathrm{~N}=15)\end{array}$ & & $\begin{array}{l}\mathrm{A} 1 / \mathrm{A} 1 \\
(\mathrm{~N}=1)\end{array}$ & \\
\hline & $\mathrm{N}(\%)$ & Mean (SD) & $\mathrm{N}(\%)$ & Mean (SD) & $\mathrm{N}(\%)$ & Mean (SD) \\
\hline Age, years & & $14.5(1.8)$ & & $15(2.7)$ & & 14.1 \\
\hline Caucasian ethnicity & $31(100)$ & & $14(93)$ & & $1(100)$ & \\
\hline Height $(\mathrm{cm})$ & & $174(9)$ & & $174(12)$ & & 174 \\
\hline Height z-score & & $0.59(1.1)$ & & $0.28(1.2)$ & & 0.62 \\
\hline Weight (kg) & & $62(14)$ & & $64(18)$ & & 49 \\
\hline Weight z-score & & $0.6(1.0)$ & & $0.6(1.2)$ & & -0.52 \\
\hline BMI & & $20(3)$ & & $21(4)$ & & 16 \\
\hline BMI z-score & & $0.26(0.8)$ & & $0.39(0.9)$ & & -1.5 \\
\hline \multicolumn{7}{|l|}{ Primary diagnosis } \\
\hline ASD* & $30(97)$ & & $15(100)$ & & $0(0)$ & \\
\hline $\mathrm{DBD}^{* *}$ & $1(3)$ & & $0(0)$ & & $1(100)$ & \\
\hline Risperidone (mg/day) & & $1.7(1)$ & & $1.5(0.9)$ & & 0.25 \\
\hline Duration of use in months & & $47.6(22.8)$ & & $64.5(37.2)$ & & 60 \\
\hline $\mathrm{RIS}^{* * *} \mu \mathrm{g} / \mathrm{l}$ & & $3.0(5.8)$ & & $2.9(3.9)$ & & 1 \\
\hline 9-OH RIS**** $\mu \mathrm{g} / \mathrm{l}$ & & $9.2(5)$ & & $9.5(11)$ & & 3 \\
\hline \multicolumn{7}{|l|}{ Concomitant medication: } \\
\hline Melatonin & $1(3)$ & & $1(7)$ & & $0(0)$ & \\
\hline Psychostimulants & $7(23)$ & & $0(0)$ & & $1(100)$ & \\
\hline Atomoxetine & $2(6)$ & & $0(0)$ & & $0(0)$ & \\
\hline Prolactin level ng/ml & & $16.2(8.4)$ & & $28.8(26)$ & & 2.4 \\
\hline Hyperprolactinemia $\$$ & $14(45)$ & & $9(60)$ & & 0 & \\
\hline
\end{tabular}

${ }^{*} \mathrm{ASD}=$ autism spectrum disorders; ${ }^{* *} \mathrm{DBD}=$ disruptive behavior disorders; ${ }^{* * *} \mathrm{RIS}=$ plasma levels of risperidone; ${ }^{* * * * 9-0 H}$ RIS=plasma levels of 9-0H risperidone; \$Hyperprolactinemia was defined as a prolactin level above the 97.5th percentile for normative data for age and gender (Emlinger et al. 2002); z-scores were calculated using normative data for age and gender (Fredriks et al. 20001,2). 
Table 3. Characteristics of male children and adolescents $(\mathrm{N}=46)$ with autism spectrum disorders or disruptive behavior disorders with long-term risperidone treatment per stratum of CYP2D6 activity.

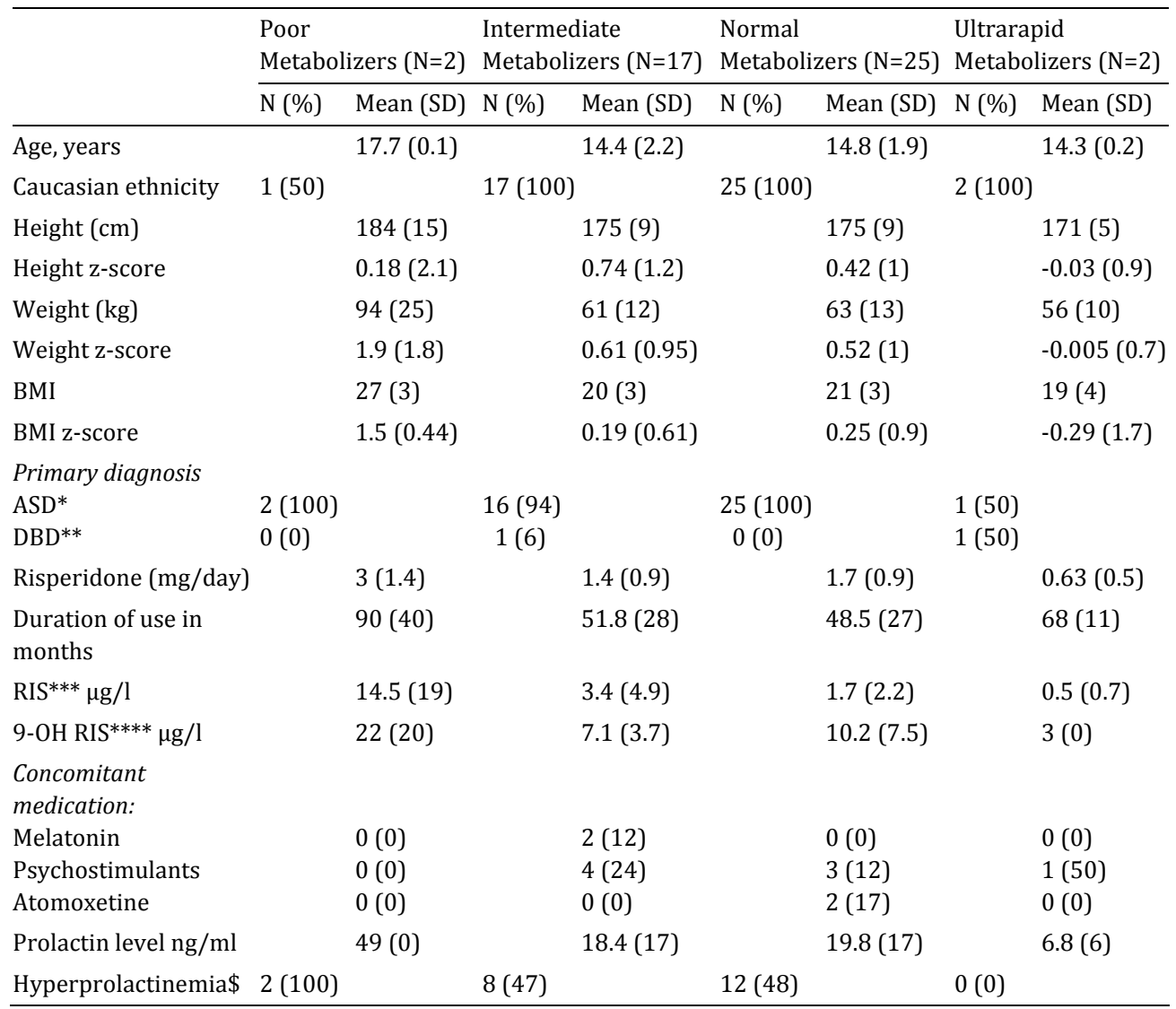

${ }^{*} \mathrm{ASD}=$ autism spectrum disorders; ${ }^{* *} \mathrm{DBD}=$ disruptive behavior disorders; ${ }^{* * *} \mathrm{RIS}=$ plasma levels of risperidone; ${ }^{* * *} 9-\mathrm{OH}$ RIS=plasma levels of $9-\mathrm{OH}$ risperidone; \$Hyperprolactinemia was defined as a prolactin level above the 97.5th percentile for normative data for age and gender (Emlinger et al. 2002); z-scores were calculated using normative data for age and gender (Fredriks et al. 20001,2).

\subsection{Discussion}

This study shows that there are no correlations between prolactin level and the presence of at least one Taq1A A1 allele of the DRD2 gene in risperidone treated boys with ASD or DBD. A previous study in male and female patients with schizophrenia also showed no correlation between antipsychotic-induced prolactin levels and dopamine-related polymorphisms [19].

There is one other study investigating the effect of the presence of at least one Taq1A A1 allele on prolactin levels in 90 non-Hispanic Caucasian children (mean age 12 years, primarily boys, primarily pre-pubertal, with any psychiatric diagno- 
sis) long-term (mean treatment duration of 3 years) treated with risperidone. This study showed that the Taq1A A1 allele carriers had significantly higher prolactin levels [20]. The higher prolactin levels in response to AP treatment in these patients may be the result of having fewer unbound dopamine receptors at any given AP dose. Individuals with the Taq1A A1 allele have a reduced density of brain D2 receptors $[14,15,41]$. An early brain autopsy study [41] found a significant reduction of about $30 \%$ in the number of D2 dopamine receptors in the caudate nucleus of Taq1A A1allele carriers compared with non-carriers. However, our study did not replicate these findings. One previous study investigated the influence of CYP2D6 genetic variants on the prevalence of adverse drug reactions, including hyperprolactinemia, in risperidone treated adult patients $(\mathrm{N}=537)$ showed that the poor metabolizer phenotype may be associated with risperidone adverse drug reactions and discontinuation [28]. Another study in children showed that the CYP2D6 ultrarapid metabolism may be a risk factor for more pronounced prolactin elevation (25 children with ASD, mean age 8 years) [27], however these children were short-term treated (eight weeks) and the group with ultrarapid metabolism consisted of merely 2 patients [27]. Larger studies in children and adolescents long-term treated with risperidone are needed to draw conclusions about the influence of CYP2D6 on prolactin levels and prolactin related side effects. Moreover, children and adolescents have different drug metabolism and tolerability than adults; e.g. due to age dependent alterations in body water and serum protein composition [37]. Furthermore, their brains and the ratio of the D1 and D2 dopamine receptors density in the striatum falls with age, after age 20 years, D1 receptors decrease at $3.2 \%$ per decade and D2 receptors decrease at about $2.2 \%$ per decade [36, 42]. Therefore it is important to investigate whether the findings regarding variants in the dopamine D2 receptor and CYP2D6 genotypes in adults [17] also apply to children and adolescents in the different age categories.

\subsection{Limitations}

This study had some limitations that should be taken into account when interpreting the results and which should be addressed in future studies. First, our sample size was small. In addition prolactin-elevating concomitant medication was permitted, such as atomoxetine and melatonin [5, 43, 44], which could have influenced the prolactin levels. However, the prolactin-elevating effect of this concomitant medication is considered to be minor compared with that of the antipsychotic used [44]. Furthermore, eight boys were on concomitant methylphenidate medication that theoretically could have decreased prolactin levels given the dopaminergic activity of methylphenidate [39], however if this would be true the prolactin levels measured in our study were an underestimate. Furthermore, the risperidone dose was two times higher in the reduced CYP2D6 activity group and four times higher in the no activity CYP2D6 group compared to the ultrarapid CYP2D6 metabolizer group, therefore, and because of the small number of patiens, it was not possible to prop- 
erly analyse these data and draw any conclusions about the prolactin levels and 9hydroxy risperidone levels in the different CYP2D6 activity groups.

Furthermore, we employed a cross-sectional design, did not assess pretreatment prolactin levels, and cannot establish causality. Nonetheless a crosssectional design is suitable for a genetic based study because the genes are there in predisposition. Finally, in the genotyping of CYP2D6 only those functional alleles with the highest incidence $(* 3, * 4, * 5, * 6$ and the gene duplication) were analysed. Theoretically, other non-functional alleles could be present in our study population. However, given the low incidence of other non-functional alleles their influence is expected to be minimal [45].

\subsection{Conclusion}

Our findings suggest that the TaqA1 A1 allele of the D2DR gene do not contribute to one's susceptibility to AP-induced hyperprolactinemia, and as a result to developing prolactin related adverse events such as amenorrhea, galactorrhea, and sexual dysfunctioning. It is important to appreciate that hyperprolactinemia is present without these adverse events in about fifty percent of male adolescents [46, 47, 48]. However, irrespective of the presence of manifest prolactin related adverse events, patients with hyperprolactinemia may be at risk for more serious side effects such as lower bone mineral density [11, 29].

\section{References}

1. Aman MG, McDougle CJ, Scahill L, Handen B, Arnold LE, Johnson C, et al. Medication and parent training in children with pervasive developmental disorders and serious behavior problems: results from a randomized clinical trial. J Am Acad Child Adolesc Psychiatry 2009; 48:1143-54.

2. McCracken JT, McGough J, Shah B, Cronin P, Hong D, Aman MG, et al. Risperidone in children with autism and serious behavioral problems. N Engl J Med 2002; 347(5):314-21.

3. Stigler KA, Diener JT, Kohn AE, Erickson CA, Posey DJ, Mc Dougle CJ. Aripiprazole in pervasive developmental disorder not otherwise specified and Asperger's disorder: a 14-week, prospective, openlabel study.J Child Adolesc Psychopharmacol. 2009; 19: 265-74.

4. Wink L, Erickson C, McDougle C. Pharmacologic treatment of behavioral symptoms associated with autism and other pervasive developmental disorders. Curr Treat Opt Neurol. 2010; 12: 529-38.

5. Molitch ME. Medication-induced hyperprolactinemia. Mayo Clin Proc. 2005; 80:1050-1057.

6. Correll CU. Monitoring and management of antipsychotic-related metabolic and endocrine adverse events in pediatric patients. Int Rev Psychiatry. 2008; 20:195-201.

7. Correll CU. Assessing and maximizing the safety and tolerability of antipsychotics used in the treatment of children and adolescents. J Clin Psychiatry. 2008; 69: 26-36.

8. Vitiello B, Correll C, van Zwieten, Zuddas A, Paredella M, Arango C. Antipsychotics in children and adolescents: increasing use, evidence for efficacy and safety concerns. Eur Neuropsychopharmacol. 2008; 19: 629-35.

9. Halbreich U, Kinon BJ, Gilmore JA, Kahn LS. Elevated prolactin levels in patients with schizophrenia: mechanisms and related adverse effects. Psychoneuroendocrinology. 2003; 28: 53-67.

10. Howard L, Kirkwood G, Leese M. Risk of hip fracture in patients with a history of schizophrenia. Br J Psychiatry. 2007; 190: 129-34. 
11. Calarge CA, Zimmerman B, Xie D, Kuperman S, Slechte JA. A cross-sectional evaluation of the effect of risperidone and selective serotonine reuptake inhibitors on bone mineral density in boys. J Clin Psychiatry. 2010; 1:338-347.

12. Roke Y, van Harten P, Buitelaar J, Tenback DE, de Rijke YB, Boot AM. Antipsychotic-induced hyperprolactinemia and testosterone levels in boys. Horm Res Paediatr. 2012; 77: 235-40.

13. Freeman ME, Kanyicska B, Lerant A, Nagy G. Prolactin: structure, function, and regulation of secretion. Physiol Rev. 2000; 80:1523-631.

14. Thompson J, Thomas N, Singleton A, Piggot M, Lloyd S, Perry EK. D2 dopamine receptor gene (DRD2) Taq1 A polymorphism: reduced dopamine D2 receptor binding in the human striatum associated with the A1 allele. Pharmacogenetics. 1997; 7: 479-84.

15. Jönsson EG, Nöthen MM, Neidt H, Forslund K, Rylander G, Matilla-Evenden M, et al. Association between a promoter polymorphism in the dopamine D2 receptor gene and schizophrenia. Schizophr Res. 1999; 40:31-6.

16. Mihara K, Suzuki A, Kondo T, Yasui-Furukori N, Ono S, Otani K, et al. Relationship between Taq1 A dopamine D2 receptor (DRD2) polymorphism and prolactin response to bromperidol. Am J Med Genet 2001; 105:271-4.

17. Young RM, Lawford BR, Barnes M, Burton SC, Ritchie T, Ward WK, et al. Prolactin levels in antipsychotic treatment of patients with schizophrenia carrying the DRD2*A1 allele. Br J Psychiatry 2004;185:147-51.

18. López-Rodríguez R, Román M, Novalbos J, Pelegrina ML, Ochoa D, Abad-Santos F DRD2 Taq1A polymorphism modulates prolactin secretion induced by atypical antipsychotics in healthy volunteers. J Clin Psychopharmacol. 2011 ;31: 555-62.

19. Yasui-Furukori N, Saito M, Tsuchimine S, Nakagami T, Sato Y, Sugawara N, Kaneko S. Association between dopamine-related polymorphisms and plasma concentrations of prolactin during risperidone treatment in schizophrenic patients. Prog Neuropsychopharmacol Biol Psychiatry. 2008 ;32 :1491-5.

20. Calarge CA, Ellingrod VL, Acion L, Bliziotes MM, Slechte JA.Variants of the dopamine D2 receptor gene and risperidone-induced hyperprolactinemia in children and adolescents. Pharmacogenet Genomics 2009;19:373-82.

21. Sachse C, Brockmöller J, Bauer S, Roots I. Cytochrome P450 2D6 variants in a Caucasian population: allele frequencies and phenotypic consequences. Am J Hum Genet 1997; 60:284-95.

22. Hendset M, Molden E, Refsum H, Hermann M. Impact of CYP2D6 genotype on steady-state serum concentrations of risperidone and 9-hydroxyrisperidone in patients using long-acting injectable risperidone. J Clin Psychopharmacol. 2009 ;29: 537-41.

23. Calarge CA, Miller DD. Predictors of Risperidone and 9-Hydroxyrisperidone Serum Concentration in Children and Adolescents. J Child Adolesc Psychopharmacol. 2011; 21: 163-169.

24. Berecz R, Dorado P, De La Rubia A, Caceres MC, Degrell I, Llerena A. The role of cytochrome P450 enzymes in the metabolism of risperidone and its clinical relevance for drug interactions. Curr Drug Targets. 2004; 5:573-9.

25. Scordo MG, Spina E, Facciolà G, Avenoso A, Johansson I, Dahl ML. Cytochrome P450 2D6 genotype and steady state plasma levels of risperidone and 9-hydroxyrisperidone. Psychopharmacology1999 D;147:300-5.

26. Bork JA, Rogers T, Wedlund PJ, de Leon J. A pilot study on risperidone metabolism: the role of cytochromes P450 2D6 and 3A. J Clin Psychiatry 1999; 60:469-76.

27. Troost PW, Lahuis BE, Hermans MH, Buitelaar JK, van Engeland H, Scahill L, et al. Prolactin release in children treated with risperidone: impact and role of CYP2D6 metabolism. J Clin Psychopharmacol 2007; 27:52-7

28. De Leon J, Susce MT, Pan RM, Fairchild M, Koch WH, Wedlund PJ. The CYP2D6 poor metabolizer phenotype may be associated with risperidone adverse drug reactions and discontinuation. J Clin Psychiatry 2005;66:15-27.

29. Roke Y, Harten van PN, Buitelaar JK, Tenback DE, Quekel LG, de Rijke YB, et al. Bone mineral density and body composition in male adolescents with autism spectrum disorders with and without antipsychotic treatment. Eur J Endocrinol. 2012; 167: 855-63. 
30. Verhelst J, Abs R. Hyperprolactinemia: pathophysiology and management. Treat Endocrinol 2003; 2:23-32.

31. Melmed S, Casanueva FF, Hoffman AR, Kleinberg DL, Montori VM, Slechte JA, et al. Diagnosis and treatment of hyperprolactinemia: an Endocrine Society clinical practice guideline. J Clin Endocrinol Metab 2011; 96:273-88.

32. Fredriks AM, van Buuren S, Burgmeijer RJ, Meulmeester JF, Beuker RJ, Brugman E, et al. Continuing positive secular growth change in The Netherlands 1955-1997. Pediatr. Res 2000; 47:316-23.

33. Fredriks AM, van Buuren S, Wit JM, Verloove-Vanhorick SP. Body index measurements in 1996-7 compared with 1980. Arch Dis Child 2000; 82:107-12.

34. McKenna T. Should macroprolactin be measured in all hyperprolactinaemic sera? Clin Endocrinol 2009; 71:466-9.

35. Novalbos J, López-Rodríguez R, Román M, Gallego-Sandín S, Ochoa D, Abad-Santos F. Effects of CYP2D6 genotype on the pharmacokinetics, pharmacodynamics, and safety of risperidone in healthy volunteers. J Clin Psychopharmacol. 2010 ;30: 504-11

36. Seeman P, Bzowej NH, Guan HC, Bergeron C, Reynolds GP, Bird ED, et al. Human brain dopamine receptors in children and aging adults. Synapse 1987; 1:399-404.

37. Kearns GL, Reed MD. Clinical pharmacokinetics in infants and children: a reappraisal. Clinical Pharmacokinetics 1989;17:29-67.

38. Knegtering R, Baselmans P. Predominant role of the 9-hydroxy metabolite of risperidone in elevating blood prolactin levels. Am J Psychiatry 2005; 162:1010-2.

39. Weizman R, Dick J, Gil-Ad I, Weitz R, Tyano S, Laron Z. Effects of acute and chronic methylphenidate administration on beta-endorphin, growth hormone, prolactin and cortisol in children with attention deficit disorder and hyperactivity. Life Sci 1987 ;40: 2247-52.

40. Emlinger MW, Kühnel W, Ranke MB. Reference ranges for serum concentrations of Lutotropin (LH), Follitropin (FSH), Estradiol (E2), Prolactin, Progesterone, Sex Hormone Binding Globuline (SHBG), Dehydroepiandrosterone sulfate (DHEAS), Cortisol and Ferritin in neonates, children and young adults. Clin Chem Lab Med 2002; 40:1151-1160.

41. Noble EP, Blum K, Ritchie T, Montgomery A, Sheridan PJ. Allelic association of the D2 dopamine receptor gene with receptor-binding characteristics in alcoholism. Arch Gen Psychiatry. 199148 : 648-54.

42. Kuwabara H, McCaul ME, Wand GS, Earley CJ, Allen RP, Weerts EM, et al. Dissociative changes in the Bmax and $\mathrm{KD}$ of dopamine $\mathrm{D}_{2} / \mathrm{D}_{3}$ receptors with aging observed in functional subdivisions of the striatum: a revisit with an improved data analysis method. J Nucl Med 2012; 53:805-12.

43. Blaicher W, Imhof MH, Gruber DM, Schneeberger C, Sator MO, Huber JC, et al. Endocrinological disorders. Focusing on melatonin's interactions. Gynecol Obstet Invest 1999; 48:179-82.

44. Coker F, Taylor D. Antidepressant-induced hyperprolactinaemia. CNS Drug 2010; 24:563-574.

45. Menoyo A, del Rio E, Baiget M. Characterization of variant alleles of cytochrome CYP2D6 in a Spanish population. Cell Biochem Funct 2006; 24:381-5.

46. Anderson GM, Scahill L, McCracken JT, McDougle CJ, Aman MG, Tierney E, et al. Effects of short- and long-term risperidone treatment on prolactin levels in children with autism. Biol Psychiatry 2007; 61: 545-50.

47. Staller J. The effect of long-term antipsychotic treatment on prolactin. J Child Adolesc Psychopharmacol 2006;16:317-26.

48. Roke Y, Buitelaar JK, Boot, AM, Tenback D, Harten van PN. Risk of hyperprolactinemia and sexual side effects in boys aged 10-20 years old with autism spectrum disorders or disruptive behavior disorder treated with risperidone. J Chid Adolesc Psychopharmacol 2012; 22: 432-9. 


\section{CHAPTER 7}

\section{Summary and discussion}

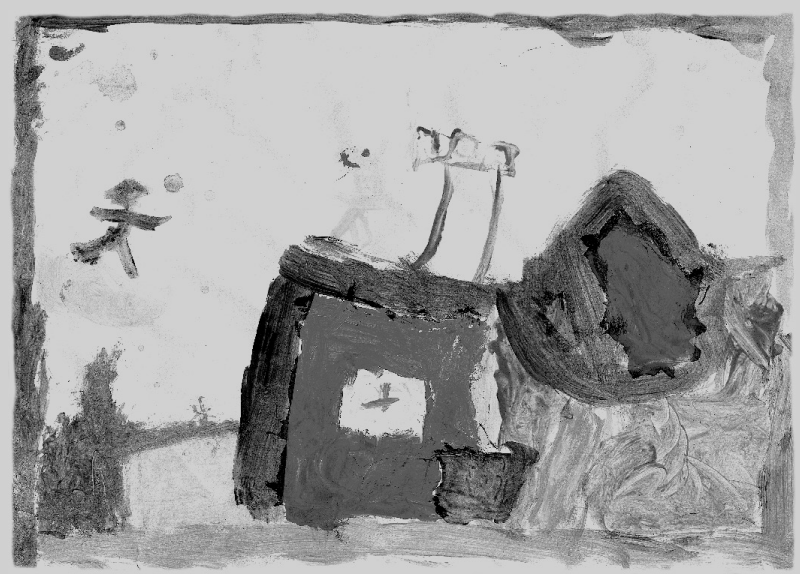


CHAPTER 7 


\section{Aim of the thesis}

The overall aim of this thesis was to evaluate the prevalence and (genetic) risk factors of antipsychotic (AP)-induced hyperprolactinemia and prolactin-related side effects (e.g., gynecomastia, galactorrhea, sexual functioning disorders) in young males with autism spectrum disorder (ASD) and / or disruptive behavior disorder (DBD) treated with APs long-term ( $>16$ months). Further, this study investigated whether young males with AP-induced hyperprolactinemia had hypogonadotropic hypogonadism, delayed puberty, and diminished BMD (bone mineral density) when compared to males without hyperprolactinemia with and without AP treatment and compared to healthy controls.

\section{PART 1 - Chapter 2: Prevalence of (persistent) hyperprolactinemia in children and adolescents: A descriptive review}

In a descriptive review 29 studies were selected after a literature search in the English Medline/ Embase/ Psychinfo/ EBM databases (1965-August 2008). One thousand, three hundred and ninety children and adolescents (weighted average mean age of 10 years, of which $83 \%$ boys) were primarily treated with risperidone (with a weighted average mean dose of 1.6 milligrams per day). After weighted average mean treatment duration of 35 weeks, $62 \%$ of these children and adolescents were hyperprolactinemic (Roke 2009). This descriptive review documents that maintenance treatment with risperidone is associated with persistent elevation of prolactin levels for periods up to two years. The very limited long-term data for pimozide, olanzapine, and quetiapine prohibit drawing conclusions for these antipsychotics (Roke 2009). Based on the high prevalence of AP-induced hyperprolactinemia in children and adolescents, the clinical consequences of AP-induced hyperprolactinemia should be investigated through systematic long-term observational studies including specific questionnaires as well as physical examinations and age and gender-matched reference values for prolactin levels.

\section{PART 2a - Chapter 3-5: Antipsychotic-induced hyperprolactinemia in children and adolescents: A cross-sectional study}

First I will present the main conclusions of the articles described in this thesis, then I will discuss the clinical consequences of AP-induced hyperprolactinemia in a different paragraph on page 83-84.

In our cross-sectional study all participants were recruited from the total patient population of the outpatient adolescent clinic of the GGz Central Psychiatric Center, the Netherlands, from October 2006 to November 2009. We included 56 boys in the AP-treated group (treatment with any antipsychotic medication continuously for more than 16 months) and 47 boys in the medication-naïve group. All 
participants had an IQ above 85 and were excluded if they had a history of thyroid disorders, syndromes, or other chronic diseases affecting puberty, endocrine disorders, if they used oral corticosteroids or anticonvulsants, or if they had a known cause of hyperprolactinemia (Verhelst 2003, Melmed 2011). The findings were that:

- Hyperprolactinemia is a common side effect (49\%) in boys treated long-term with risperidone.

- $43 \%$ of the AP-treated boys had gynecomastia, versus $21 \%$ of the boys in the AP-naïve group. There was no association between the occurrence of gynecomastia and prolactin levels.

- Boys with AP-induced hyperprolactinemia were also more likely to report diminished sexual functioning (erectile and/or orgasm dysfunction, and loss of sexual interest) than boys not treated with antipsychotics.

- AP-induced hyperprolactinemia had no prolactin-related side effects in $46 \%$ of these boys.

- AP-induced hyperprolactinemia is related to significantly lower testosterone levels though within the normal reference range corrected for age and gender.

- LH, FSH and Inhibin B levels and the Tanner stages of puberty were the same for the boys with and without AP-induced hyperprolactinemia.

- The mean volumetric lumbar spine BMD z-score was lower in the AP-treated boys with hyperprolactinemia than in the AP-treated boys without hyperprolactinemia. The volumetric BMD of the lumbar spine is a good predictor of future fractures (especially wrist and forearm fractures), and therefore our findings suggest that AP-induced hyperprolactinemia may have a negative influence on BMD, especially of trabecular bone, such as of the lumbar vertebrae (Jones 2006, Boot 2010).

- $7-11 \%$ of the AP-induced hyperprolactinemic boys had low BMD of the lumbar spine (a z-score $<-2$ ). In adult patients a z-score of $<-2$ is defined as osteoporosis. The International Society for Clinical Densitometry has decided to use the phrase "low BMD" for pediatric patients because children and adolescents are still in the dynamic process of attaining their peak bone mass; however it remains a potential serious side effect, and may increase the risk of fractures (Lewiecki 2008, Bianchi 2008).

\section{PART 2b- Chapter 6: Genetic risk factors}

The Taq1A A1 allele of the DRD2 gene and the activity of the CYP2D6 enzyme complex were investigated in our cross-sectional study as possible risk factors for the development of hyperprolactinemia. Our main conclusion was that the presence of at least one Taq1A A1 allele of the DRD2 gene was positively associated with higher prolactin levels. Furthermore, the prolactin levels and 9-hydroxy risperidone levels increased with reduced or no activity of CYP2D6. However our study lacked power 
to draw firm conclusions about the influence of the activity of the CYP2D6 enzyme complex on prolactin levels.

Therefore, our findings suggest that variants of the D2DR gene may contribute to one's susceptibility to AP-induced hyperprolactinemia, and as a result contribute to developing prolactin-related adverse events such as amenorrhea, galactorrhea, and sexual dysfunctioning. Screening for genes relevant to the effect and side effects of pharmacological treatment may improve the effectiveness of the treatment and reduce side effects, thereby increasing patient quality of life and reducing the costs of treatment (Chou 2000). However, the variants of the D2DR gene and CYP2D6 enzyme are not specific enough to be used in clinical practice (Kirchheiner 2010).

\section{Comparison of our total study population with normative data}

Given the cross-sectional design of our study we compared the results of our total study population $(\mathrm{N}=113)$ of boys with ASD and/ or DBD with or without AP treatment with normative data on height, weight, BMI z-scores, Tanner stages, levels of 25-hydroxyvitamin $\mathrm{D}_{3}$, body composition, and BMD (Fredriks 20001,2). The findings were that:

- Our total study population took 1.6 years longer to attain the same Tanner stage compared to normative data with normal mean z-scores for height $(0.40)$, weight (0.48), and BMI (0.44). When correcting for autism versus DBD, autism showed a trend towards significance for being later in attaining the same stage of puberty than healthy controls.

- Thirteen of the $113(12 \%)$ boys had deficient levels of 25-hydroxyvitamin $\mathrm{D}_{3}$ ( $<30 \mathrm{nmol} / \mathrm{L}$ ) and 37 (36\%) had insufficient ( $<50 \mathrm{nmol} / \mathrm{L})$ levels (Allgrove 2009. These are higher proportions than reported for Dutch young adult males without psychiatric disorders (4\% and 22\% respectively) (Boot 2011).

- Our total study population had a lower mean lean tissue mass, a higher percentage of total body fat than healthy controls; however the BMD of our total study population was not different when compared to normative data (Boot 2010).

These findings suggest first that future research should investigate the relationship between the disorder of ASD and a possible delay in the attainment of Tanner stages of puberty. Second, the higher prevalence of 25-hydroxyvitamin $\mathrm{D}_{3}$ deficiencies and insufficiencies is an important finding, since 25 -hydroxyvitamin $\mathrm{D}_{3}$ is a major determinant of bone mineralization at school age (Pekkinen 2012). Supplements of 25-hydroxyvitamin $\mathrm{D}_{3}$ may prevent problems in the bone mineralization process. Third, our study population had a higher percentage of total body fat and lower lean tissue mass compared to normative data. This higher percentage of body fat may be a risk factor for future cardiovascular disease (Lavie 2012). Further, the lower lean tissue mass, which is mainly muscle mass, is highly related to bone mass 
in children and is important for the attainment of peak bone mass (Boot 2010). One explanation for the higher percentage of body fat and lower lean tissue mass in our study group could be that the boys with ASD participate less in organized outdoor sports activities, and their preferred leisure activities often involve an indoor setting. These preferred indoor activities and the consequent lack of sunlight are probably also the reason for the higher prevalence of 25 -hydroxyvitamin $\mathrm{D}_{3}$ deficiencies and insufficiencies among this group. These findings suggest that children and adolescents with ASD should be stimulated to take part in outdoor physical activities. Our study compared results from our total study group with normative data; this cross-sectional design cannot establish causality. Furthermore, our study had limited power and used self-assessment to investigate Tanner stages of puberty; future studies should be longitudinal, have a larger sample size and thus more statistical power than our study and should also investigate the attainment of Tanner stages of puberty with a physical examination instead of self-assessment and assess testes volume with an orchidometer.

\section{Considerations for the prevention and treatment of hyperprolactinemia}

\section{Clinical consequences}

\section{Bone mineral density}

Our cross-sectional study (Roke 20123) and the study by Calarge et al. (2010) show a relationship between AP-induced hyperprolactinemia and diminished BMD in APtreated boys. These two studies are the first studies investigating the effect of APinduced hyperprolactinemia on bone mineral density in children and adolescents. Our study also showed that within the hyperprolactinemic group 7-11\% of the boys had low BMD of the lumbar spine, which is a potential serious side effect and may lead to bone fragility (Lewiecki 2008). An earlier 2-year longitudinal study by Colao et al. (2000) investigated prolactinoma-induced hyperprolactinemia and the effect on bone mass in 20 adults and 20 adolescents and found that the adolescents had persistent irreversible bone loss, even after dopamine agonistic treatment, which restored normal prolactin levels. In the adult patient group the bone loss process was reversible after treatment with dopamine agonistic drugs. This study shows that adolescence is an important and vulnerable period for the attainment of peak bone mass and that disturbances during this process may be irreversible. It should be noted however that the prolactin elevation in prolactinomas is 2-4 fold higher than in AP-induced elevations, and that we do not know at which threshold value of prolactin elevation the negative effect on bone mineral density begins. Because of the possible negative effect on bone mineralization in adolescence, we recommend active monitoring of prolactin levels and treatment of AP-induced hyperprolacti- 
nemia until long-term follow-up studies indicate the otherwise. In the event of hyperprolactinemia, the dose should be reduced or another drug should be prescribed.

\section{Bone mineral density and fractures in ASD}

There are two previous studies, which investigated the effect of ASD on bone status (Hediger 2008, Mouridsen 2012). One study evaluated fracture prevalence and found this to be lower for patients with ASD, i.e. 12\% for the patients with ASD versus $25 \%$ for the comparison group (follow-up for 30 years, $\mathrm{N}=118$ ) (Mouridsen 2012). The other study investigated bone cortical thickness in children with ASD (mean age 7 years, $\mathrm{N}=75$ ) measured on a hand-wrist radiograph. When compared with normative data, especially the boys with ASD with a dairy-free diet had reduced bone cortical thickness (Hediger 2008). The patients of our study had a normal calcium intake and a fracture prevalence rate of about $20 \%$ (19\% for the ASD boys with hyperprolactinemia versus $21 \%$ for the ASD boys without hyperprolactinemia), which was also low, compared to the normative data fracture rate of $37 \%$ measured at a mean age of 23 years (Boot 2010). As mentioned before our study population had higher proportions of 25-hydroxyvitamin $\mathrm{D}_{3}$ deficiency and insuffi-

ciency compared to the normative data. 25 -hydroxyvitamin $\mathrm{D}_{3}$ is a determinant of BMD in children and adolescents. One explanation could be that boys with ASD have less organized outdoor sports activities, and their preferred leisure activities often involve an indoor setting, which would protect them from sustaining fractures but also makes than susceptible for 25-hydroxyvitamin $\mathrm{D}_{3}$ deficiency or insufficiency's (MacDonald 2011). It is reassuring from a clinical perspective that the psychiatric condition of ASD does not seem to lead to a higher fracture prevalence rate. In our study in boys with ASD or DBD bone mineral density was not significantly different from normal. However, one should be careful when prescribing AP with prolactin-elevating qualities because of the potential negative influence of hyperprolactinemia on BMD.

\section{Hypogonadotropic hypogonadism}

High prolactin levels may inhibit the pulsatile secretion of gonadotropin-releasing hormone, which by reducing the release of gonadotrophic hormones can cause hypogonadism. The effect of AP-induced hyperprolactinemia on testosterone levels has not been investigated in adolescent boys before. The significantly lower testosterone levels in boys with AP-induced hyperprolactinemia compared to boys with ASD or DBD without AP treatment were still within age- and gender-matched reference ranges. The gonadotrophic hormones were in the normal range. We can only speculate that the lower testosterone levels may lead to delayed puberty and sexual functioning disorders. There is one retrospective study, which found no influence on the attainment of Tanner stages of puberty among youths treated with risperidone (Dunbar 2004); however follow-up was limited to one year and a delay in puberty may take longer to take effect (McKeever 2000, Rosen 2001). Our study 
was cross-sectional, had limited power, and used self-assessment to investigate Tanner stages of puberty; future studies should be longitudinal, have a larger sample size and thus more statistical power than our study, and should also investigate the attainment of Tanner stages of puberty with a physical examination instead of self-assessment and assess testes volume with an orchidometer. Hypogonadism is related to small testicular volume. More power and more precise measurement should clarify the relationship between low(er) testosterone levels and the possible negative influence on the progression of puberty.

\section{Sexual functioning}

Hyperprolactinemia was associated with sexual side effects. Fourteen percent of the boys in our study with AP-induced hyperprolactinemia experienced sexual side effect. An earlier study that used a specific questionnaire for adverse sexual events showed a prevalence of $25 \%$ sexual dysfunction among adolescents treated with risperidone $(\mathrm{N}=21)$, olanzapine $(\mathrm{N}=13)$ and quetiapine $(\mathrm{N}=6)$ irrespective of prolactin levels and type of AP used; however this study included $45 \%$ females and irregular menses, gynecomastia and galactorrhea were part of the questionnaire; no actual sexual dysfunction was reported (Saito 2004). In studies of adults with schizophrenia or mood disorders who were treated with risperidone, the rate of diminished sexual functioning due to hyperprolactinemia was about $40 \%$ (Bobes 2003, Knegtering 2004 and 2006). Since the boys included in our study could have been sexually inexperienced or inactive, they might have not been able to selfassess their sexual functioning as well as adult patients. Moreover boys with ASD have difficulties with communication skills, which could have biased our results. Therefore the results of studies in adults with schizophrenia cannot be directly compared to boys with ASD. The sexual functioning data in our study from the Antipsychotic Sexual Functioning Questionnaire (ASFQ) may have been biased by recall and time. The boys had to reflect back to the time when they did not use risperidone. Moreover, some of the boys may have started risperidone before puberty and may have become sexually mature thereafter, so that they might have considered their sexual functioning as unchanged $20 \%$ for the cases and $10 \%$ for the comparison group) or unknown (cases, 30\% and comparison group, 40\%) whereas it was, in fact, suppressed. Moreover, boys who were sexually inexperienced or inactive could not make a before and after comparison. Therefore the actual rate of sexual side effects may be higher than we measured in our study. Nevertheless a significant number of boys (1 in 8) experienced sexual dysfunction in relation to AP-induced hyperprolactinemia. Therefore the clinician should actively and systematically ask about the sexual functioning before the start and over the course of treatment. 


\section{Monitoring}

Systematic longitudinal follow-up studies have not been performed to investigate the clinical consequences for children and adolescents of long-term AP-induced hyperprolactinemia on hypogonadotropic hypogonadism and bone mineral density. However, the data in this thesis and in earlier cross-sectional studies are sufficient cause for concern for us to advise active monitoring of prolactin levels and change of treatment in case of AP-induced hyperprolactinemia if clinically feasible. Another argument for active monitoring is that about half of our study population had APinduced hyperprolactinemia without any obvious prolactin-related symptoms (e.g., gynecomastia, galactorrhea, sexual dysfunctioning). Therefore, we recommend assessment of serum prolactin levels before and during treatment with prolactinelevating antipsychotics (Staller 2006, Citrome 2008, Ho 2011). To establish the diagnosis of hyperprolactinemia, the Endocrine Society recommends (in their practical guideline, Melmed 2011) a single measurement of serum prolactin; a level above the upper limit of normal confirms the diagnosis of hyperprolactinemia as long as the serum sample is obtained without excessive venipuncture stress. Previous short-term studies show a steep increase of the prolactin level within the first six weeks (Aman 2002, Snyder 2002, Biederman 2005) followed by a slow decline after one year of AP treatment (Turgay 2002, Croonenberghs 2005, Stevens 2005, Anderson 2007, Migliardi 2009). Average prolactin levels remained above the reference value after two (Staller 2006, Reyes 2006) and three years of continued AP use (Calarge 2010, Roke 20121,2,3) although two studies reported a tendency towards normalization of prolactin after respectively 12 months (Migliardi 2009) and 22 months (Anderson 2007) of AP treatment. Our results are based on a carefully performed study in a sample of adolescents with long-term treatment of AP and indicate that after a mean of 51.5 months, half of the adolescents still had APinduced hyperprolactinemia.

Since prolactin levels rise steeply during the first six weeks of AP treatment and decline to a plateau phase after three months (Findling 2004), we recommend monitoring prolactin levels after the first three months of treatment and repeating the test every year. Whenever the dose of AP is increased, prolactin levels also increase because of the clear dose-response relationship (Knegtering 2005). Furthermore prolactin-related side effects such as sexual functioning disorders should be addressed before and during treatment, since these sexual side effects occurred in $14 \%$ of the boys in our study with ASD treated with prolactin-elevating AP. Since self-report is a less valid method to assess these side effects, we recommend using a standardized questionnaire, such as the ASFQ (Knegtering 2003). We also suggest investigating the presence of gynecomastia and galactorrhea before and during treatment. We recommend using a questionnaire to check for symptoms of gynecomastia or galactorrhea (Saito 2004) and also a physical examination of the breasts (Roke 20121). The physician may also interview the patient about the following topics: a (family) history of fractures, calcium intake, sun exposure, and 
exercise. This assessment of risk factors for future osteoporosis may help the physician to decide how to treat the hyperprolactinemia and to give the patient advice on exercise and dietary intake to minimalize the risk of future osteoporosis. Since 25-hydroxyvitamin $\mathrm{D}_{3}$ is a major determinant of bone mineralization and bone strength in children and adolescents (Boot 2011, Pekkinen 2012), we recommend assessment of serum 25-hydroxyvitamin $\mathrm{D}_{3}$ and starting supplementation when necessary (figure 1).

\section{Treatment}

APs are very effective in reducing maladaptive behaviors such as irritability, selfinjury, stereotypies, and hyperactivity in children and adolescents with ASD, and reduce irritability and aggressive behavior in children and adolescents with DBD (Aman 2009, Wink 2010). However, these drugs may have side effects such as APinduced hyperprolactinemia. If hyperprolactinemia develops the AP treatment should be stopped if this is clinically feasible. Prolactin levels should normalize within days depending on the half-life (T 1/2) of the drug (Pollock 1998, Turrone 2002). Alternatively, the dosage should be reduced as there is a dose-response relation with prolactin levels (Knegtering 2005) or another AP agent without prolactin-elevating qualities should be tried (e.g., quetiapine, aripiprazol, clozapine) (Stevens 2005, Greenaway 2009). If these strategies fail, aripiprazole addition may lead to normalization of prolactin levels. Aripiprazol is a partial agonist of the dopamine D2 receptor and therefore the addition of aripiprazol leads to normalization of prolactin levels within one week of treatment (Byerly 2009). If the hyperprolactinemia persists despite these steps, further examination of the patient is necessary (Ho 2011) (figure 1).

\section{Summary of recommendations}

We recommend:

- monitoring the prolactin level before treatment, after three months of treatment and repeating this every year or three months after dose increase.

- using a standardized questionnaire, such as the ASFQ, to measure sexual side effects (Knegtering 2003).

- investigating the presence of gynecomastia and galactorrhea before and during treatment using a questionnaire (Saito 2004) and also a physical examination of the breasts (2Roke 2012).

- assessing serum 25-hydroxyvitamin $\mathrm{D}_{3}$ and start supplementation if necessary.

- assessing risk factors for future osteoporosis.

- changing treatment in case of AP-induced hyperprolactinemia. 


\section{Patient with potential prolactin elevating AP}

Assessment of prolactin level and prolactin related side effects: gynecomastia, galactorrhea, and sexual side effects. Determine risk factors of osteoporosis such as family history, lifestyle and dietary calcium intake and assess 25 -hydroxyvitamin $\mathrm{D}_{3}$ level

\begin{tabular}{|c|c|}
\hline AP-induced hyperprolactinemia & Normal prolactin level \\
\hline Step 1 stop AP & \\
\hline Step 2 dosage reduction & \\
\hline Step 3 switch to quetiapine, clozapine, aripiprazol & \\
\hline Step 4 addition of aripiprazol & \\
\hline $\begin{array}{l}\text { Persistent hyperprolactinemia despite step } 1-4 \\
\text { Further investigation of the patient to exclude other } \\
\text { causes for hyperprolactinemia }\end{array}$ & $\begin{array}{l}\text { Normal prolactin level } \\
\text { No action }\end{array}$ \\
\hline \multicolumn{2}{|c|}{ No other reason for hyperprolactinemia and stopping/ or switching is clinically non feasible: } \\
\hline \multicolumn{2}{|l|}{ Investigate the risk factors of osteoporosis: } \\
\hline \multicolumn{2}{|l|}{ Dietary calcium intake and lifestyle advice } \\
\hline \multicolumn{2}{|c|}{ Family history of osteoporosis } \\
\hline \multicolumn{2}{|c|}{ Assess 25 -hydroxyvitamin $\mathrm{D}_{3}$, if $<35 \mathrm{nmol} / \mathrm{L}$ suppletion is necessary** } \\
\hline \multicolumn{2}{|l|}{ Investigate bone mineral density (BMD) lumbar spine: } \\
\hline \multicolumn{2}{|l|}{ Dual X-ray Absorptiometry (DEXA) } \\
\hline Low BMD $\left(<-2 \mathrm{SD}^{*}\right)$ & Normal prolactin level \\
\hline Rethink step 1 to 4 : stop or switch AP & No action \\
\hline
\end{tabular}

Figure 1. Flowchart: monitoring and treatment of antipsychotic (AP)-induced hyperprolactinemia

* in case of small stature adjust for height

** Winzenberg T, Powell S, Shwa KA, Jones G. Effects of vitamin D supplementation on bone density in healthy children: systematic review and meta-analysis. BMJ. 2011 Jan 25;342:c7254

\section{Genotyping}

Our results also provide further input to clinical considerations and discussions about whether a risk assessment (genotyping) for hyperprolactinemia should be 
performed before prescribing antipsychotics such as risperidone to children and adolescents with psychiatric disorders. A risk assessment may reduce treatment expenses and may reduce adverse events (Chou 2000). However, the variants of D2DR gene and CYP2D6 enzyme are not specific enough yet to be used in clinical practice (Kirchheiner 2010).

\section{Challenges and future research}

\section{Challenges}

The problem with AP-induced hyperprolactinemia is that we do not know at which threshold value side effects (e.g., gynecomastia, diminished sexual functioning, galactorrhea) and complications such as diminished BMD and hypogonadotropic hypogonadism may begin. Half of the patients with hyperprolactinemia experienced no side effects. The question is whether these patients, those with hyperprolactinemia without evident side effects, are at increased risk for future complications. In our cross-sectional study (Roke 20123) the boys with AP-induced hyperprolactinemia and low BMD (z-score < -2) had no other prolactin-related side effects. Low BMD, especially in children and adolescents, is a serious side effect (Lewiecki 2008), which may lead to future clinical consequences such as higher bone fragility and osteoporosis. Hyperprolactinemia seems to be a long-term side effect of AP in half the children and adolescents treated, and could potentially influence processes such as the attainment of the peak bone mass. BMD continues to increase during adolescence, and in boys peak bone mass reaches a plateau between 18 to 23 years of age (Boot 2010). Still, it is possible that once the prolactin concentration normalizes, bone mineralization increases to normal. The impact of hyperprolactinemia on BMD is clinically relevant only if it leads to increased bone fragility and fractures.

\section{Future research:}

\section{AP-induced hyperprolactinemia and bone mineral density}

Our study had no longitudinal follow-up design and could thus not establish causality. Follow-up studies with more power are needed to investigate over time what is the influence of long-term hyperprolactinemia on bone mineral density, peak bone mass, bone fragility, bone fractures, and the biochemical bone markers, and to examine whether the process of bone loss is reversible or not. These studies should also disentangle the effects of the psychiatric conditions (ASD or DBD) and the effects of AP treatment and hyperprolactinemia and the effect of the disease and lifestyle itself. These future studies can provide the answer to the question on the clinical relevance raised in the previous paragraph. 


\section{Future research:}

\section{AP-induced hyperprolactinemia and hypogonadotropic hypogonadism}

Future studies should be longitudinal, have more power than our study, and should evaluate Tanner stages and testicular volume. With more power and more precise measurement over time (including a physical examination rather than self-assessment of puberty), the relationship between low(er) testosterone levels and the influence on the progression of puberty should become clear. One future study has already started: the EU 7th framework program (PERS - Pediatric European Risperidone Studies) will study the short and long-term efficacy and safety of risperidone in children with $C D$ and other serious psychiatric disorders. As part of this program a 2-year observational long-term study will be conducted with about 400 children and adolescents treated with risperidone to assess the drug's effects on endocrinological, cognitive, bone mineral density, and other clinical measures.

\section{Future research:}

\section{AP-induced hyperprolactinemia and hypogonadism and cardiovascular hazards}

Hypogonadotropic hypogonadism due to hyperprolactinemia may affect lipid and glucose metabolism (Sonmez 2011, Miner 2011) and should be investigated in future research. Hyperprolactinemia diminishes testosterone levels and low testosterone levels may have a negative effect on lipid and glucose metabolism. A retrospective analysis among 332 male patients with hypogonadism (mean age 22 years) showed higher fasting glucose, insulin and triglyceride levels as well as a higher arterial blood pressure and waist circumference when compared to 395 ageand body mass index (BMI)-matched healthy young men (Sonmez 2011). Another 12 month prospective observational cohort study ( $N=849$, mean age 52 , males) showed that middle-aged men with hypogonadism exhibited a high prevalence of cardiometabolic risk factors that were correlated with testosterone levels. This suggests that low testosterone levels are associated with adverse medical conditions that pose serious health risks, especially in younger men (Miner 2011). Future research should investigate at which low threshold testosterone values may cause cardiovascular health risks and if AP-induced hyperprolactinemia could be the cause of such a hypogonadic state. Theoretically high prolactin levels may be an indicator of future cardiovascular problems. Another considaration is that the boys with ASD and DBD participating in our study already had a higher total percentage of body fat when compared to normative data. This higher percentage of body fat is a risk factor for future cardiovascular disease (Lavie 2012); boys with ASD participate less in organized outdoor sports activities, and their preferred leisure activities often involve an indoor setting, which could be part of the explanation for their higher percentage of body fat. This could be another argument in the proactive monitoring of prolactin levels. In conclusion, this research confirms that Aps repre- 
sent an effective means of treating the negative effects of ASDs and DBDs in children and adolescents but they are not without dangers for children and adolescents. Clinicians should take these these dangers into consideration, and researchers should further investigate them.

\section{References}

Allgrove J, Shaw N. Calcium and Bone Disorders in Children and Adolescents. Karger Basel 2009.

Aman MG, De Smedt G, Derivan A, Lyons B, Findling RL. Double-blind, placebo-controlled study of risperidone for the treatment of disruptive behaviors in children with subaverage intelligence. Am J Psychiatry. 159: 1337-46, 2002.

Aman MG, McDougle CJ, Scahill L, Handen B, Arnold LE, Johnson C, Stigler KA, Bearss K, Butter E, Swiezy NB, Sukhodolsky DD, Ramadan Y, Pozdol SL, Nikolov R, Lecavalier L, Kohn AE, Koenig K, Hollway JA, Korzekwa P, Gavaletz A, Mulick JA, Hall KL, Dziura J, Ritz L, Trollinger S, Yu S, Vitiello B, Wagner A. Medication and Parent Training in Children With Pervasive Developmental Disorders and Serious Behavior Problems: Results From a Randomized Clinical Trial. J Am Acad Child Adolesc Psychiatry. 48:1143-54, 2009.

Anderson GM, Scahill L, McCracken JT, McDougle CJ, Aman MG, Tierney E. Effects of short- and long-term risperidone treatment on prolactin levels in children with autism. Biol Psychiatry. 61: 545-50, 2007.

Bianchi ML. Osteoporosis in children and adolescents. Bone. 41: 486-95, 2007.

Biederman J, Mick E, Wozniak J, Aleardi M, Spencer T, Faraone SV. An open-label trial of risperidone in children and adolescents with bipolar disorder. J Child Adolesc Psychopharmacol. 15: 311-317, 2005.

Bobes J, Garc APMP, Rejas J, Hernandez G, Garcia-Garcia M, Rico-Villademoros F. Frequency of sexual dysfunction and other reproductive side-effects in patients with schizophrenia treated with risperidone, olanzapine, quetiapine, or haloperidol: the results of the EIRE study. J Sex Marital Ther. 29: 125-47, 2003.

Boot AM, de Ridder M, van der Sluis I, van Slobbe I, Krenning E, Keizer-Schrama S. Peak bone mineral density, lean body mass and fractures. Bone. 46: 336-41, 2010.

Boot AM, Krenning E, de Muinck Keizer-Schrama S. The relation between 25-hydroxyvitamin D with peak bone mineral density and body composition in healthy young adults. J Pediatr Endocrinol Metab. 24: 355-60, 2011.

Byerly JM, Marcus RN, Quynh-Van Tran, Eudicone JM,Whitehead R, Baker R. Effects of aripiprazole on prolactin levels in subjects with schizophrenia during cross-titration with risperidone or olanzapine: Analysis of a randomized, open-label study. Schizophrenia Research. 107: 218-222, 2009.

Calarge CA, Zimmerman B, Xie D, Kuperman S, Schlechte JA. A cross-sectional evaluation of the effect of risperidone and selective serotonine reuptake inhibitors on bone mineral density in boys. J Clin Psychiatry 1:338-347, 2010.

Citrome L. Current guidelines and their recommendations for prolactin monitoring in psychosis. J Psychopharmacol 22:90-7, 2008.

Chou, WH, Yan FX, de Leon J, Barnhill J, Rogers T, Cronin M, Pho M, Xiao V, Ryder TB, Liu WW, Teiling C, Wedlund PJ. Extension of a pilot study: Impact from the cytochrome P450 2D6 polymorphism on outcome and costs associated with severe mental illness. Journal of Clinical Psychopharmacology. 20: 246-251, 2000.

Colao A, Di Somma C, Loche S, Di Sarno A, Klain M, Pivonello R, Pietrosante M, Salvatore M, Lombardi G. Prolactinomas in adolescents: persistent bone loss after 2 years of prolactin normalization. Clin Endocrinol. 52:319-27, 2000.

Croohnenberghs J, Fegert JM, Findling RL, De Smedt G, Van Dongen S. Risperidone in children with disruptive behavior disorders and subaverage intelligence: a 1-year, open-label study of 504 patients. J Am Acad Child Adolesc Psychiatry. 44: 64-72, 2005. 
Dunbar F, Kusumakar V, Daneman D, Schulz M. Growth and sexual maturation during long-term treatment with risperidone. Am J Psychiatry. 161: 918-20, 2004.

Findling RL, McNamara NK. Atypical antipsychotics in the treatment of children and adolescents: clinical applications. J Clin Psychiatry. 65: 30-44, 2004.

Fredriks AM, van Buuren S, Burgmeijer RJ, Meulmeester JF, Beuker RJ, Brugman E, Roede MJ, VerlooveVanhorick SP, Wit JM. Continuing positive secular growth change in The Netherlands 1955-1997. Pediatr. Res. 47:316-23, 20001.

Fredriks AM, van Buuren S, Wit JM, Verloove-Vanhorick SP. Body index measurements in 1996-7 compared with 1980. Arch Dis Child. 82:107-12, 20002.

Greenaway M, Elbe D. Focus on aripiprazole: a review of its use in child and adolescent psychiatry. J Can Acad Child Psychiatry. 18:250-60, 2009.

Hediger ML, England LJ, Molloy CA, Yu KF, Manning-Courtney P, Mills JL. Reduced bone cortical thickness in boys with autism or autism spectrum disorder.J Autism Dev Disord. 38:848-56, 2008.

Ho J, Panagiotopoulos C, McCrindle B, Grisaru S, Pringsheim T, CAMESA guideline group. The Canadian Alliance for Monitoring Effectiveness and Safety of Antipsychotics in Children (CAMESA) Guideline Project: Management Recommendations for Metabolic Complications Associated with Second Generation Antipsychotic Use in Children and Youth. J Can Acad Child Adolesc Psychiatry. 20:234-41, 2011.

Jones G, Ma D, Cameron F. Bone density interpretation and relevance in Caucasian children aged 9-17 years of age: insights from a population-based fracture study. J Clin Densitom. 9: 202-9, 2006.

Kirchheiner J, Seeringer A, Viviani R. Pharmacogenetics in psychiatry--a useful clinical tool or wishful thinking for the future? Curr Pharm Des. 16(2):136-44, 2010.

Knegtering H, van der Moolen AE, Castelein S, Kluiter H, van den Bosch RJ. What are the effects of antipsychotics on sexual dysfunctions and endocrine functioning? Psychoneuroendocrinology. 28:109-23, 2003

Knegtering R, Castelein S, Bous H, Van Der Linde J, Bruggeman R, Kluiter H: A randomized open-label study of the impact of quetiapine versus risperidone on sexual functioning. J Clin Psychopharmacol 24: 56-61, 2004.

Knegtering R, Baselmans P. Predominant role of the 9-hydroxy metabolite of risperidone in elevating blood prolactin levels. Am J Psychiatry. 162:1010-2, 2005.

Knegtering H, Boks M, Blijd C, Castelein S, van den Bosch RJ, Wiersma D. A randomized open-label comparison of the impact of olanzapine versus risperidone on sexual functioning. J Sex Marital Ther. 32: 315-26, 2006.

Lavie CJ, De Schutter A, Patel DA, Romero-Corral A, Artham SM, Milani RV. Body composition and survival in stable coronary heart disease: impact of lean mass index and body fat in the "obesity paradox". J Am Coll Cardiol. 60:1374-80, 2012.

Lewiecki EM, Gordon CM, Baim S, Leonard MB, Bishop NJ, Bianchi M, Kalkwarf HJ, Langman CB, Plotkin H, Rauch F, Zemel BS, Binkley N, Bilezikian JP, Kendler DL, Hans DB, Silverman S.International Society for Clinical Densitometry 2007 Adult and Pediatric Official Positions. Bone. 43: 1115-1121, 2008.

Macdonald M, Esposito P, Ulrich D. The physical activity patterns of children with autism. BMC Res Notes.18 : 4-422, 2011.

McKeever M. Delayed Puberty. Pediatrics in Review. 21: 250-251, 2000.

Melmed S, Casanueva FF, Hoffman AR, Kleinberg DL, Montori VM, Schlechte JA, Wass JA. Diagnosis and treatment of hyperprolactinemia: an Endocrine Society clinical practice guideline. J Clin Endocrinol Metab. 96: 273-88, 2011.

Migliardi G, Spina E, D'Arrigo C, Gagliano A, Germanò E, Siracusano R, Diaz FJ, de Leon J. Short- and longterm effects on prolactin of risperidone and olanzapine treatments in children and adolescents. Prog Neuropsychopharmacol Biol Psychiatry. 33:1496-501, 2009.

Miner MM, Khera M, Bhattacharya RK, Blick G, Kushner H.oriarty-Kelsey M, Harwood JE, Travers SH, Zeitler PS, Nadeau KJ Baseline data from the TRiUS registry: symptoms and comorbidities of testosterone deficiency. M Postgrad Med. 123:17-27, 2011. 
Mouridsen S, Rich B, Isager T. Fractures in individuals with and without a history of infantile autsm. A Danish register study based on hospital discharge diagnoses. J Autism Dev Disord. 42: 619-624, 2012.

Pekkinen M, Viljakainen H, Saarnio E, Lamberg-Allardt C, Mäkitie O. Vitamin d is a major determinant of bone mineral density at school age. PLoS One. 7: 1-7, 2012.

Pollock A, McLaren EH. Serum prolactin concentration in patients taking neuroleptic drugs. Clin Endocrinol. 49: 513-6,1998.

Reyes M, Croonenberghs J, Augustyns I, Eerdekens M. Long-term use of risperidone in children with disruptive behavior disorders and subaverage intelligence: efficacy, safety, and tolerability. J Child Adolesc Psychopharmacol. 16: 260-72, 2006.

Roke Y, Van Harten PN, Boot AM, Buitelaar JK. Antipsychotic medication in children and adolescents: A descriptive review of the effects on prolactin level and associated side effects.J Child Adolesc Psychopharmacol. 19: 403-1, 2009.

Roke Y, Buitelaar JK, Boot AM, Tenback D, van Harten PN. Risk of hyperprolactinemia and sexual side effects in males 10-20 years old diagnosed with autism spectrum disorders or disruptive behavior disorder and treated with risperidone. J Child Adolesc Psychopharmacol. 22: 432-9, 20121.

Roke Y, van Harten PN, Buitelaar JK, Tenback DE, de Rijke YB, Boot AM. Antipsychotic-induced hyperprolactinemia and testosterone levels in boys. Horm Res Paediatr. 77: 235-40, 2012.2

Roke Y, van Harten P, Buitelaar J, Tenback D, Quekel L, de Rijke Y, Boot A. Bone mineral density in male adolescents with autism spectrum disorders and disruptive behavior disorder with or without antipsychotic treatment. Eur J Endocrinol. 167 855-63, 20123.

Rosen D, Foster C. Delayed Puberty. Pediatrics in Review. 22: 309-315, 2001.

Saito E, Correll CU, Gallelli K, McMeniman M, Parikh UH, Malhotra AK. A prospective study of hyperprolactinemia in children and adolescents treated with atypical antipsychotic agents. J Child Adolesc Psychopharmacol. 14: 350-8, 2004.

Sonmez A, Haymana C, Bolu E, Aydogdu A, Tapan S, Serdar M, Altun B, Barcin C, Taslipinar A, Meric C, Uckaya G, Kutlu M. Metabolic syndrome and the effect of testosterone treatment in young men with congenital hypogonadotropic hypogonadism. Eur J Endocrinol. 164: 759-64, 2011.

Snyder R, Turgay A, Aman M, Binder C, Fisman S, Carroll A. Effects of risperidone on conduct and disruptive behavior disorders in children with subaverage IQs. J Am Acad Child Adolesc Psychiatry. 41: 1026-36, 2002.

Staller J. The effect of long-term antipsychotic treatment on prolactin. J Child Adolesc Psychopharmacol. 16: 317-26, 2006.

Stevens JR, Kymissis PI, Baker AJ. Elevated prolactin levels in male youths treated with risperidone and quetiapine. J Child Adolesc Psychopharmacol. 15: 893-900, 2005.

Turgay A, Binder C, Snyder R, Fisman S. Long-term safety and efficacy of risperidone for the treatment of disruptive behavior disorders in children with subaverage IQs. Pediatrics. 110: e34, 2002.

Turrone P, Kapur S, Seeman MV, Flint AJ. Elevation of prolactin levels by atypical antipsychotics. Am J Psychiatry 159: 133-135, 2002.

Verhelst J, Abs R. Hyperprolactinemia: pathophysiology and management. Treat Endocrinol. 2: 23-32, 2003.

Wink LK, Erickson CA, McDougle CJ. Pharmacologic treatment of behavioral symptoms associated with autism and other pervasive developmental disorders. Curr Treat Opt Neurol. 12: 529-38, 2010. 


\section{Samenvatting}

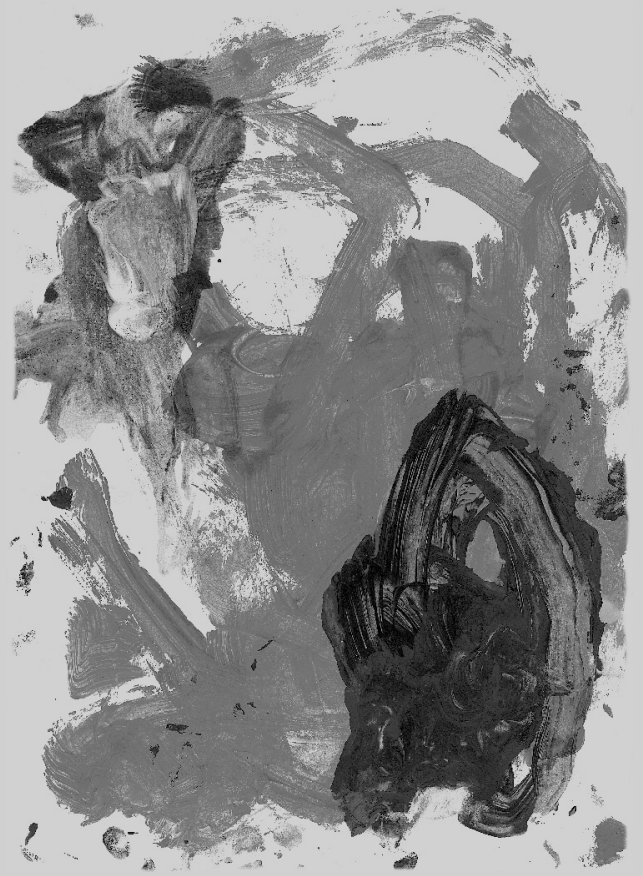


SAMENVAT TING 
In de laatste jaren is de belangstelling voor, en de toepassing van farmacologische interventies in de kinder- en jeugdpsychiatrie aanzienlijk toegenomen, vooral bij psychotische en externaliserende stoornissen. De veiligheid en de effectiviteit van farmacologische interventies op de kinderleeftijd zijn slechts voor een beperkt aantal psychiatrische stoornissen onderzocht. Off-label voorschrijven (onder de leeftijdsgrenzen en buiten de indicatiegebieden) is in de kinderpsychiatrie eerder regel dan uitzondering. Door het meer voorschrijven van psychofarmaca, zoals antipsychotica (AP) in de kinder- en jeugdpsychiatrie (16.000 kinderen en jongeren kregen een AP voorgeschreven in Nederland in 2012; bron Stichting Farmaceutische Kerngetallen), treden vaker ongewenste effecten op. Voorbeelden zijn metabole bijwerkingen zoals obesitas, hyperglykemie en dyslipidemie, neurologische bijwerkingen zoals bewegingsstoornissen en endocriene bijwerkingen zoals hyperprolactinemie. Dit proefschrift richt zich op één van die bijwerkingen, namelijk de AP-geïnduceerde hyperprolactinemie.

De meeste AP blokkeren in mindere of meerdere mate de dopamine 2 (D2)receptorblokker. Hierdoor wordt de dopamineconcentratie verlaagd. Dopamine wordt ook wel prolactin inhibiting factor genoemd; door verlaging van de dopamineconcentratie valt de rem weg op prolactine in de hypofysevoorkwab, waardoor deze verhoogd wordt. Dit kan leiden tot hyperprolactinemie. Hoe sterker de D2blokkerende werking van het AP, hoe meer kans er is op hyperprolactinemie. Risperidon is geen sterke D2-blokker, maar doordat risperidon en de metaboliet 9hydroxyrisperidon hydrofiele stoffen zijn, gaan ze niet door de bloed-hersenbarrière en blijft de concentratie risperidon en 9-hydroxyrisperidon hoog rondom de hypofyse die net buiten de bloed-hersenbarrière ligt. Daarbij speelt ook nog mee dat 9-hydroxyrisperidon een lange halfwaardetijd heeft ( $\mathrm{t} 1 / 2=24 \mathrm{uur}$ ) en daardoor langdurig de hypofyse beïnvloedt en de prolactinespiegel derhalve verhoogt. De definitie van hyperprolactinemie volgens de Clinical Practice Guidelines van the Endocrine Society (2011), is een in het serum gemeten te hoge waarde voor de leeftijd en het geslacht van het hormoon prolactine. Voor mannen is sprake van hyperprolactinemie boven de $18 \mathrm{ng} / \mathrm{ml}$ en voor vrouwen boven de $30 \mathrm{ng} / \mathrm{ml}$. Bij kinderen en jongeren hangt de concentratie af van de leeftijd, het geslacht en de etniciteit. In de prolactinestudie, waar dit proefschrift over gaat, is een waarde boven het 97,5e percentiel voor leeftijd en geslacht van blanke jongeren gehanteerd.

Het doel van dit proefschrift is het vaststellen van de incidentie van APgeïnduceerde hyperprolactinemie en het in kaart brengen van het voorkomen van mogelijk door hyperprolactinemie veroorzaakte bijwerkingen op korte en lange termijn, zoals gynaecomastie, galactorroe, seksuele functiestoornissen, vertraagde puberteitsontwikkeling, hypogonadotroop hypogonadisme en verminderde botdichtheid.

Een ander doel is om op basis van deze resultaten meer inzicht te kunnen geven in de mogelijke klinische consequenties van AP-geïnduceerde hyperprolactinemie en mede daardoor tot een monitoring- en behandeladvies te kunnen komen. 
Hoofdstuk 1 beschrijft de eventuele gevolgen van AP-geïnduceerde hyperprolactinemie voor de korte (gynaecomastie, galactorroe, amenorroe, seksuele functiestoornissen) en de lange termijn (hypogonadotroop hypogonadisme, puberteitsvertraging, verminderde botdichtheid en verhoogd risico op maligniteiten). Risperidon is het meest gebruikte AP in de kinder- en jeugdpsychiatrie en vormt het enige AP waarmee langetermijnstudies met voldoende aantallen kinderen en jongeren zijn gedaan naar het voorkomen van hyperprolactinemie. Volgens een meta-analyse in 2009 is de prolactinespiegel blijvend verhoogd bij $62 \%$ van de kinderen en jongeren. Het merendeel van de studiepopulatie betrof jongens (83\%) met een gemiddelde dosering risperidon van 1,6 mg per dag bij een gemiddelde duur van 35 weken behandeling. Recentere studies over langere termijn laten een prevalentie van hyperprolactinemie zien van $50 \%$ na gemiddeld 3 jaar risperidongebruik. Ongunstige effecten ontstaan pas wanneer de hyperprolactinemie een kritische grens overschrijdt, die per individu verschilt. Effecten die kunnen optreden bij hyperprolactinemie zijn: oligomenorroe/amenorroe, gynaecomastie, galactorroe, libidoverlaging, orgasmestoornissen, erectie- en ejaculatiestoornissen en fertiliteitsproblemen. Amenorroe treedt op bij een prolactinespiegel rond de $60 \mathrm{ng} / \mathrm{ml}$; voor de overige klachten is geen drempelwaarde bekend. De adolescentie is de belangrijkste periode voor de aanleg van de piekbotmassa (= de maximale hoeveelheid bot die tot het 25e levensjaar wordt verkregen). Verstoringen tijdens de aanleg van de piekbotmassa kunnen later meer kans geven op osteoporose. Hyperprolactinemie kan direct en indirect een negatieve rol bij de botstofwisseling spelen.

Hyperprolactinemie heeft een direct remmend effect op de botombouw, door de botafbraak meer te stimuleren dan de botaanmaak. Daarnaast zorgt hyperprolactinemie door het veroorzaken van hypogonadotroop hypogonadisme indirect voor een remmend effect op de botaanmaak. Bij hypogonadotroop hypogonadisme is er sprake van lagere spiegels van geslachtshormonen, hetgeen een negatief effect heeft op de botdichtheid. Het verminderen van de geslachtshormonen kan mogelijk ook een remmende werking hebben op de puberteitsontwikkeling en op de ontwikkeling van de seksualiteit. Er is geen prospectief onderzoek bekend waarin het effect van hyperprolactinemie op de botdichtheid en/of de puberteit en seksuele ontwikkeling is onderzocht.

Hoofdstuk 2 is een beschrijvend overzicht van de studies die tot en met 2008 gedaan zijn naar de incidentie van AP-geïnduceerde hyperprolactinemie bij kinderen en jongeren en de incidentie van bijkomende prolactinegerelateerde klachten. In de databases van Medline, Embase en PsycINFO en EBM-databases (1965-augustus 2008) is gezocht met de volgende zoektermen: "risperidone", "olanzapine", "pimozide", "clozapine", "quetiapine", "haloperidol", "aripiprazole", "amisulpiride", "ziprasidone", "(a)typical antipsychotics", "adverse effects", "side effects", "hyperprolactinaemia", "bone mineral density", “children”, "adolescents”, "prolactinoma”, "osteoporosis", "prolactin”, "hypogonadism”, "bone density”, "sex hormone”, "androgen", "estrogen", "metabolic", “endocrine”, "puberty disorders", "delayed pu- 
berty", "polymorphism", "genetic" and "puberty". Gegevens over prolactinespiegels zijn niet beschikbaar voor haloperidol, pimozide, risperidon, olanzapine, clozapine, ziprasidon en quetiapine.

De gebruikte dosering van de verschillende AP is omgerekend naar een chloorpromazine-equivalente dosering. Er zijn 29 studies met een studieduur van 3 weken of meer gevonden: respectievelijk met risperidon $(\mathrm{N}=20$, gewogen gemiddelde dosering 1,6 mg per dag), olanzapine ( $\mathrm{N}=7$, gewogen gemiddelde dosering $12,7 \mathrm{mg}$ per dag), quetiapine ( $\mathrm{N}=5$, gewogen gemiddelde dosering $378,5 \mathrm{mg}$ per dag), haloperidol $(\mathrm{N}=4$, gewogen gemiddelde dosering $7,2 \mathrm{mg}$ per dag), pimozide $(\mathrm{N}=3$, gewogen gemiddelde dosering $3,7 \mathrm{mg}$ per dag), clozapine $(\mathrm{N}=2$, gewogen gemiddelde dosering $269,9 \mathrm{mg}$ per dag) en met ziprasidon ( $\mathrm{N}=1$, gemiddelde dosering $98,3 \mathrm{mg}$ per dag). De onderzoeksduur is wisselend en varieert van 3 tot 106 weken. Van de 29 publicaties zijn er 6 gebaseerd op dezelfde populatie. De onderzochte populatie is heterogeen in diagnose, van kinderen en jongeren met autismespectrumstoornis (ASS) of bipolaire stoornis tot kinderen en jongeren met schizofrenie. Ook de intelligentie varieerde van normaal tot matig verstandelijk beperkt.

De onderzoeksmethode verschilt per studie: 17 studies hebben een openlabelopzet, 4 studies een observationele opzet en 8 studies zijn dubbelblind uitgevoerd. In 7 risperidonstudies wordt de prolactinespiegel tussen de 48 en 106 weken bepaald. Van de 29 studies hebben er 10 een prospectieve opzet, met prolactinespiegel als primaire uitkomstmaat. Voor olanzapine, quetiapine en pimozide zijn slechts data van 1 langetermijnstudie bekend. Voor clozapine en ziprasidon zijn alleen prolactinedata over een periode van 6 weken bekend.

Het totale aantal bestudeerde patiënten is $1382,170,72,56,46,30$ en 12 voor respectievelijk risperidon, olanzapine, quetiapine, haloperidol, pimozide, clozapine en ziprasidon.

Het totale aantal jongens in deze studies ligt tussen de 63-83\%. De kinderen en jongeren die behandeling krijgen met risperidon, pimozide of haloperidol hebben een gewogen gemiddelde leeftijd van rond de 10 jaar. Voor quetiapine, clozapine, olanzapine en ziprasidon ligt de gewogen gemiddelde leeftijd tussen de 13 en 15 jaar.

Alle AP behalve clozapine, ziprasidon en quetiapine verhoogden de prolactinespiegel van uitgangswaarden van $8,0 \mathrm{ng} / \mathrm{ml}$ naar $25-28 \mathrm{ng} / \mathrm{ml}$ na $4-8$ weken behandeling. De incidentie van hyperprolactinemie (zoals beschreven in hoofdstuk 2) gedurende behandeling met haloperidol, pimozide, risperidon, olanzapine en quetiapine is respectievelijk $90 \%, 80 \%, 62 \%, 31 \%$ en $12 \%$. Alleen voor risperidon zijn voldoende langetermijndata bekend om te kunnen concluderen dat een behandeling van 2 jaar kan leiden tot een blijvende AP-geïnduceerde hyperprolactinemie.

Van de prolactinegerelateerde bijwerkingen zijn alleen gynaecomastie, galactorroe, amenorroe en seksuele functiestoornissen onderzocht. Kinderen en jongeren die behandeld worden met olanzapine, haloperidol, quetiapine en risperidon rapporteren respectievelijk 14\%, 14\%, 6\% en 5\% klachten gerelateerd aan hyperprolactinemie. De frequentst gemelde prolactinegerelateerde bijwerkingen zijn 
gynaecomastie (risperidon 3\%, olanzapine 6\% en haloperidol 7\%) en onregelmatige menstruatie (risperidon 6\%, haloperidol 15\% en quetiapine 12\%). Nadeel is dat de incidentie gemeten is door middel van spontane zelfrapportage, wat een niet heel betrouwbare meting geeft en kan leiden tot te weinig rapporteren.

Met betrekking tot de geslachtshormonen en de botdichtheid zijn er geen gegevens bekend.

Twee studies hebben naar de invloed van AP-geïnduceerde hyperprolactinemie op de puberteit gekeken. Deze studies vinden geen vertragende invloed van de APgeïnduceerde hyperprolactinemie op de puberteitsontwikkeling. Echter, aangezien deze studies een follow-upduur hebben van 1 jaar, is er geen goede conclusie te trekken over puberteitsvertraging.

Hoofdstuk 3 richt zich op het onderzoeken van de incidentie van AP-geïnduceerde hyperprolactinemie en het voorkomen van aan prolactine gerelateerde bijwerkingen zoals gynaecomastie, galactorroe en seksuele functiestoornissen. Dit onderzoek is uitgevoerd binnen de kinder- en jeugdpsychiatrische afdeling van GGZ Centraal Fornhese, bij jongens met een autismespectrumstoornis (ASS) en of een disruptive behavior disorder (DBD) tussen de 10-20 jaar (gemiddelde leeftijd 15 jaar). Er zijn 98 jongens met ASS en 10 jongens met DBD geïncludeerd. De AP-groep bestaat uit jongens die langer dan 16 maanden met risperidon behandeld zijn (groep 1, $\mathrm{N}=51$, gemiddelde leeftijd 15 jaar). Groep 2 bestaat uit jongens die nooit met AP behandeld zijn ( $N=47$, gemiddelde leeftijd 15 jaar). Groep 1 en 2 zijn vergelijkbaar voor leeftijd, lengte- en gewicht-z-score, diagnose, puberteitsstadium en overige gebruikte medicatie. De 2 groepen verschillen alleen van elkaar wat betreft de BMI-zscore: voor groep 1 was de score 0,2 en voor groep 2 was deze $-0,09$. Opvallend is dat de jongens die al langdurig met AP behandeld zijn, gemiddeld genomen geen overgewicht hadden.

De prolactinespiegel is in het serum bepaald en prolactine gerelateerde bijwerkingen zijn gemeten door middel van gevalideerde vragenlijsten en een lichamelijk onderzoek. Uit dit onderzoek is als resultaat naar voren gekomen dat $47 \%$ van de met AP behandelde jongens een hyperprolactinemie heeft (groep 1), tegenover 2\% van de jongens in groep 2. De jongens uit groep 1 zijn gemiddeld 53 maanden met risperidon behandeld, met een gemiddelde dosis van 1,5 mg per dag. Van de jongens met een AP-geïnduceerde hyperprolactinemie heeft $46 \%$ geen klachten van die hyperprolactinemie.

Van de groep jongens in dit onderzoek heeft 40\% van de AP-gebruikers (groep 1) gynaecomastie ten opzichte van $20 \%$ van de controlegroep (groep 2). De "lifetime"-prevalentie (proportie van mensen in een populatie die ooit gynaecomastie hebben gehad) van het krijgen van gynaecomastie bij gezonde jongens die geen AP gebruiken, ligt rond de 50\%, met een hoogtepunt van voorkomen tijdens de puberteit. Het krijgen of hebben van gynaecomastie is significant gerelateerd aan APgebruik, maar niet aan de hyperprolactinemie. Waarschijnlijk komt deze verhoging van het aantal jongens met gynaecomastie door een relatief teveel aan oestrogenen 
door lagere testosteronspiegels. Geen enkele jongere met of zonder AP-gebruik heeft galactorroe. De gynaecomastie en galactorroe zijn gemeten met een vragenlijst en een lichamelijk onderzoek.

Van de jongens met langdurig AP-gebruik heeft 14\% een seksuele functiestoornis: $4(8 \%)$ van hen hebben een verminderd of geen orgasme, $5(10 \%)$ hebben problemen met ejaculeren (minder of niet), 1 (2\%) jongen kan geen erectie meer krijgen en 2 (4\%) jongens geven aan een verminderde interesse in seks te hebben. Deze seksuele functiestoornissen zijn significant gerelateerd aan een te hoge prolactinespiegel. In de controlegroep rapporteert geen enkele jongere een seksuele functiestoornis.

Deze resultaten geven weer dat AP-geïnduceerde hyperprolactinemie persisteert gedurende de behandeling en dat ongeveer de helft van de jongens geen klachten daarvan ondervindt. De vraag is of deze groep jongens mogelijk risico loopt op eventuele langetermijneffecten van door de AP geïnduceerde hyperprolactinemie, zoals hypogonadotroop hypogonadisme, puberteitsvertraging en een verminderde botdichtheid. Van de jongens met ASS die behandeld zijn met een AP geeft $14 \%$ aan last te hebben van een seksuele functiestoornis. Dit aantal is waarschijnlijk een onderschatting. Voor jongeren met ASS is het lastig om terug te denken in de tijd voor het AP-gebruik, sommige jongens zijn al voor hun puberteit behandeld met AP en kunnen derhalve geen verschil opmerken in de situatie voor en na de behandeling. Een substantieel aantal jongeren (30\% uit groep 1 en $40 \%$ uit groep 2) kan de vraag niet beantwoorden en antwoordt "onbekend" op de vragen over de seksuele bijwerkingen.

Uit deze studie komt ook naar voren dat de huidige dosis van het AP de hyperprolactinemie voorspelt.

Hoofdstuk 4 onderzoekt de invloed van AP-geïnduceerde hyperprolactinemie op de puberteitsontwikkeling, testosteron, luteïniserend hormoon (LH), follikelstimulerend hormoon (FSH) en inhibine B. Inhibine B wordt geproduceerd door de Sertoli-cellen van de testes onder invloed van FSH en is een marker voor fertiliteit bij jongens. De groep jongens met AP-geïnduceerde hyperprolactinemie $(\mathrm{N}=28)$ is vergeleken met de groep jongens zonder hyperprolactinemie met AP-gebruik $(\mathrm{N}=$ 29 ) en zonder AP-gebruik ( $N=37)$. De groepen zijn vergelijkbaar wat betreft gemiddelde leeftijd, gewicht-, lengte- en BMI-z-score, duur van de behandeling (gemiddeld meer dan 4 jaar) en diagnose. De groepen verschillen in gemiddelde dosering AP. De groep met AP-geïnduceerde hyperprolactinemie heeft een significant hogere dagdosering.

De resultaten van dit onderzoek laten zien dat AP-geïnduceerde hyperprolactinemie leidt tot significant lagere testosteronspiegels. LH-, FSH- en inhibine Bwaarden en de puberteitsstadia zijn vergelijkbaar voor de groep met en zonder APgeïnduceerde hyperprolactinemie. De verlaagde testosteronspiegels van de groep met AP-geïnduceerde hyperprolactinemie blijven wel binnen de normaalwaarden voor de leeftijd en het geslacht. De vraag is of deze verlaging klinisch relevant is. 
Een andere bevinding van onze studie is dat de totale patiëntengroep ( $N=104) 1,6$ jaar later is in het behalen van het puberteitsstadium ten opzichte van Nederlandse jongens van dezelfde leeftijd. Deze puberteitsvertraging is gerelateerd aan het hebben van een ASS en niet aan de diagnose DBD.

Het doel van hoofdstuk $\mathbf{5}$ is de relatie te onderzoeken tussen enerzijds de APgeïnduceerde hyperprolactinemie en anderzijds de botmarkers en de botdichtheid. De prolactinespiegel en factoren (botmarkers) betreffende botaanmaak (P1NP en BAF) en botafbraak (CTx) zijn in het bloed gemeten. Botmarkers zijn stoffen in het bloed die het dynamische aspect van botaanmaak weergeven (P1NP = procollageen type 1 amino-terminal propeptide en BAF = botalkalische fosfatase) of van botafbraak (CTx = cross-linked C-telopeptide van type 1-collageen). Daarnaast is er een "dual-energy X-ray"-absorptiometrie (DXA)-meting gedaan om de botdichtheid te bepalen. De jongens met AP-geïnduceerde hyperprolactinemie $(\mathrm{N}=27)$ zijn vergeleken met de jongens met AP zonder hyperprolactinemie $(\mathrm{N}=29)$ en met de jongens zonder AP $(\mathrm{N}=47)$.

Dit onderzoek toont aan dat de jongens met AP-geïnduceerde hyperprolactinemie een lagere volumetrische botdichtheid van de lumbale wervelkolom hebben dan de jongens met AP gebruik zonder hyperprolactinemie $(\mathrm{N}=29)$. Van die jongeren met AP-geïnduceerde hyperprolactinemie heeft 7-11\% een botdichtheid die sterk verlaagd is (meer dan twee standaarddeviaties onder het gemiddelde). De jongens met AP-geïnduceerde hyperprolactinemie hebben lagere botaanmaak(P1NP) en botafbraakmarkers (CTx) dan de jongens zonder hyperprolactinemie. Dit wijst op een remmende invloed van AP-geïnduceerde hyperprolactinemie op de botombouw. Longitudinaal onderzoek is nodig om deze bevindingen verder te onderzoeken.

Een andere bevinding is dat deze jongens met AP-geïnduceerde hyperprolactinemie een hoger percentage lichaamsvet hebben dan jongeren zonder APgeïnduceerde hyperprolactinemie. Een hoger percentage lichaamsvet is op oudere leeftijd een risicofactor voor hart- en vaatziekten.

Behandeling met AP geeft vaak hyperprolactinemie bij jongens met ASS. Uit ons onderzoek blijkt dat deze behandeling zeker geen verwaarloosbare gevolgen zou kunnen hebben voor de botombouw. In de praktijk moet hiermee volgens ons rekening gehouden worden, in ieder geval tot er prospectief goed uitgevoerd onderzoek is dat het tegendeel bewijst.

In hoofdstuk 6 is onderzocht of er een genetische associatie is tussen APgeïnduceerde hyperprolactinemie en het voorkomen van het Taq1A A1-allel van het dopamine D2-receptorgen en/of CYP2D6-polymorfismen. Voor deze studie zijn alleen de jongens met ASS en/of DBD die gedurende lange termijn behandeld werden met risperidon geïncludeerd. Prolactine-, risperidon- en 9-hydroxyrisperidonspiegels zijn bepaald en de deelnemers zijn gegenotypeerd voor CYP2D6polymorfismen en het Taq1A A1-allel van het dopamine D2-receptorgen. 
Het Taq1A A1-allel is geassocieerd met verminderde dichtheid van dopaminereceptoren in de hersenen. Patiënten met dit allel kunnen gevoeliger zijn voor het krijgen van een AP-geïnduceerde hyperprolactinemie. Voor CYP2D6 geldt dat dit polymorfisme een belangrijke rol speelt bij de omzetting van verschillende AP, waaronder risperidon, in de lever. Op die manier kan de medicijnspiegel beïnvloed worden. Normale metaboliseerders hebben 1 of 2 functionele CYP2D6-allelen; slechte metaboliseerders hebben geen functionele allelen (7\% blanken, 1\% Aziaten, 3\% Afrikanen). Snelle metaboliseerders hebben duplicaties van het CYP2D6-gen (2\% blanken, 25\% Ethiopiërs). De langzame metaboliseerders breken de medicijnen minder snel af, waardoor er hogere bloedspiegels zijn in vergelijking met normale of snelle metaboliseerders. De hogere AP-spiegels kunnen een verhoogd risico geven op APgeïnduceerde hyperprolactinemie.

In onze studie zijn de prolactinespiegels positief en significant geassocieerd met risperidon- en 9-hydroxyrisperidonspiegels en met de orale dosis risperidon in milligrammen per kilogram. De prolactine- en 9-hydroxyrisperidonspiegels worden hoger met een verminderde of geen activiteit van het CYP2D6-gen. In onze studie is geen relatie gevonden tussen AP-geïnduceerde hyperprolactinemie en het Taq1A A1-allel van het dopamine D2-receptorgen.

Tot slot geeft hoofdstuk 7 een advies omtrent de monitoring en de behandeling van AP-geïnduceerde hyperprolactinemie. Het is van belang om een uitgangssituatie vast te leggen voordat de behandeling met het AP start. De aanwezigheid van gynaecomastie, galactorroe, het seksuele functioneren, de regelmaat van de menstruatie en het puberteitsstadium kunnen worden vastgesteld door middel van vragenlijsten of door middel van een lichamelijk onderzoek. Een efficiënte - met tact uit te voeren - methode om gynaecomastie vast te stellen is om met de vlakke hand bij beide tepels te voelen of er een klierschijf palpabel is en of deze pijnlijk is. Anamnestisch kan nagevraagd worden of de tepels gezwollen en/of pijnlijk zijn. Naast het vaststellen en uitvragen van deze klachten is het ook belangrijk om in kaart te brengen of de patiënt voldoende calciumrijk eet, voldoende aan zonlicht is blootgesteld (vitamine D), voldoende beweegt en of er een familiaire belasting is voor osteoporose.

Voor de start van de behandeling met een AP wordt de prolactinespiegel bepaald. Standaard wordt deze bepaald in de ochtend, 2 uur na het ontwaken. Dan zijn de spiegels het laagst. Een eenmalige meting is voldoende voor het vaststellen van een AP-geïnduceerde hyperprolactinemie. Als de patiënt op de juiste dosering is ingesteld, wordt de spiegel 3 maanden later opnieuw bepaald. Na verhoging van de dosering wordt de prolactinespiegel na ongeveer 3 maanden opnieuw gecontroleerd. De termijn van 3 maanden is gekozen omdat in de eerste 6 weken na het starten of verhogen van een AP vaak een initiële sterke stijging van de prolactinespiegel optreedt, veelal gevolgd door een daling, blijkbaar doordat tolerantie optreedt. Als na 3 maanden nog een verhoogde prolactinespiegel bestaat, zal deze persisteren. 
Controle van de prolactinespiegel is ook geïndiceerd bij prolactinegerelateerde klachten zoals gynaecomastie, galactorroe, seksuele functiestoornissen en verminderde of verdwenen menstruatie als deze mogelijk samenhangen met de APbehandeling. Controle van de prolactinespiegel is niet alleen aan te raden bij adolescenten, zoals geadviseerd door de werkgroep somatische complicaties bij antipsychoticagebruik, maar ook bij kinderen en volwassenen.

Er zijn naast AP-gebruik ook andere oorzaken voor een hyperprolactinemie (o.a. hypothyreoïdie, prolactinoom, nierfalen, leverziekten en gebruik van andere prolactineverhogende medicatie). Een klinisch handvat is dat sterk verhoogde prolactinespiegels (boven de $100 \mathrm{ng} / \mathrm{ml}$ ) vaak een andere oorzaak hebben dan de behandeling met AP.

De aanwezigheid van hyperprolactinemie voor de start van de AP is een reden voor verder onderzoek. Zolang de effecten van AP-geïnduceerde hyperprolactinemie op de groei en ontwikkeling niet duidelijk zijn en zolang we niet weten welke drempelwaarde gevolgen heeft, is het raadzaam bij iedere verhoging van prolactine boven de normaalwaarden als volgt actie te ondernemen.

Behandeling van hyperprolactinemie

Het AP kan bij kinderen met een ASS en/of DBD een uiterst gunstig effect op de doelsymptomen hebben. In de onderstaande adviezen moet altijd meegewogen worden hoe belangrijk het AP is in de behandeling van het kind.

1. Stoppen van het AP-gebruik geeft meestal binnen 96 uur, afhankelijk van de halfwaardetijd van het AP, een normalisering van de prolactinespiegel.

2. Verlagen van de dosering tot de minimaal werkzame dosering geeft vaak effect om de prolactinespiegel te normaliseren.

3. Als verlagen niet goed mogelijk is, kan er geswitcht worden naar een AP dat de prolactinespiegel niet verhoogt (quetiapine, clozapine, aripiprazol).

4. In de literatuur wordt additie met aripiprazol ook beschreven om de hyperprolactinemie te verminderen. Omdat het nog niet duidelijk is of de hypoprolactinemie die bij 60\% van de kinderen door aripiprazol ontstaat klinische consequenties heeft, is hiermee ook enige voorzichtigheid aan te raden.

5. Als dosisvermindering of switchen niet mogelijk is en de AP-geïnduceerde hyperprolactinemie persisteert, dan kan een meting van de botdichtheid middels een DXA-scan worden overwogen. Daarnaast zijn preventieve maatregelen belangrijk om de botdichtheid zo goed mogelijk te houden. Preventieve maatregelen zijn onder meer voldoende lichaamsbeweging, voldoende blootstelling aan zonlicht, voldoende inname van vitamine $\mathrm{D}$ en andere voedingsadviezen (calcium- en vitamine D-suppletie). 


\section{Dankwoord}

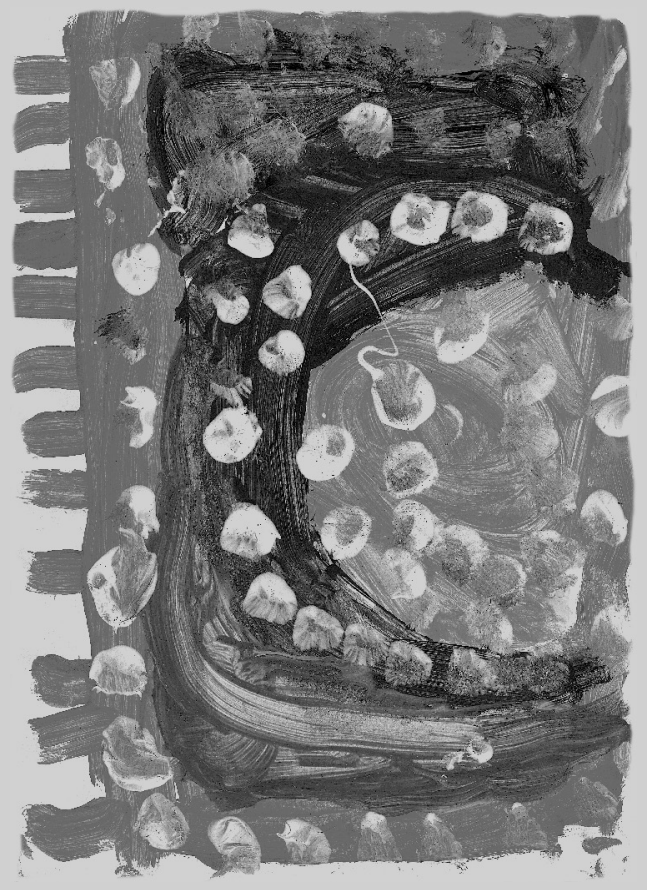


DAN KWOORD 
Om te beginnen wil ik alle deelnemers (en hun ouders en/of voogden) aan mijn onderzoek hierbij heel erg bedanken. Zonder jullie was dit proefschrift niet tot stand gekomen.

Onderzoek is van groot belang om de kwaliteit van patiëntenzorg te verbeteren. Met dit doel is dit onderzoek gestart; mijn dank is groot dat jullie hieraan hebben meegewerkt. Ik vond de onderzoeksdagen (vragenlijsten, bloedafname en dan nog de botdichtheidsmeting), de dagen van inclusie, de leukste. Jullie waren inspirerend en ontwapenend. Ik herinner me vele gesprekken en situaties, sommigen van jullie zijn nu bij mij onder behandeling en het is een groot genoegen zo lang met jullie "mee te mogen lopen".

Ik weet nog goed dat ik begon met dit onderzoek, op de dag dat ik tweemaal achtereen de vraag kreeg van een ouder of antipsychotische medicatie geen kwaad kon voor de groei en ontwikkeling van hun kind. Na enige verdieping in alle beschikbare literatuur begon het me te dagen: er is geen goed antwoord op deze vraag. Ik ging met enige verontwaardiging naar mijn opleider, Peter van Harten, die zei: "Waarom schrijf je geen studieprotocol en ga je fondsen werven om het zelf te gaan onderzoeken"... en ik dacht "tja, waarom eigenlijk niet". En zo is het begonnen, zeven jaar geleden.

Veel mensen hebben een bijdrage geleverd aan dit promotieonderzoek, waarvoor ik allen zeer dankbaar ben. Vanwege het grote aantal mensen loop ik het risico iemand over te slaan. Dank dus ook aan degenen die ik eventueel vergeten ben.

Allereerst wil ik mijn beide promotors, prof. dr. Peter van Harten en prof. dr. Jan Buitelaar, bedanken.

Peter, eerst was je mijn A-opleider ( 9 jaar geleden), en vervolgens werd je tijdens de opleiding en later als psychiater, achtereenvolgens mijn copromotor en promotor. Jij bent een grote bron van inspiratie voor mij, jouw kennis en kunde, jouw discipline en inzet en eerlijkheid waren kwaliteiten die ik al als opleideling heel erg waardeerde. Door samen te werken aan dit onderzoek heb ik je nog beter leren kennen, jouw vertrouwen, steun en interesse hebben mij beïnvloed en gevormd. Je hebt me gestuurd, maar ook de vrijheid gegeven om mijn eigen mening te vormen. In de afgelopen jaren heb ik gemerkt dat ik mede hierdoor een persoonlijke ontwikkeling heb doorgemaakt.

Jan, vanwege de afstand tussen Nijmegen en Bilthoven, hebben wij veel per email en telefoon gecommuniceerd. Dit verliep heel goed dankzij jouw gave om te weten wanneer jij mij de goede kant op moest sturen. Net als ik inhoudelijk vastliep of als logistieke zaken niet lukten (editors die niets meer van zich lieten horen), was één e-mailtje van jou voldoende om de boel weer vlot te trekken. Mijn dank is groot Jan, voor je inzet, eerlijkheid en ook voor je brede kennis en vermogen om de juiste dingen in de juiste context te zetten. 
Annemieke, jij bent de ideale copromotor voor mij geweest. Ik weet nog goed de eerste keer dat ik je opzocht in het Erasmus: jij straalde kennis en rust uit; intuïtief wist ik dat het goed zat. Jij werkt nu als kinderarts-endocrinoloog in Groningen, wat ook niet echt in de buurt van Bilthoven ligt. Met jou was het contact altijd persoonlijk, we bespraken hoe het ging met onze kinderen, en het bijbehorende en allerlei andere leuke, maar ook frustrerende onderzoekszaken. Juist dat persoonlijke en warme van jou gecombineerd met je deskundigheid en pragmatische instelling (stuur nu maar in, verbeteren doe je wel in de volgende versie) maakte de samenwerking met jou heel erg fijn.

De leden van de leescommissie, prof. dr. I.Y.R. Myin-Germeys, prof. dr. T.A.M.J. van Amelsvoort, prof. dr. S.L.S. Drop, prof. dr. J.P.C.J. Selten en dr. W. Staal, wil ik hartelijk bedanken voor de aandacht en tijd die zij besteed hebben aan het lezen van mijn proefschrift.

\section{Erik de Groot en Annet Uithof.}

Erik, onderzoekscoördinator bij toen nog de Symfora groep, zonder jou was ik al lang en breed gestopt met onderzoek doen. Jij hebt mij geholpen met alle hobbels die op de route lagen: fondsen werven, contacten met fondsen onderhouden, steun krijgen van de raad van bestuur, het maken van een financieel overzicht. En weet je nog: samen naar de medisch-ethische commissie. Uitleggen waarom ik die kinderen allerlei naar hun idee ongepaste seksuele vragen ging stellen. Wat was ik zenuwachtig en wat hebben we er om kunnen lachen achteraf.

Annet, wat een verschil heb jij ook gemaakt. Binnen een groot instituut als het onze maakte jij het makkelijker voor mij, je dacht mee, nam me werk uit handen. Geen moeite te groot en altijd vrolijk!

De onderzoeksassistenten, Gerard, Martijn, Anne en Job, jullie waren een geweldige steun. Met jullie alle vier deel ik leuke herinneringen aan een fijne samenwerking.

Martijn, jij zult altijd de jongen van de interne post blijven (need I say more!), en ik denk nog regelmatig terug aan hoe wij met de buisjes bloed (ja ja: 3 jaar werk in een doos op vriesijs) gespreid in 3 ritten (want stel je voor dat er iets mee gebeurt, al het werk voor niets) naar het Erasmus reden in de winter met de ramen open, want anders kon je van het vriesijs flauwvallen. Wij voelden net op de snelweg dan al de eerste tekenen van een flauwte opkomen, gelukkig hebben we het overleefd!

Alle medewerkers van Innova, in het bijzonder Anne Willems: Anne, heel erg bedankt voor de zaken die jij achter de schermen regelt! Thierry, bedankt voor het invoegen van mijn tabellen in mijn manuscript!

Dr. Diederik Tenback, ik zal nog met veel plezier terugdenken aan de statistische analyses die we samen deden. Jij bent een inspirator als het gaat om de combinatie kansen, patiëntenzorg en wetenschap. Jij bent een voortrekker bij vele innovatieve 
ideeën die alle de patiëntenzorg ten goede komen. Bedankt voor de fijne smaenwerking!

Dr. Rob Bakker, lieve collega. Ik was je paranimf samen met Hanneke. Wat waren we er trots op jou en je Tom te mogen vergezellen op zo'n belangrijke dag. Wat fijn ook dat je me een kijkje in de nabije keuken gaf. Ik ben erg benieuwd wat jij nu gaat doen, iets met zebravissen? Ook nog veel dank voor je hulp met de stukken over genetica.

Prof. dr. Barbara Franke, jij hebt me geholpen in de wereld van de allelen, erg nuttig. Bedankt voor je geduld om me keer op keer weer uit te leggen hoe het nu eigenlijk zit met al die CYP2D6-en TaqA1 A1/A2-allelen!

Tessel Galesloot, wij deden samen de statistiek voor het hoofdstuk over genetica. Wat ben jij snel en gestructureerd! Je deed me versteld staan, bedankt voor je inzet!

Dr. Yolanda de Rijke, wij hebben samen de hormoonbepalingen en botmarkers bekeken en bedacht. Heel erg bedankt voor de plezierige samenwerking, je feedback en je interesse in mij en mijn promotieonderwerp.

Ik wil mijn dank uitspreken aan de medewerkers van Saltro: Vera Talen en Mieke van der Geest, bedankt voor de fantastische logistiek rondom de bloedafnames. Heel bijzonder dat het zo soepel en vlekkeloos verlopen is.

Ook wil ik een aantal medewerkers van GGZ Centraal bedanken, in het bijzonder Angelique Salimans en Ans Zandee. Ontzettend bedankt voor jullie hulp bij de PR, het mij helpen voor een interview of andere spannende dingen. Dankzij jullie hulp bleef ik kalm en rustig en kon ik mijn boodschap overbrengen. Hildegard Brouwer, Toos van Polanen en Mirjam Rus, bedankt voor jullie geduld en medeleven! Bedankt voor het flexibele inplannen van overlegmomenten met Peter.

Mijn dank gaat ook uit naar een aantal medewerkers van het Meander Medisch Centrum: dr. Lorentz Quekel en Martha Peters, bedankt voor jullie vertrouwen dat mijn onderzoek wel zou gaan lukken en dat ik meer dan 5 patiënten zou gaan includeren. Marinus en Gerrit, super hoe jullie mijn jongeren konden geruststellen en hen hebben gemeten met de DXA-meter. Bedankt voor de fijne samenwerking, het branden van de cd'tjes. Het was altijd in orde.

Ik wil mijn dank ook uitspreken aan de Open Ankh, het Fonds Wetenschappelijk Onderzoek Seksualiteit, en de Stichting tot steun VCVGZ voor de (deel)financiering van mijn promotieonderzoek. In het bijzonder ben ik Nel van Son dankbaar voor haar interesse, feedback en aanmoedigingen. Nel, het was heel erg fijn en leerzaam 
om ieder half jaar mijn voortgang met jou face to face te bespreken, heel hartelijk bedankt daarvoor.

Arnold Allertz, mijn onderzoek is bij jou begonnen. Peter had het geopperd, ik had erover nagedacht; nu alleen nog de logistieke zaken regelen. Jij hebt dit voor mij mede mogelijk gemaakt. Heel erg bedankt daarvoor en heel erg bedankt dat ik mijn toekomstige onderzoek mag voortzetten op andere terreinen binnen het werkgebied van Fornhese en Emerhese.

Bas Koevoet en Frits Liefferink, heel hartelijk bedankt voor de onderzoekstijd die ik binnen mijn aanstelling op de Meregaard van jullie heb gekregen! Bedankt ook voor jullie steun en interesse. Bas, de werkbegeleidingsgesprekken met jou heb ik als inspirerend heb ervaren.

Erica Harteveld, bedankt voor je steun en vertrouwen, maar ook de tijd en ruimte die ik kreeg om binnen de jeugdpolikliniek van Fornhese Amersfoort mijn onderzoek te mogen uitvoeren.

Guus van Voorst, bedankt voor je steun en je humor. Is er een onderwerp waar je niet alles over weet? MacGyver move over, here comes MacGus! Ik hoop op veel toekomstig onderzoek binnen Emerhese en een nog langdurige samenwerking met jou!

Collega's van Emerhese en Fornhese jullie allemaal heel erg bedankt voor de aandacht en interesse voor mijn onderzoek.

De leden van de raad van bestuur, dr. Thea Heeren, dr. Bas Schreuder en ir. Henk ter Avest, en Innova wil ik bedanken voor de ruimte (tijd en geld) voor mijn promotieonderzoek. Ook wil ik mijn collega's bedanken voor hun belangstelling, en in het bijzonder Hanneke Heemskerk, Chris Bavinck en Graziella van der Luit. Hanneke omdat ze mij op het spoor van hyperprolactinemie als bijwerking heeft gezet en Graziella en Chris om wie zij zijn.

Ik wil Peter Moleman bedanken voor zijn interesse in de antipsychoticageïnduceerde hyperprolcatinemie. Peter, bedankt voor je feedback en voor de kans om mijn resultaten te delen met een grote groep collega's via Psyfar.

Ik wil dankzeggen aan alle bibliothecaressen van GGz Centraal, die altijd veel artikelen (en snel) voor mij hebben opgezocht en opgevraagd, zonder deze literatuur was promoveren onmogelijk geweest.

Dessa Brashear en Jane Sykes, veel dank voor het controleren en corrigeren van mijn Engels. 
Tevens wil ik Len Cuppens (Universiteit Maastricht) en Ruud Leliveld en Jordan Custers (Datawyse) bedanken voor hun adviezen, begeleiding en logistiek rondom mijn promotie.

Mijn paranimfen, Sylvie Roke en Christel Hessels. Sylvie, jij bent mijn zus; jij bent zo goed in alles wat je doet. Ik kijk met veel bewondering en plezier hoe jij de wetenschappelijke wereld bestormt. Wat heb ik in de rats gezeten toen jij dat ongeluk kreeg; gelukkig ben je hersteld. Ik ben blij en trots dat jij mijn zus bent en de tante van Youri, Robin en Stijn. Christel, vriendin en medepromovendus. Jij was mijn collega bij Fornhese, mijn overbuurvrouw met alle reserveonderdelen (zelfs broeken voor het geval iemand eruit scheurde) en altijd een goed humeur; jij behandelaar van de meisjes met persoonlijkheidsstoornissen en ik van de jongens met autismespectrumstoornissen, een groter contrast is niet denkbaar, toch vullen we elkaar heel goed aan. Ik hoop nog heel lang jouw vriendin te kunnen zijn!

Lieve vrienden en vriendinnen, dankzij jullie steun en liefde is dit alles geworden wat het is. Ik ben dankbaar zoveel lieve mensen in mijn leven te hebben en hoop dat dat nog lang zo blijft.

Lieve Gea en Hans, Lieve Johan bedankt voor jullie hulp en steun gedurende mijn promotietraject.

Lieve paps en mams, van jullie heb ik geleerd wat doorzetten is en hoe leuk leren eigenlijk is. Ik geniet ervan hoe jullie nu die dingen ook weer aan mijn kinderen leren.

Jullie maken mede mogelijk dat ik met zoveel plezier mijn werk en onderzoek kan doen, dankzij jullie steun en liefde. Zoveel dank daarvoor! Ik hoop nog heel lang zo te mogen genieten van het naast elkaar wonen.

Lieve Ralph, jij bent mijn man al zoveel jaren. 10 jaar getrouwd, maar al zeker 20 jaar samen, nog steeds het middelpunt van mijn leven. Jij en de kinderen, om jullie draait het voor mij en natuurlijk maakt jouw hulp het verschil. Ralph, dit boekje is een eerbetoon aan jou en de kinderen. Jullie zijn mijn leven.

En tot slot Youri, Robin en Stijn, mijn kinderen. Aan jullie draag ik dit boek op, jullie zijn samen met jullie papa mijn alles. Jullie hebben mij geholpen om te kunnen relativeren de afgelopen 7 jaar. Ik hoop dat jullie, net als ik, alles uit het leven halen wat er uit te halen valt. Wij zullen er alles aan doen om dat voor jullie mogelijk te maken. 

Curriculum Vitae

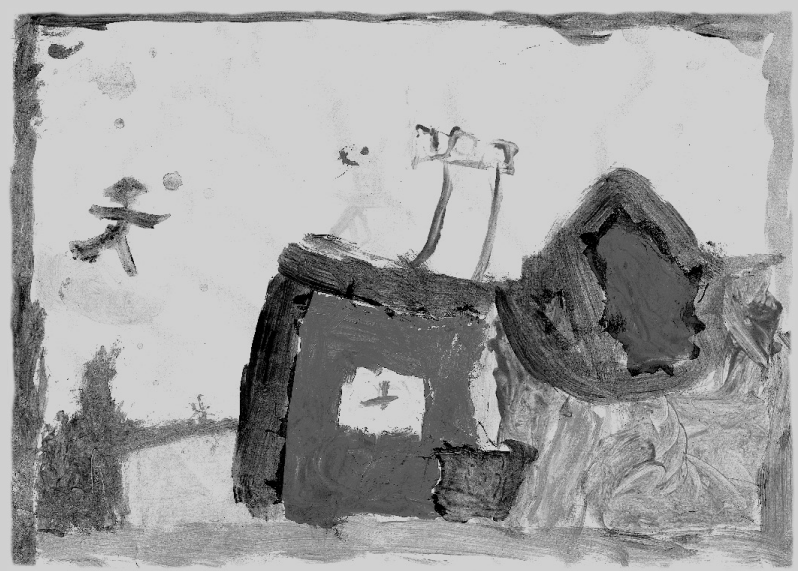


CURRICULUM VITAE 
Yvette Roke was born March 17th, 1976, in De Bilt. At the age of 18 she moved to Utrecht. She attended medical school at UMCU University in Utrecht prior to her psychiatric training at Zon en Schild in Amersfoort. She became interested in scientific research during medical school were she undertook a chart review study at the department of neonatology, investigating different breathing technique's on premature children and the risk of this breathing technique on intracranial haemorrhage.

She began her Ph.D. programme during her psychiatric training under the supervision of Prof. Peter van Harten (at the time also the supervisor of psychiatric training) and Prof. Jan Buitelaar.

She is married to Ralph de Geest, they have three children, two sons Youri (7 years of age) and Stijn (two years of age) and one daughter, Robin (five years of age). 